UNIVERSIDADE DE BRASÍLIA

FACULDADE DE TECNOLOGIA

DEPARTAMENTO DE ENGENHARIA ELÉTRICA

\title{
ANÁLISE DE CUSTO-BENEFÍCIO DA IMPLANTAÇÃO DAS REDES ELÉTRICAS INTELIGENTES NAS CONCESSIONÁRIAS DE DISTRIBUIÇÃO DE ENERGIA ELÉTRICA DO BRASIL
}

\section{MARCOS VENICIUS LEITE VASCONCELOS}

ORIENTADOR: PROF. DR. ANÉSIO DE LELES FERREIRA FILHO DISSERTAÇÃO DE MESTRADO EM ENGENHARIA ELÉTRICA

PUBLICAÇÃO: PPGEE.DM- 648/16

BRASÍLIA/DF: DEZEMBRO - 2016 
UNIVERSIDADE DE BRASÍLIA

FACULDADE DE TECNOLOGIA

\section{DEPARTAMENTO DE ENGENHARIA ELÉTRICA \\ ANÁLISE DE CUSTO-BENEFÍCIO DA IMPLANTAÇÃO DAS REDES INTELIGENTES NAS CONCESSONÁRIAS DE DISTRIBUIÇÃO DE ENERGIA ELÉTRICA DO BRASIL}

\section{MARCOS VENICIUS LEITE VASCONCELOS}

DISSERTAÇÃO DE MESTRADO SUBMETIDA AO DEPARTAMENTO DE ENGENHARIA ELÉTRICA DA FACULDADE DE TECNOLOGIA DA UNIVERSIDADE DE BRASÍLIA, COMO PARTE DOS REQUISITOS NECESSÁRIOS PARA A OBTENÇÃO DO GRAU DE MESTRE.

APROVADA POR:

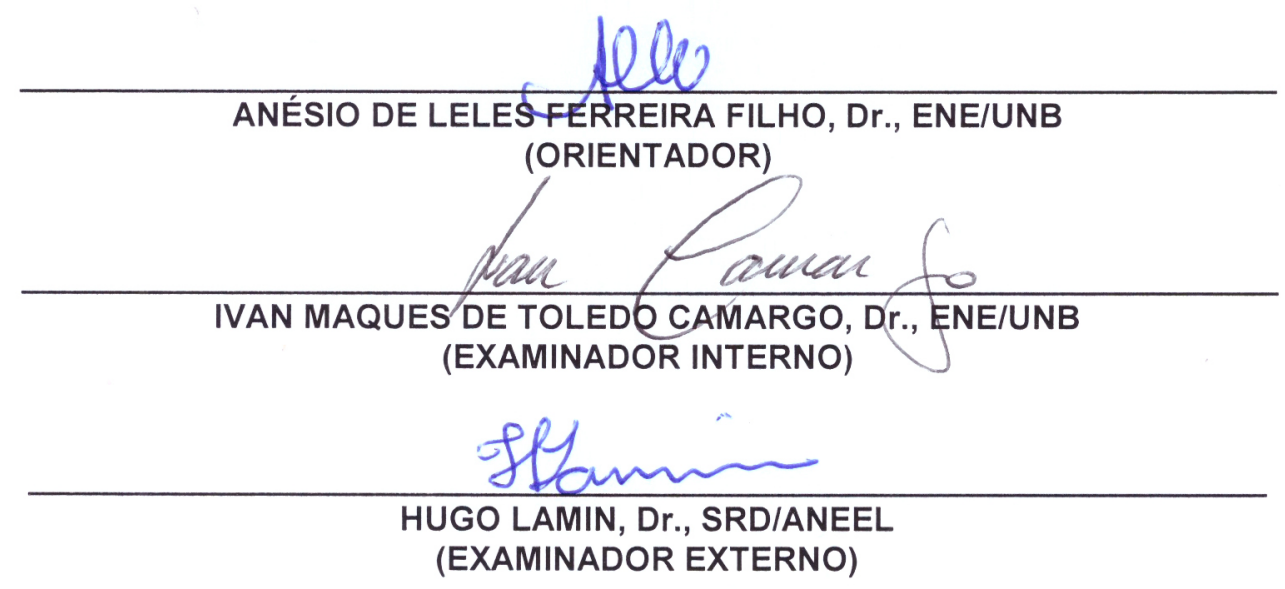




\section{FICHA CATALOGRÁFICA}

\begin{tabular}{|c|c|}
\hline \multicolumn{2}{|c|}{ VASCONCELOS, MARCOS V. L. } \\
\hline \multirow{2}{*}{\multicolumn{2}{|c|}{$\begin{array}{l}\text { Análise de custo-benefício da implantação das redes elétricas inteligentes nas concessionárias } \\
\text { de distribuicão de energia elétrica do Brasil [Distrito Federal] } 2016 .\end{array}$}} \\
\hline & \\
\hline \multicolumn{2}{|c|}{ xv, 88p., 210 x 297 mm (ENE/FT/UnB, Mestre, Engenharia Elétrica, 2016). } \\
\hline \multirow{2}{*}{\multicolumn{2}{|c|}{$\begin{array}{l}\text { Dissertação de Mestrado - Universidade de Brasília. Faculdade de Tecnologia. Departamento } \\
\text { de Engenharia Elétrica }\end{array}$}} \\
\hline & \\
\hline \multicolumn{2}{|c|}{$\begin{array}{l}\text { de Engenharia Elétrica } \\
\text { 1. Redes Elétricas Inteligentes }\end{array}$} \\
\hline $\begin{array}{l}\text { 3. Análise de Custo-Benefício } \\
\text { 5. Regulação }\end{array}$ & 4. Clusterização \\
\hline \multicolumn{2}{|l|}{ 5. Regulação } \\
\hline \multicolumn{2}{|l|}{ I. ENE/FT/UnB } \\
\hline
\end{tabular}

\section{REFERÊNCIA BIBLIOGRÁFICA}

VASCONCELOS, MARCOS V. L. (2016). Análise de custo-benefício da implantação das redes elétricas inteligentes nas concessionárias de distribuição de energia elétrica do Brasil. Dissertação de Mestrado em Engenharia Elétrica, Publicação PPGEE.DM- 648/16, Departamento de Engenharia Elétrica, Universidade de Brasília, Brasília, DF, 88p.

\section{CESSÃO DE DIREITOS}

AUTOR: Marcos Venicius Leite Vasconcelos.

TÍTULO: Análise de custo-benefício da implantação das redes elétricas inteligentes nas concessionárias de distribuição de energia elétrica do Brasil.

GRAU: Mestre ANO: 2016

É concedida à Universidade de Brasília permissão para reproduzir cópias desta dissertação de mestrado e para emprestar ou vender tais cópias somente para propósitos acadêmicos e científicos. $\mathrm{O}$ autor reserva outros direitos de publicação e nenhuma parte desta dissertação de mestrado pode ser reproduzida sem autorização por escrito do autor.

Universidade de Brasília - UnB.

Faculdade de Tecnologia.

Departamento de Engenharia Elétrica.

CEP 70.910-900 Brasília - DF - Brasil. 
Aos meus pais, que tanto lutaram para que eu chegasse até aqui. 


\section{AGRADECIMENTOS}

A Deus, senhor de todas as coisas, que sempre me deu forças para seguir em frente.

Aos meus pais, pelo apoio irrestrito e por tanto terem lutado para prover uma educação de qualidade aos filhos.

À minha esposa, Marihá, pelo incentivo e carinho. Agradeço também pela compreensão nas horas em que este trabalho demandou toda minha atenção.

Aos meus irmãos, Marcelo e Mário, pelas palavras de estímulo sempre presentes.

Aos colegas da SRD/ANEEL. Em especial, agradeço aos amigos Hugo, pelo suporte com materiais e arquivos, Davi Vidal, pelas contribuições ao texto, e Leonardo e Marcelo, pelo apoio no levantamento dos dados.

Ao Professor Anésio, pelos valiosos ensinamentos e pela dedicação na orientação.

Ao Professor Felipe, pela enriquecedora orientação no início deste trabalho. 


\title{
RESUMO
}

\section{ANÁLISE DE CUSTO-BENEFÍCIO DA IMPLANTAÇÃo DAS REDES ELÉTRICAS INTELIGENTES NAS CONCESSIONÁRIAS DE DISTRIBUIÇÃO DE ENERGIA ELÉTRICA DO BRASIL}

\author{
Autor: Marcos Venicius Leite Vasconcelos \\ Orientador: Anésio de Leles Ferreira Filho \\ Programa de Pós-graduação em Engenharia Elétrica \\ Brasília, Dezembro de 2016
}

A implantação das Redes Elétricas Inteligentes (REI) tem resultado em significativos benefícios ao setor de distribuição de energia elétrica em diferentes países. Todavia, os investimentos associados a esta empreitada são volumosos, o que indica a necessidade de uma avaliação de sua viabilidade econômica e, consequentemente, de seus motivadores.

Alguns estudos já responderam a essa demanda em nível nacional. Entretanto, ainda não há no Brasil uma análise que incorpore as características específicas das diferentes empresas de distribuição.

Nesse contexto, o presente trabalho tem como objetivo executar uma análise do custobenefício da implantação das REI nas diversas concessionárias brasileiras de distribuição. Para tanto, estima-se o Valor Presente (VP) de 3 categorias de custos e 8 de benefícios e, por meio de processos de clusterização e técnica de correlação, identificam-se os motivadores para as novas tecnologias.

Os resultados apontam, considerando-se as condições ora adotadas, que das 62 distribuidoras avaliadas, em 25 não há viabilidade para a implantação das REI, ou seja, em 37 empresas percebe-se atratividade econômica. Ademais, constatou-se que os motivadores para essas redes no país são a redução de perdas não técnicas, o aumento da eficiência energética e a melhoria da qualidade do serviço.

Com base nesses resultados, o trabalho oferece subsídios para elaboradores de políticas públicas em nível nacional e regional, para a agência reguladora e para as distribuidoras. 


\title{
ABSTRACT \\ COST-BENEFIT ANALYSIS OF SMART GRIDS IMPLEMENTATION IN THE BRAZILAN ELECTRICITY DISTRIBUTION UTILITIES
}

\author{
Author: Marcos Venicius Leite Vasconcelos \\ Supervisor: Anésio de Leles Ferreira Filho \\ Electrical Engineering Postgraduate Program \\ Brasília, December 2016
}

The implementation of Smart Grids has resulted in significant benefits in the electricity distribution sector of different countries. However, the associated investments are huge, which indicates the need for an assessment of their economic viability and, consequently, of their motivators.

Some studies have already addressed this need at a national level. However, there is still no analysis in Brazil that incorporates the specific characteristics of the different distribution utilities.

In this context, the present study aims to perform a cost-benefit analysis of Smart Grids implementation in the Brazilian electricity distribution companies. In order to accomplish this, the Present Value (PV) of 3 cost and 8 benefit categories is estimated and, through clustering processes and correlation techniques, the motivators for the new technologies are identified.

The results indicate that, under the conditions adopted, in 37 out of the 62 assessed utilities, economic viability for the implementation of Smart Grids is already observed. In addition, it was verified that the motivators for intelligent networks in the country are non-technical losses reduction, energy efficiency increase and service quality improvement.

Based on these results, the study offers subsidies for, public policy makers at regional and national level, for the regulatory agency and for the distribution utilities. 


\section{SUMÁRIO}

1- INTRODUÇÃO

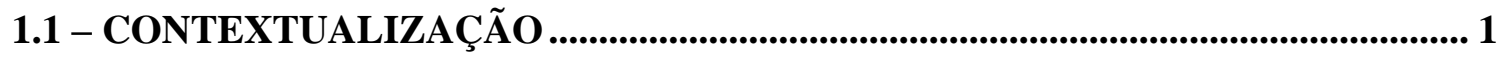

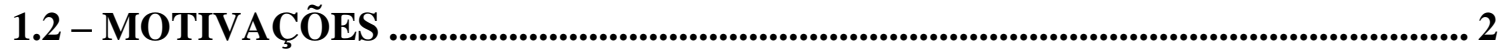

1.3 - OBJETIVOS ........................................................................................................................... 4

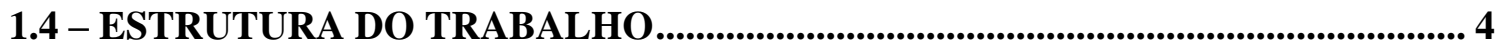

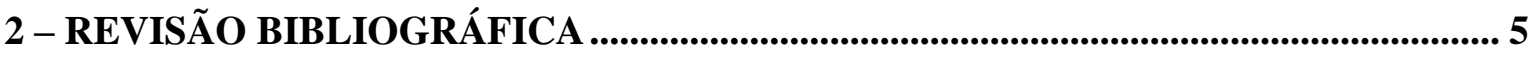

2.1 - REDES ELÉTRICAS INTELIGENTES................................................................ 5

2.1.1 - Definição ................................................................................................................................................ 5

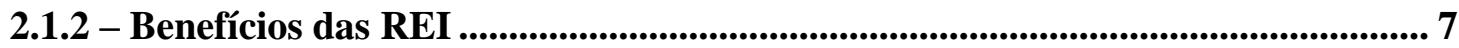

2.1.3 - Conjuntura Internacional .......................................................................... 9

2.1.4- Conjuntura Nacional ............................................................................................... 11

2.2 - ANÁLISE DE CUSTO-BENEFÍCIO DA IMPLANTAÇÃO DAS REI ................. 14

2.2.1 - Aspectos teóricos de análises de custo-benefício ................................................ 14

2.2.2 - Custo-benefício da implantação das REI......................................................... 15

2.2.2.1 - Estudos de custo-benefício da implantação das REI no Brasil........................ 15

2.2.2.2 - Motivadores para implantação das REI no Brasil ........................................ 17

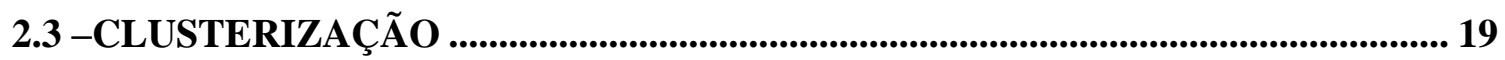

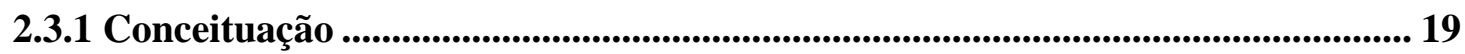

2.3.2 Métodos de clusterização............................................................................................ 20

2.3.3 Algoritmos de clusterização ......................................................................................... 21

2.3.3.1 Algoritmo de média das distâncias entre os objetos ........................................ 22

2.3.3.2 Algoritmo da distância dos centroides ........................................................... 22

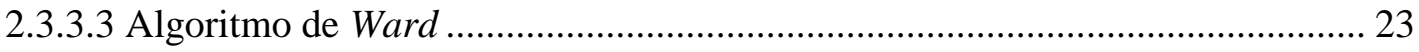

2.3.4 Homogeneidade e Heterogeneidade .................................................................................. 23

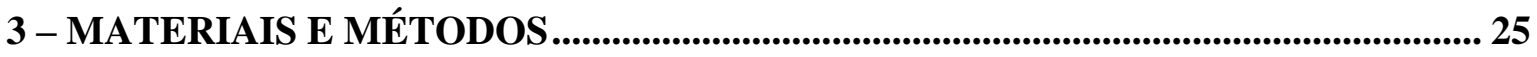

3.1 - EQUIPAMENTOS, TECNOLOGIAS, FUNCIONALIDADES E NÍVEL DE

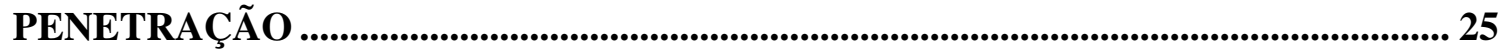

3.1.1 - Medição Eletrônica Inteligente........................................................................................ 25

3.1.1.1 - Mostradores Digitais (In Home Display) ...................................................... 27

3.1.2 - Infraestrutura de telecomunicações ................................................................................ 27

3.1.3 - Automação .............................................................................................................................. 28

3.1.4 - Tecnologia da Informaçãa...................................................................................................... 29

3.2 -DADOS UTILIZADOS ...................................................................................................... 29

3.2.1 Levantamento dos Dados ........................................................................................ 29 
3.2.2 Custos e benefícios ........................................................................................................ 32

3.2.3 Prazos e taxas considerados ...................................................................................................... 34

3.2.4 Perfil de Implantação ....................................................................................................... 35

3.2.5 - Normalização dos Resultados .............................................................................................. 36

3.3 - CLUSTERIZAÇÃO ..................................................................................................... 37

3.3.1 Algoritmos de clusterização ............................................................................. 38

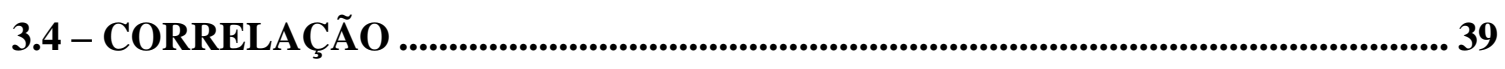

4 - APRESENTAÇÃO E ANÁLISE DOS RESULTADOS ........................................... 40

4.1 CUSTOS E BENEFÍCIOS DA IMPLANTAÇÃO DAS REI .................................. 40

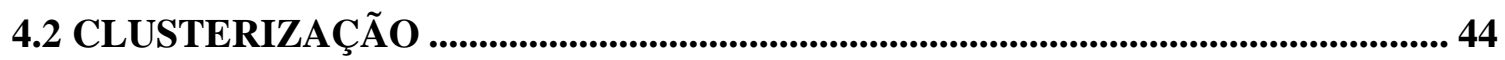

4.2.1 Definição do algoritmo a ser aplicado........................................................... 45

4.2.2 Clusterização das distribuidoras com base no VPL do custo-benefício da implantação das REI ...................................................................................................... 47

4.2.3 Clusterização das distribuidoras com base nos 11 atributos de custos e de

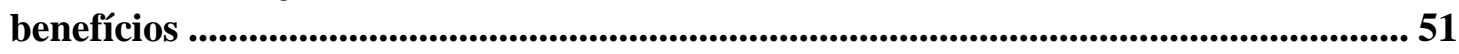

4.3 INVESTIGAÇÃO SOBRE OS MOTIVADORES PARA IMPLANTAÇÃO DAS

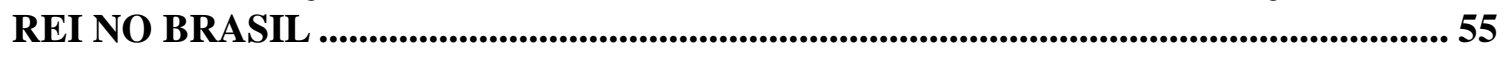

4.3.1 Avaliação da representatividade dos atributos para o VPL do custo-benefício

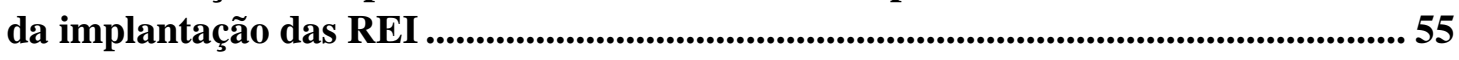

4.3.2 Correlação de Pearson e motivadores da implantação das REI no Brasil ........ 58

4.4 ANÁLISE DE SENSIBILIDADE DO VALOR DO MEDIDOR ELETRÔNICO INTELIGENTE

4.4.1 Evolução do saldo da implantação das REI em relação ao valor do medidor eletrônico inteligente...................................................................................................................... 64

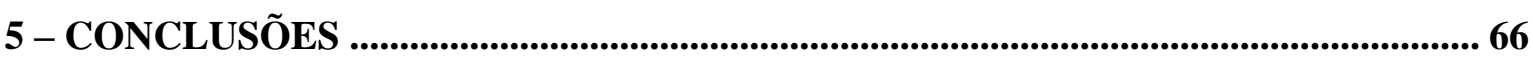

5.1 - CONTRIBUIÇÕES DO TRABALHO .......................................................................... 66

5.2 - SUGESTÃO DE TRABALHOS FUTUROS......................................................... 68

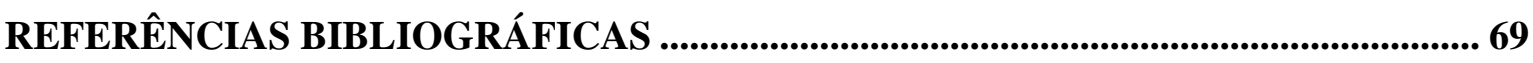

APÊNDICE A - DADOS UTILIZADOS ................................................................... 73

A.1 NÚMERO DE UNIDADES CONSUMIDORAS E SEU CRESCIMENTO MÉDIO

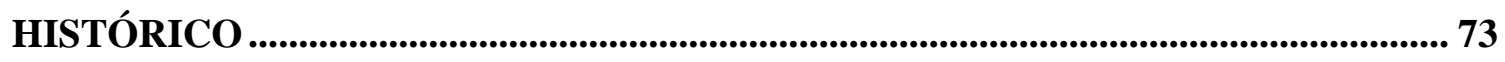

A.2 MERCADO E SEU CRESCIMENTO MÉDIO HISTÓRICO.................................... 74

A.3 WACC REAL DEPOIS DE IMPOSTOS ...................................................................... 76

A.4 RECEITA DE FORNECIMENTO E TARIFA MÉDIA ........................................ 76

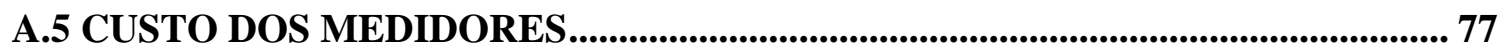

A.6 GASTOS COM LOGÍSTICA, LEGAIS E COM CAMPANHAS DE COMUNICAÇÃO ........................................................................................................................................... 78

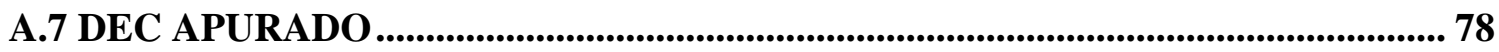


A.8 ENERGIA NÃ̃ DISTRIBUÍDA (END) ........................................................................ 79

A.9 COMPENSAÇÕES POR VIOLAÇÃO DE INDICADORES ..................................... 80

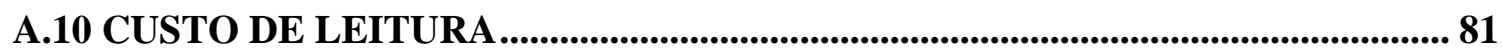

A.11 CUSTOS DA RELIGAÇÃO NORMAL, DE EMERGÊNCIA E DO DESLIGAMENTO PROGRAMADO ........................................................................ 81

A.12 VALOR DA COMPRA DE ENERGIA …....................................................................... 82

A.13 GASTO COM EXPANSÃO DA REDE, DEMANDA DE PONTA E SEU CRESCIMENTO MÉDIO HISTÓRICO ................................................................................. 84

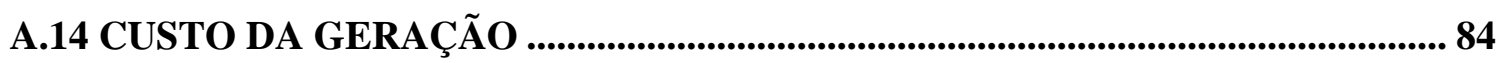

A.15 PERDAS TÉCNICAS E NÃO TÉCNICAS APURADAS......................................... 85

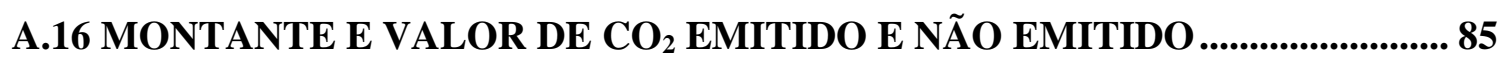

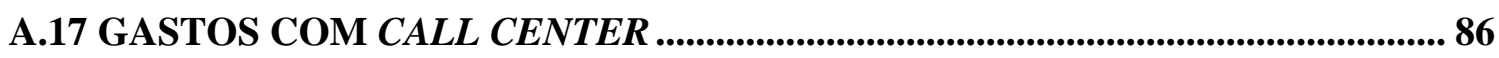

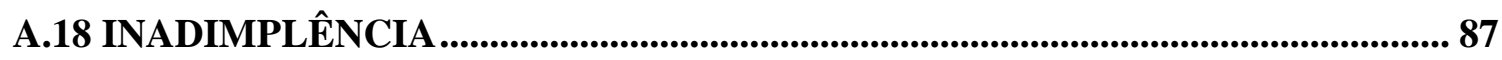

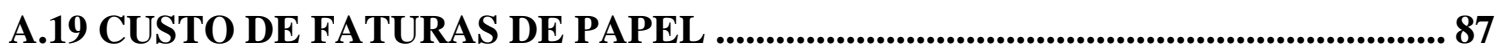

A.20 PERCEPÇÃO DOS CUSTOS E DOS BENEFÍCIOS PELOS AGENTES DO

SETOR ELÉTRICO E PELA SOCIEDADE ................................................................ 87 


\section{LISTA DE TABELAS}

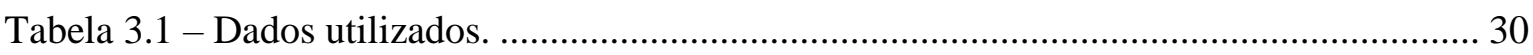

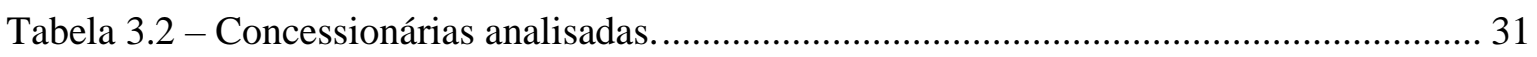

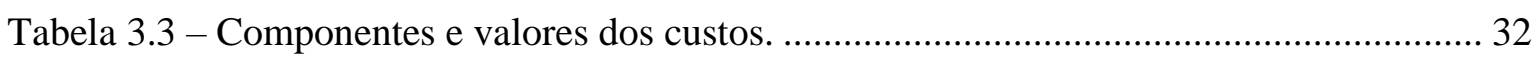

Tabela 3.4 - Componentes, valores e percentuais de benefícios.............................................. 33

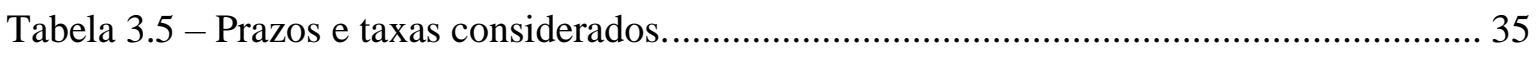

Tabela 3.6 - Ordenação das concessionárias nos processos de clusterização........................... 37

Tabela 3.7 - Representação dos atributos de custos e de benefícios utilizados nos processos de

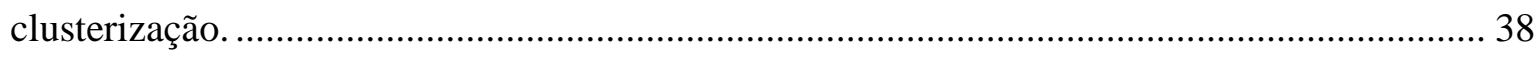

Tabela 4.1 - VP normalizado dos custos e dos benefícios da implantação das REI nas 62 concessionárias.

Tabela 4.2 - Média e desvio padrão das 3 componentes de custos e 8 de benefícios da implantação das REI nas 62 empresas analisadas.

Tabela 4.3 - Resultados da clusterização das 62 distribuidoras empregando-se o algoritmo de média das distâncias.

Tabela 4.4 - Resultados da clusterização das 62 distribuidoras empregando-se o algoritmo de distância dos centroides.

Tabela 4.5 - Resultados da clusterização das 62 distribuidoras empregando-se o algoritmo de

Ward.

Tabela 4.6 - $\mathrm{R}^{2}$ e SR ${ }^{2}$ da clusterização das distribuidoras com base no VPL do custo-benefício da implantação das REI.

Tabela 4.7 - Grupos formados na clusterização das distribuidoras com base no VPL do custobenefício da implantação das REI.

Tabela 4.8 - $\mathrm{R}^{2}$ e SR ${ }^{2}$ da clusterização das distribuidoras com base no VP dos 11 atributos de custos e benefícios da implantação das REI.

Tabela 4.9 - Grupos formados na clusterização das distribuidoras com base no VP dos 3 custos e 8 benefícios da implantação das REI.

Tabela 4.10 - Coeficientes de correlação de Pearson.

Tabela 4.11 - Coeficientes de correlação de Pearson das componentes de perdas técnicas e não técnicas com o atributo de "PERDAS" e destes com o saldo da implantação das REI. ..... 61

Tabela 4.12 - VP normalizado das duas componentes do atributo de "PERDAS".

Tabela 4.13 - Concessionárias nas quais foi realizada a análise de sensibilidade do custo do medidor eletrônico inteligente. 


\section{LISTA DE FIGURAS}

Figura 2.1 - Modelo conceitual das REI. Adaptado de (NIST, 2009). ...................................... 6

Figura 2.2 - Cenários atual e futuro do setor elétrico. Adaptado de (IEA, 2011)....................... 7

Figura 2.3 - Projetos sobre as REI em diferentes países (ENERGY UK, 2012). ...................... 9

Figura 2.4 - Distribuição regional dos projetos sobre as REI no Brasil (CGEE, 2012). .......... 13

Figura 2.5 - Distribuição regional do investimento realizado em projetos sobre as REI no

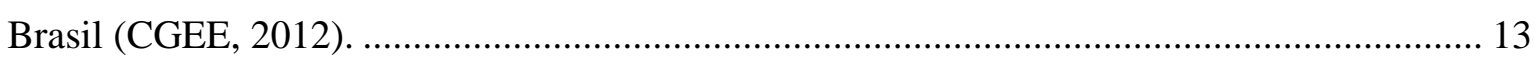

Figura 2.6 - Dendrograma de um processo de clusterização hierárquica aglomerativa de 5

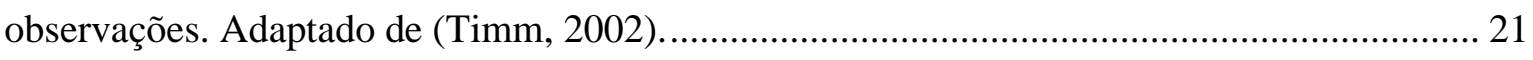

Figura 3.1 - Exemplos de medidores eletrônicos inteligentes. Fonte: (Lamin, 2013)............. 26

Figura 3.2 - Exemplos de mostradores digitais. Fonte: (Lamin, 2013) . ................................. 27

Figura 3.3 - Estrutura de telecomunicações considerada. Fonte: (Lamin, 2013). .................... 28

Figura 3.4 - Perfil de implantação dos medidores e equipamentos de telecomunicações e

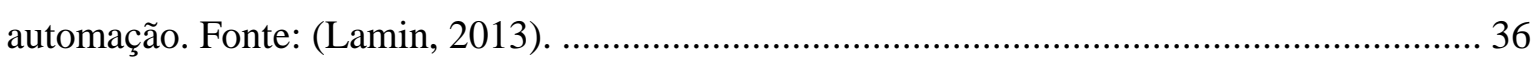

Figura 4.1 - VPL normalizado do custo-benefício da implantação das REI nas 62

distribuidoras.

Figura 4.2 - Evolução do parâmetro $\mathrm{SR}^{2}$ em relação à quantidade de clusters formados no processo de agrupamento. 48

Figura 4.3 - Dendrograma da clusterização com base no VPL do custo-benefício da implantação das REI nas 62 concessionárias. 50

Figura 4.4 - Dendrograma da clusterização com base nas 3 componentes de custos e 8 de benefícios 54

Figura 4.5 - Dendrograma da clusterização baseada nos atributos "AQ_INST" e "PERDAS".

Figura 4.6 - Dendrograma da clusterização das distribuidoras excluindo-se, unicamente, o atributo "AQ_INST". 56

Figura 4.7 - Dendrograma da clusterização das distribuidoras excluindo-se, unicamente, o atributo "PERDAS",

Figura 4.8 - Diagramas de dispersão de parte dos atributos considerados. 60

Figura 4.9 - Evolução do saldo da implantação das REI em relação ao valor de compra do medidor eletrônico inteligente. 


\section{LISTA DE ABREVIATURAS E SIGLAS}

\begin{tabular}{|c|c|c|}
\hline ABDI & - & Agência Brasileira de Desenvolvimento Industrial \\
\hline ABRADEE & - & Associação Brasileira de Distribuidores de Energia Elétrica \\
\hline ADSL & - & Asymmetric Digital Subscriber Line \\
\hline AES-SUL & - & Aes Sul Distribuidora Gaúcha de Energia S/A \\
\hline AME & - & Amazonas Distribuidora de Energia S/A \\
\hline AMPLA & - & Ampla Energia e Serviços S/A \\
\hline ANEEL & - & Agência Nacional de Energia Elétrica \\
\hline AQ_INST & - & Aquisição e Instalação \\
\hline BANDEIRANTE & - & Bandeirante Energia S/A \\
\hline BDGD & - & Base de Dados Geográficas da Distribuidora \\
\hline BOA VISTA & - & Boa Vista Energia S/A \\
\hline CAIUÁ & - & Caiuá Distribuição de Energia S/A \\
\hline CALLCEN_INADIM & - & Call Center e Inadimplência \\
\hline CEA & - & Companhia de Eletricidade do Amapá \\
\hline CEAL & - & Companhia Energética de Alagoas \\
\hline CEB & - & Ceb Distribuição S/A \\
\hline CEEE & - & Companhia Estadual de Distribuição de Energia Elétrica \\
\hline CELESC & - & Celesc Distribuição S.A. \\
\hline CELG & - & Celg Distribuição S.A. \\
\hline CELPA & - & Centrais Elétricas do Pará S/A \\
\hline CELPE & - & Companhia Energética de Pernambuco \\
\hline CEMAR & - & Companhia Energética do Maranhão \\
\hline CEMIG & - & Cemig Distribuição S/A \\
\hline CEPISA & - & Companhia Energética do Piauí \\
\hline CERON & - & Centrais Elétricas de Rondônia S/A \\
\hline CFLO & - & Companhia Força e Luz do Oeste \\
\hline CGEE & - & Centro de Gestão e Estudos Estratégicos \\
\hline CHESP & - & Companhia Hidroelétrica São Patrício \\
\hline CNEE & - & Companhia Nacional de Energia Elétrica \\
\hline COCEL & - & Companhia Campolarguense de Energia \\
\hline COELBA & - & Companhia de Eletricidade do Estado da Bahia \\
\hline COELCE & - & Companhia Energética do Ceará \\
\hline COFINS & - & Contribuição para o Financiamento da Seguridade Social \\
\hline CONTIN & - & Continuidade \\
\hline COOPERALIANÇA & - & Cooperativa Aliança \\
\hline COPEL & - & Copel Distribuição S/A \\
\hline COSERN & - & Companhia Energética do Rio Grande do Norte \\
\hline CPFL JAGUARI & - & Companhia Jaguari de Energia \\
\hline $\begin{array}{l}\text { CPFL } \\
\text { LESTEPAULISTA }\end{array}$ & - & Companhia Leste Paulista de Energia \\
\hline CPFL MOCOCA & - & Companhia Luz e Força de Mococa \\
\hline CPFL PAULISTA & - & Companhia Paulista de Força e Luz \\
\hline CPFL PIRATININGA & - & Companhia Piratininga de Força e Luz \\
\hline CPFL SANTACRUZ & - & Companhia Luz e Força Santa Cruz \\
\hline CPFL SULPAULISTA & - & Companhia Sul Paulista de Energia \\
\hline CUS_EVITADOS & - & Custos Evitados \\
\hline
\end{tabular}




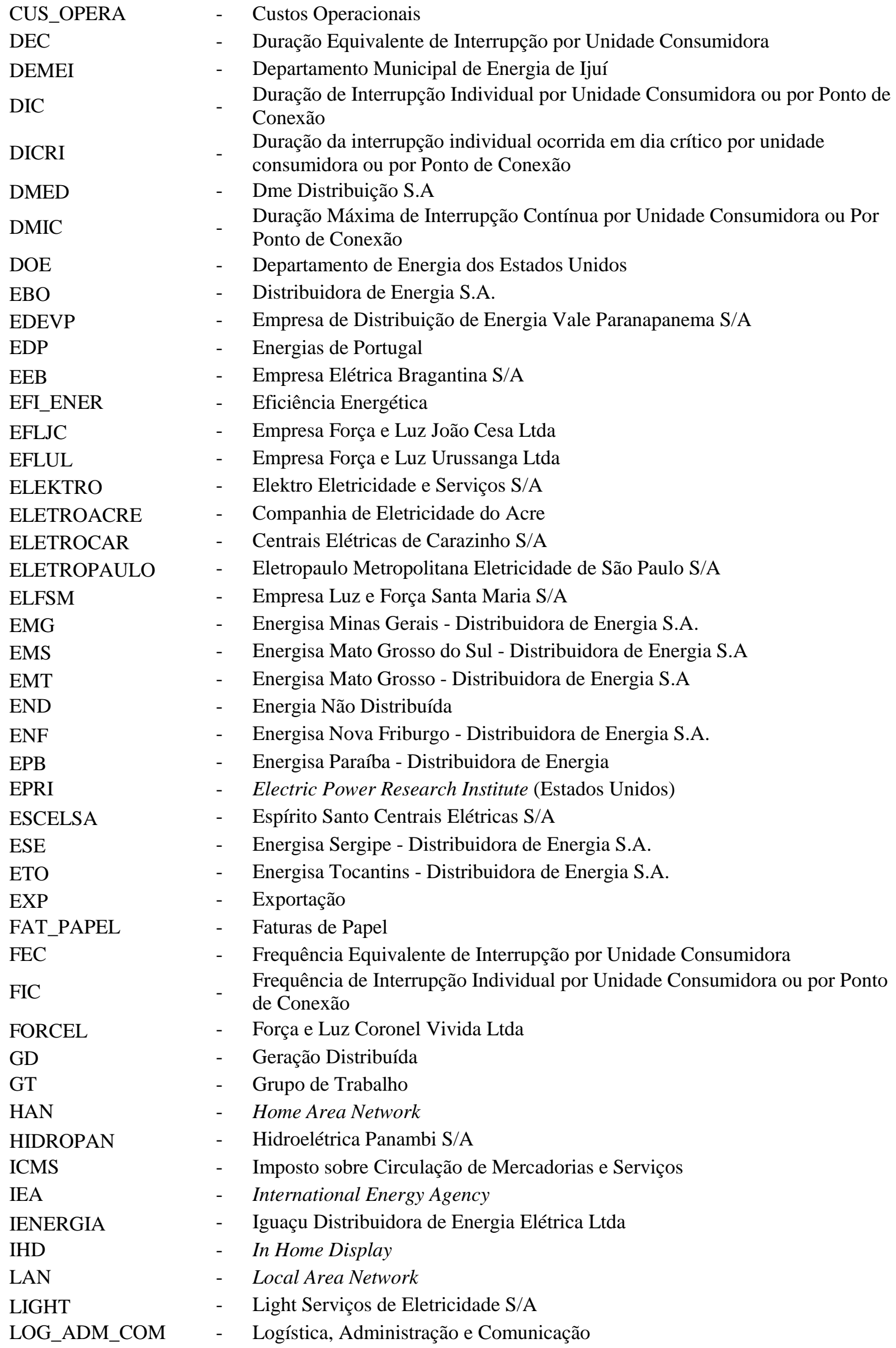




\begin{tabular}{|c|c|c|}
\hline MCPSE & - & Manual de Controle Patrimonial do Setor Elétrico \\
\hline MCT & - & Ministério da Ciência, Tecnologia, Inovação e Comunicações \\
\hline MME & - & Ministério de Minas e Energia \\
\hline MUX & - & Muxfeldt Marin \& Cia. Ltda \\
\hline NIST & - & National Institute of Standards and Technology (Estados Unidos) \\
\hline NT & - & Não Técnicas \\
\hline O\&M & - & Operação e Manutenção \\
\hline O\&M_SUBSC & - & O\&M e Subscrição \\
\hline OB & - & Observação \\
\hline P\&D & - & Pesquisa e Desenvolvimento \\
\hline PDD & - & Plano de Desenvolvimento da Distribuição \\
\hline PIS & - & Programa de Integração Social \\
\hline PLC & - & Power Line Comunication \\
\hline PRORET & - & Procedimentos de Regulação Tarifária \\
\hline RAN & - & Region Area Network \\
\hline REI & - & Redes Elétricas Inteligentes \\
\hline RGE & - & Rio Grande Energia S/A \\
\hline SAD & - & Sistema de Apoio à Decisão \\
\hline SGTF & - & Smart Grids Task Force \\
\hline SULGIPE & - & Companhia Sul Sergipana de Eletricidade \\
\hline TI & - & Tecnologia da Informação \\
\hline TSEE & - & Tarifa Social de Energia Elétrica \\
\hline $\mathrm{UC}$ & - & Unidades Consumidoras \\
\hline UHENPAL & - & Usina Hidroelétrica Nova Palma Ltda \\
\hline UK & - & United Kigdom \\
\hline VP & - & Valor Presente \\
\hline VPL & - & Valor Presente Líquido \\
\hline WACC & - & Weighted Average Cost of Capital \\
\hline WAN & - & Wide Area Network \\
\hline
\end{tabular}




\section{1- INTRODUÇÃO}

\section{1 - CONTEXTUALIZAÇÃ̃O}

Os Sistemas Elétricos de Potência deparam-se hoje com novas exigências de uma sociedade digitalizada e conscientizada ambientalmente, com demandas por mais qualidade, segurança, flexibilidade e sustentabilidade (MME, 2011). No serviço de distribuição, essa realidade se reflete na necessidade de uma melhor qualidade do serviço, menores níveis de perdas de energia, e um maior controle do pico de demanda, entre outros aspectos.

No Brasil, esse cenário mostra-se ainda mais desafiador. O indicador DEC (Duração Equivalente de Interrupção por Unidade Consumidora) apurado no país, subiu de 15,81 horas em 2004 para 18,60 horas em 2015, apontando períodos maiores de interrupção do fornecimento. No tocante às perdas, o valor percebido pelas empresas em 2014 representou $13,3 \%$ da energia total injetada nas redes de distribuição, gerando despesas da ordem de $\mathrm{R} \$$ 9,6 bilhões (ANEEL, 2016e). Quanto ao pico de demanda, as distribuidoras investiram mais de R 10 bilhões em 2015 com a expansão do sistema (ANEEL, 2016a).

Configurando-se como uma promissora ferramenta para modificar esse cenário, as Redes Elétricas Inteligentes (REI) têm resultado em significativos ganhos no setor de distribuição em diferentes países. Verificam-se reduções de até 30\% nos indicadores de continuidade DEC e FEC (Frequência Equivalente de Interrupção por Unidade Consumidora), e de mais de 40\% nas perdas não técnicas em alguns projetos (Lamin, 2013). Além disso, o Ministério de Minas e Energia (MME) estima em 5\% a redução do pico de demanda no país decorrente da implantação dessas redes. (MME, 2011).

Em contrapartida, os investimentos para implantação das REI são volumosos. Na Europa, estima-se que até 2020 sejam investidos $€ 56$ bilhões (EC, 2011). No Brasil, o Ministério de Minas e Energia (MME) previu custos da ordem de R \$ 20 bilhões (MME, 2011). Já Lamin (2013) identificou uma necessidade de recursos de até R \$ 67 bilhões, a valores de 2013, ao longo de 30 anos. Portanto, apesar dos potenciais benefícios decorrentes da implantação das REI, esses montantes indicam a necessidade de uma avaliação de viabilidade econômica, e também da identificação dos seus principais motivadores no Brasil. 
Considerando-se os aspectos ora mencionados, alguns dos estudos conduzidos no Brasil avaliaram o custo-benefício da implantação das REI no país. O trabalho da Associação Brasileira de Distribuidores de Energia Elétrica (ABRADEE), realizado no âmbito de Projeto Estratégico de Pesquisa e Desenvolvimento (P\&D) da Agência Nacional de Energia Elétrica (ANEEL), mostrou que, sob a perspectiva da sociedade, a utilização das novas tecnologias apresenta custo-benefício positivo (ABRADEE, 2011). O mesmo ocorre com o estudo de Lamin (2013), que demonstrou que o Valor Presente Líquido (VPL) do saldo de uma implantação nacional também é positivo. Silva (2016) estimou os custos e benefícios em 9 concessionárias de distribuição. Seus resultados indicam a viabilidade para as REI nas 9 empresas, em cenários de maior penetração das tecnologias.

Esses trabalhos apontam ainda que os principais motivadores para o novo padrão tecnológico das redes de distribuição no país são a melhoria da qualidade do serviço, os custos evitados com a expansão do sistema, e a redução das perdas não técnicas de energia. Com efeito, considerando os estudos conduzidos no Brasil sobre as REI, percebe-se uma certa convergência para esses motivadores.

Todavia, ainda não existe uma avaliação que aborde as características específicas de todas as distribuidoras do país, tanto para uma avaliação da viabilidade econômica quanto para a identificação dos motivadores das novas redes.

Com base nesse cenário, o presente trabalho objetiva executar uma análise de custobenefício da implantação das REI nas concessionárias brasileiras de distribuição de energia elétrica, e identificar os principais motivadores para essas redes no país.

\section{2 - MOTIVAÇÕES}

Atuam hoje no Brasil, 63 concessionárias e 38 permissionárias de distribuição, que atendiam quase 77 milhões de Unidades Consumidoras (UC) ao final de 2015. Desse total, 88\% eram residenciais, com consumo médio mensal de $166 \mathrm{kWh}$. As concessionárias são responsáveis pelo atendimento de mais de $99 \%$ do mercado e do número de consumidores, representando quase a totalidade da prestação do serviço de distribuição no país (ANEEL, 2016b). 
As 63 concessionárias tiveram uma receita de fornecimento da ordem de R $\$ 134$ bilhões em $2015^{1}$, porém de forma significativamente discrepante. A maior arrecadação ultrapassou $R \$$ 13 bilhões naquele ano, enquanto a menor não atingiu R \$ 8 milhões (ANEEL, 2016b).

Essas diferenças se estendem para o consumo mensal médio, que, ao final de 2015, foi de 228 a $1.030 \mathrm{kWh}$ entre as concessionárias com o menor e o maior consumo, respectivamente. Na mesma linha, verificando-se a qualidade do serviço, existem empresas com DEC apurado igual ao triplo de outras distribuidoras.

Ainda com respeito à qualidade, quanto às compensações pela transgressão dos limites de continuidade individuais DIC, FIC, DMIC e DICRI ${ }^{2}$, identifica-se uma distribuidora que compensou seus consumidores em mais $\mathrm{R} \$ 126$ milhões em 2015, e empresa que compensou em menos de R\$ 165 no mesmo ano (ANEEL, 2016c).

Adicionalmente, no tocante às perdas não técnicas de energia, verificaram-se percentuais entre $0 \%$ e $44 \%$ em 2015. Além disso, diferenças também são percebidas em aspectos relacionados à densidade de carga, extensão de rede, distribuição de consumidores por classe de consumo, e nível de tensão, entre outros, o que justifica as discrepâncias entre as tarifas médias de fornecimento, que variavam de $275 \mathrm{R} \$ / \mathrm{MWh}$ a $547 \mathrm{R} \$ \mathrm{MWh}^{3}$ ao final de 2015 (ANEEL, 2016d).

Em virtude dessas diferenças entre as distribuidoras brasileiras, e considerando-se que os custos e os benefícios da implantação das REI variam com as características específicas das áreas de concessão, faz-se necessária a incorporação desses aspectos na análise da viabilidade econômica das novas redes no país, o que motiva a realização deste trabalho.

\footnotetext{
${ }^{1}$ Sem impostos.

${ }^{2}$ DIC - Duração de Interrupção Individual por Unidade Consumidora ou por Ponto de Conexão; FIC - Frequência de Interrupção Individual por Unidade Consumidora ou por Ponto de Conexão; DMIC - Duração Máxima de Interrupção Contínua por Unidade Consumidora ou por Ponto de Conexão; DICRI - Duração da interrupção individual ocorrida em dia crítico por unidade consumidora ou por Ponto de Conexão.

${ }^{3}$ Sem impostos.
} 


\section{3 - OBJETIVOS}

O presente trabalho tem como objetivo apresentar a análise de custo-benefício da implantação das REI nas concessionárias de distribuição de energia elétrica do Brasil. Para tanto, utiliza-se o Valor Presente Líquido (VPL) dos investimentos necessários e dos benefícios decorrentes do novo padrão tecnológico da distribuição.

Também constitui objetivo deste trabalho a identificação dos principais motivadores para essas redes no país, o que é possível por meio da aplicação de processos de clusterização ${ }^{4}$ e de técnicas de correlação nos resultados de custos e de benefícios de cada distribuidora.

\section{4 - ESTRUTURA DO TRABALHO}

Após esta introdução, o capítulo 2 traz uma revisão bibliográfica sobre as REI, abordando sua definição, benefícios e conjunturas internacional e nacional. Nesse capítulo também são apresentadas as análises de custo-benefício da implantação dessas redes já realizadas no Brasil, e alguns aspectos dos processos de clusterização.

No capítulo 3, exibem-se os materiais e métodos utilizados. Aborda-se a caracterização dos equipamentos, das tecnologias, das funcionalidades, e do nível de penetração da medição eletrônica inteligente e dos dispositivos de telecomunicações e de automação. Complementarmente, expõe-se a metodologia, valores e parâmetros aplicados na estimação dos custos e dos benefícios da implantação das REI em 62 distribuidoras, e na identificação dos seus motivadores.

O capítulo 4 expõe e analisa os resultados do trabalho. Apresentam-se as empresas nas quais não há viabilidade econômica atualmente para as novas redes e aquelas em que já se verifica essa viabilidade. Também se discorre sobre as componentes mais representativas para o saldo da implantação, e sobre os principais motivadores para as novas tecnologias no Brasil.

O capítulo 5 apresenta as conclusões do trabalho e o apêndice A exibe os dados utilizados na estimação dos custos e dos benefícios.

\footnotetext{
${ }^{4}$ Processos de clusterização permitem a identificação da representatividade das componentes de custos e benefícios avaliadas.
} 


\section{2 - REVISÃO BIBLIOGRÁFICA}

\section{1 - REDES ELÉTRICAS INTELIGENTES}

\subsection{1 - Definição}

O termo Smart Grids ou Redes Elétricas Inteligentes (REI), em tradução livre, surge com Amin e Wollenberg (2005), que as definem como "uma infraestrutura de rede elétrica em larga escala caracterizada por segurança, agilidade e resiliência/robustez que enfrenta novas ameaças e condições não previstas".

O Departamento de Energia dos Estados Unidos (DOE) conceitua as REI como "um sistema automatizado, caracterizado por um fluxo bidirecional de energia elétrica e de informações, capaz de monitorar tudo, desde usinas até as preferências dos consumidores. Esse sistema incorpora na rede os benefícios da computação distribuída e da comunicação para oferecer informações em tempo real e permitir o equilíbrio quase instantâneo de oferta e demanda" (DOE, 2009).

Segundo um documento da área de energia da Comissão Europeia, "Uma rede inteligente pode ser definida como uma rede elétrica modernizada à qual foram acrescentados um sistema digital de comunicação bidirecional entre o fornecedor e o consumidor e sistemas inteligentes de medição e de controle" (EC, 2011).

No Brasil, de acordo com o relatório do Ministério de Minas e Energia (MME) “Existem várias definições para o conceito de redes inteligentes, mas todas convergem para o uso de elementos digitais e de comunicações nas redes que transportam a energia. Esses elementos possibilitam o envio de uma gama de dados e informações para os centros de controle, onde eles são tratados, auxiliando na operação e controle do sistema como um todo" (MME, 2011).

Em sintonia com essas definições, a Figura 2.1 exibe o modelo conceitual das REI segundo o National Institute of Standards and Technology (NIST) dos EUA. 


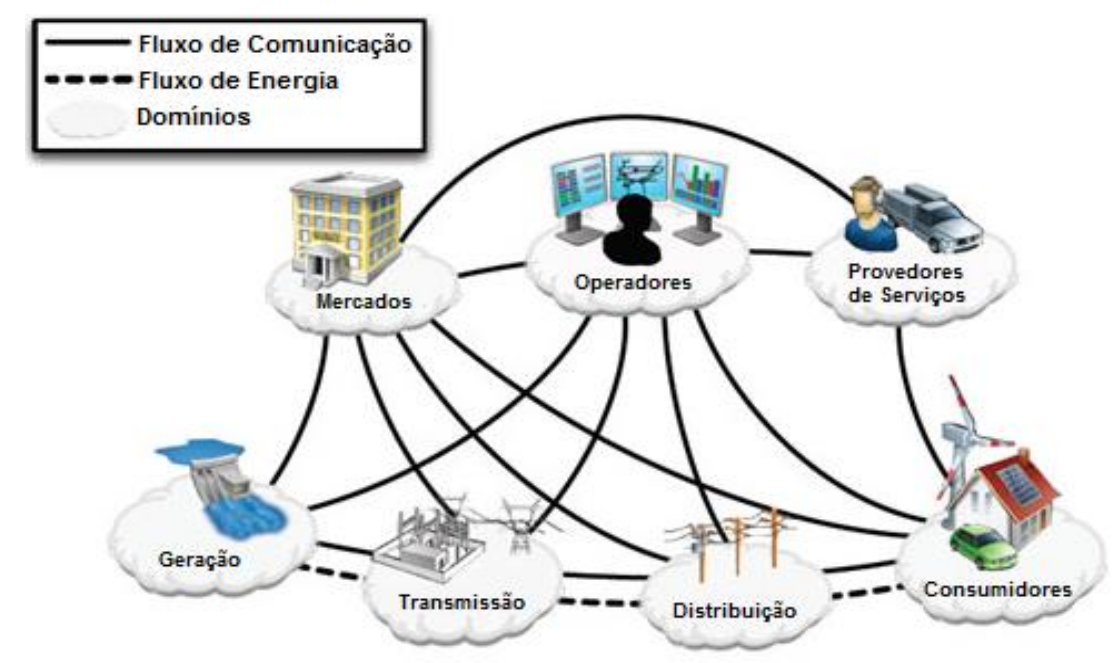

Figura 2.1 - Modelo conceitual das REI. Adaptado de (NIST, 2009).

Percebe-se na Figura 2.1 que, segundo o NIST, as REI envolvem um fluxo bidirecional entre os agentes do setor elétrico. Além disso, ao se visualizar no domínio de consumidores a presença de geração de pequeno porte e veículos elétricos, também é possível inferir que estes assumem um papel mais ativo no novo cenário.

Para viabilizar esse novo ambiente, são fundamentais diversos novos componentes que, para propiciar a maximização de funcionalidades, devem funcionar de forma integrada e coordenada, com segurança e interoperabilidade:

1) Medidores Eletrônicos Inteligentes: esses equipamentos viabilizam, dentre outras funcionalidades, a telemedição, corte e religamento remoto, novos modelos tarifários, combate a fraudes, medição da geração distribuída e disponibilização de informações em tempo real aos consumidores;

2) Infraestrutura de Telecomunicações: para permitir a troca de informações entre os consumidores e as distribuidoras, viabilizar a aquisição de dados e operar remotamente as redes, é fundamental a ampliação da infraestrutura de telecomunicações;

3) Automação: controladores Volt/VAR, chaves e religadores operados remotamente, o monitoramento em tempo real do estado da rede e a identificação instantânea de faltas eleva o patamar da qualidade do serviço de distribuição.

4) Tecnologia da Informação (TI): o alto volume de informações adquiridas nas REI, a necessidade de tomada de decisão de forma mais ágil e o novo padrão de 
gerenciamento de ativos requerem um aumento da capacidade de hardware e de software nos centros de operação e de faturamento;

A Figura 2.2 apresenta os cenários atual e futuro do setor elétrico, visando-se ilustrar as diferenças decorrentes desse novo padrão tecnológico das redes.

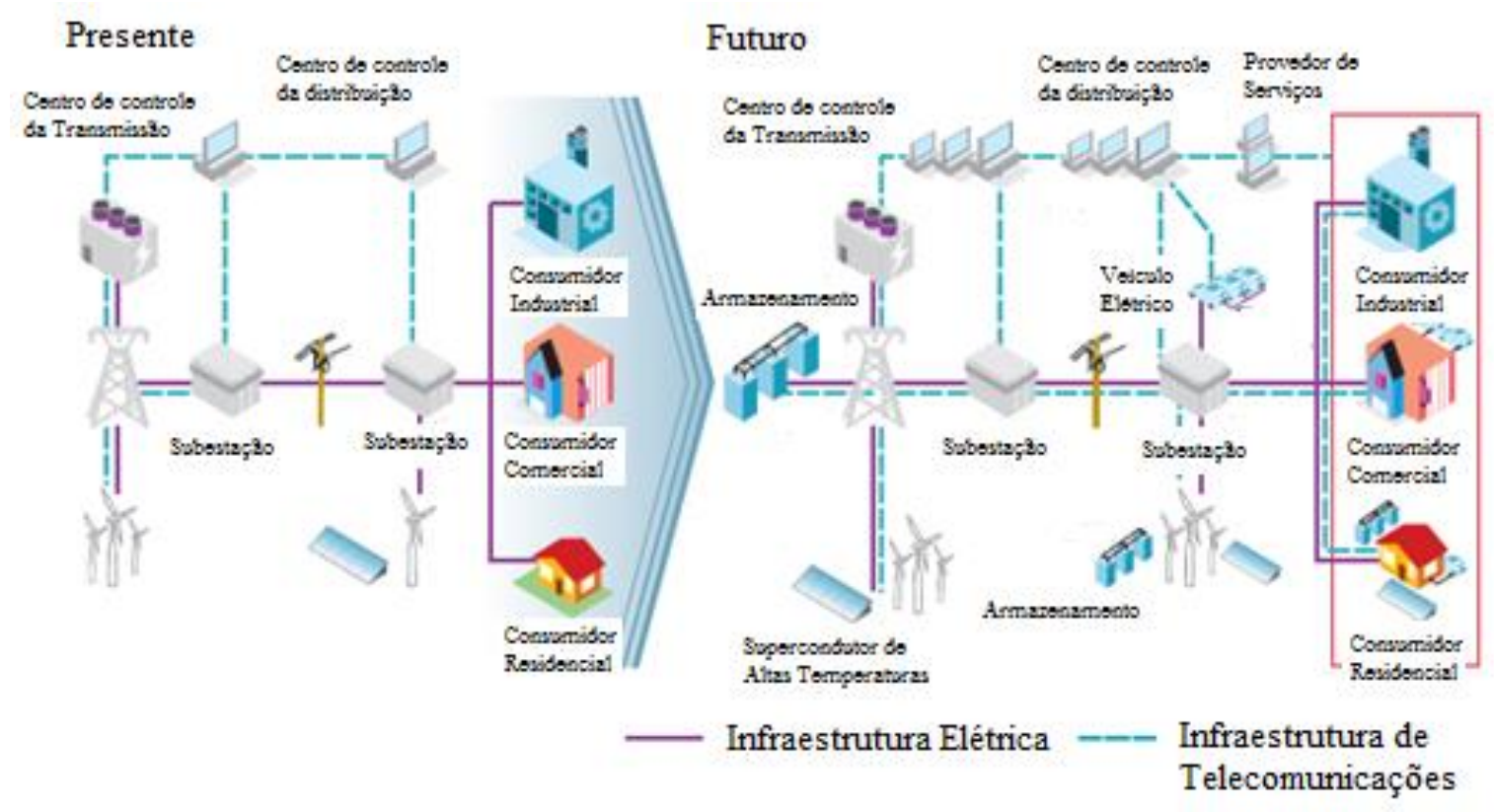

Figura 2.2 - Cenários atual e futuro do setor elétrico. Adaptado de (IEA, 2011).

Focando-se nos centros de controle da transmissão e da distribuição ilustrados na Figura 2.2, depreende-se que o futuro das redes elétricas é marcado pelo crescimento da capacidade computacional. Comparando-se os dois cenários, notam-se também as novas relações entre os integrantes do sistema, sustentadas por uma maior infraestrutura de telecomunicações. Percebe-se, ainda, o surgimento de novas tecnologias, como os supercondutores, os veículos elétricos e as ferramentas de armazenamento, e de um novo agente, o provedor de serviços.

\subsection{2 - Benefícios das REI}

O setor elétrico que está surgindo com a implantação das REI propicia benefícios que se estendem para a eficiência operacional, melhoria da qualidade do serviço e da segurança, incorporação de geração distribuída e veículos elétricos, controle de demanda, combate a perdas, dentre outros. 
Nesse ponto, as primeiras experiências de implantação, estudos e projetos pilotos sobre as novas tecnologias no Brasil e no mundo mostram resultados promissores. Por exemplo, verificam-se reduções de até 30\% nos indicadores de continuidade DEC e FEC e de mais de 40\% nas perdas não técnicas em algumas dessas iniciativas (Lamin, 2013).

O relatório do Grupo de Trabalho (GT) sobre as REI, conduzido pelo MME, estima que a implantação das novas redes no Brasil pode gerar, no setor de distribuição, uma redução de $5 \%$ da demanda de pico, o que contribui para a postergação de investimentos da ordem de $\mathrm{R} \$ 4,9$ bilhões (MME, 2011).

No que tange ao consumo, a infraestrutura de distribuição atualizada permite a aplicação de novos modelos tarifários para incentivar o uso mais eficiente da energia pelos consumidores. Experiências internacionais apontam para um potencial de redução de até $21 \%$ no consumo (Lamin, 2013).

Adicionalmente, quanto ao combate às perdas não técnicas, o programa da concessionária AMPLA, conhecido como "AMPLA CHIP”, indica resultados de redução de 50 pontos percentuais dessas perdas (Lamin, 2013). O GT do MME também considera que a redução de consumo e de perdas técnicas e não técnicas pode representar a postergação de investimentos de até R \$ 27,9 bilhões em novas plantas de geração no Brasil (MME, 2011).

Além disso, a própria geração distribuída de pequeno porte, que avança no Brasil com o advento da Resolução Normativa ANEEL $n^{\circ}$ 482/2012, pode gerar mais benefícios se inserida em uma rede mais automatizada e monitorada, e em um ambiente onde os consumidores acessam as informações mais facilmente.

Por outro lado, apesar do seu potencial, as REI não têm receita pronta. Em função disso, um estudo daquilo que essa ferramenta oferece e das realidades técnica e econômica atuais caracteriza-se como indispensável para uma eficiente transição de sistemas (Ferreira Filho et al., 2013). É nesse cenário que se inserem as iniciativas internacionais e brasileiras relativas a esse tema. 


\subsection{3 - Conjuntura Internacional}

Diversos países têm conduzido projetos de implementação, pesquisa e desenvolvimento e de demonstração sobre as REI, com diferentes motivações, escopos e tecnologias avaliadas, conforme apresentado na Figura 2.3.

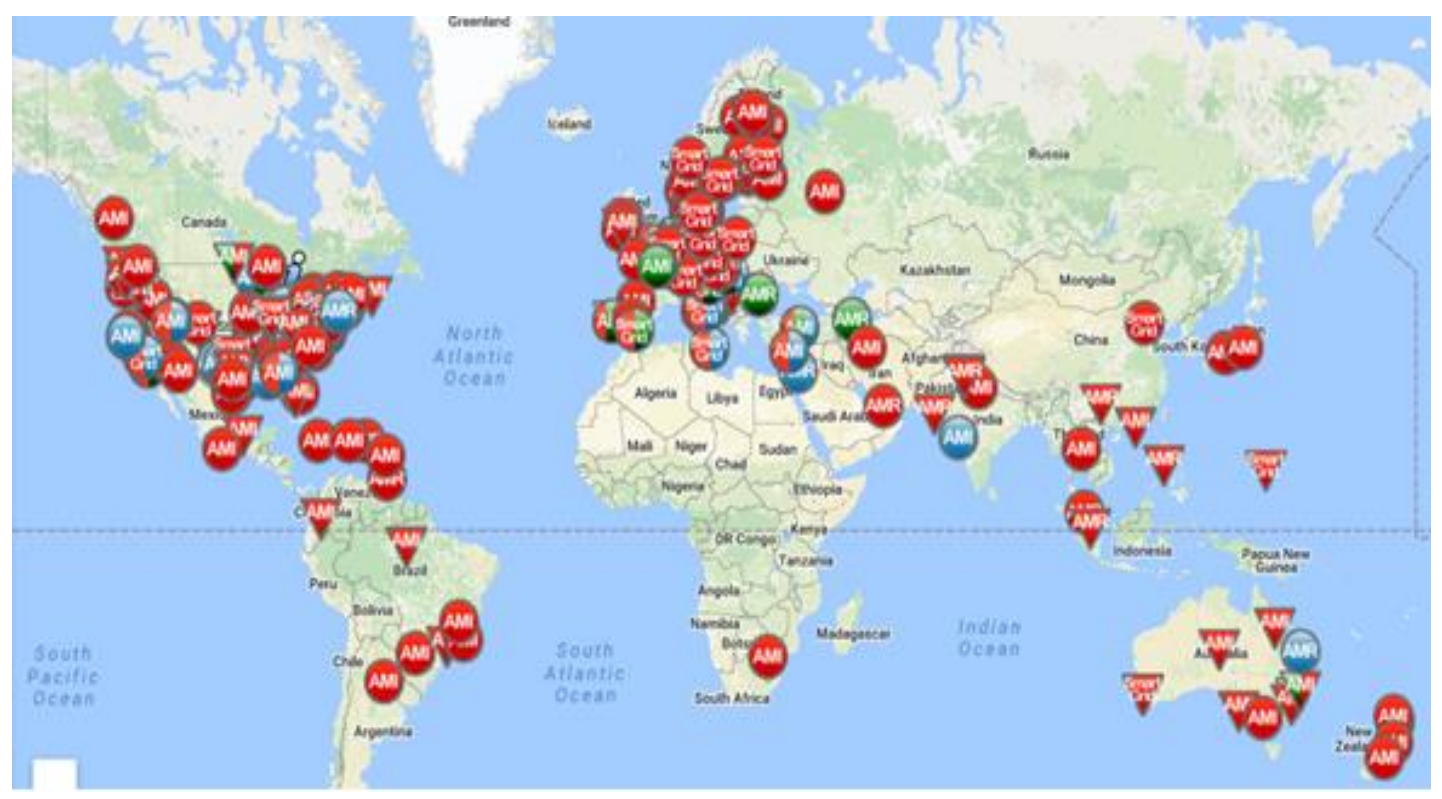

Figura 2.3 - Projetos sobre as REI em diferentes países (ENERGY UK, 2012).

Percebe-se na Figura 2.3 que em vários países, distribuídos em todos os continentes, existem projetos sobre as REI.

Nos diferentes países, pode-se citar como principais motivações para as iniciativas relacionadas às novas redes:

1) Descarbonização da matriz energética;

2) Controle da demanda;

3) Melhor gestão de ativos;

4) Inserção de veículos elétricos;

5) Melhoria da qualidade do serviço; e

6) Segurança das redes e das pessoas. 
Da análise da Figura 2.3 também é possível notar que existe uma maior concentração desses projetos nos Estados Unidos e nos países europeus. Por conta disso, é oportuno apresentar as iniciativas dessas regiões com mais detalhes.

\subsubsection{1 - Estados Unidos}

Os Estados Unidos são um dos países que mais têm investido em pesquisas relacionadas às REI, em decorrência do plano The American Recovery Act of 2009, por meio do qual são liberados mais de US\$ 3,4 bilhões para estímulo a tecnologias e a projetos de REI. Os financiamentos estão condicionados a investimentos por parte das empresas beneficiadas, que somam US\$ 4,5 bilhões (Lamin, 2013). Nota-se na Figura 2.3 que, de fato, existem inúmeros projetos relacionados às REI no país, distribuídos em vários estados.

Os principais motivadores americanos são a modernização das redes, hoje com ativos já excessivamente envelhecidos, a segurança a ataques externos e desastres naturais, e as pressões por mudanças na matriz energética, atualmente muito baseada no carvão (Ferreira Filho et al., 2013).

Por meio dos recursos disponibilizados pelo governo americano complementados pela contrapartida das empresas, totalizando US\$ 7,9 bilhões, estão sendo financiados 99 projetos, que envolvem 200 concessionárias e outras instituições. Os objetivos são modernizar a rede elétrica, fortalecer a segurança cibernética, aprimorar a interoperabilidade e coletar dados relativos à operação das REI (DOE, 2016).

\subsubsection{2 - Europa}

Na Europa, o fator de maior preocupação é ambiental, sendo este o principal motivador dos esforços referentes ao desenvolvimento de uma rede mais inteligente. Isso fica evidenciado na Agenda 20/20/20, elaborada pela Comissão Europeia, na qual são estabelecidas três principais metas: reduzir as emissões de gases do efeito estufa em pelo menos 20\%; aumentar em $20 \%$ a eficiência energética; e alcançar uma penetração de $20 \%$ de fontes renováveis (Ferreira Filho et al., 2013). 
Para atingir esses objetivos foi criado, em 2009, a Smart Grids Task Force (SGTF) com a missão de aconselhar a Comissão Europeia na elaboração de políticas e medidas regulatórias para coordenar os primeiros passos em direção à implementação das REI e auxiliar na identificação de projetos de interesse comum dos estados membros nesse tema (SGTF, 2009).

A SGTF é dividida em cinco grupos de especialistas que tratam dos seguintes temas (SGTF, 2009):

1) Padronização das REI;

2) Proteção de dados e segurança cibernética;

3) Recomendações regulatórias para a implementação das REI

4) Implementação da infraestrutura; e

5) Implementação da política industrial.

Dentro dessa estrutura estão envolvidos 459 projetos, com investimentos totais da ordem de $€ 3,15$ bilhões e 1.670 instituições participantes (EC, 2014).

\subsection{4- Conjuntura Nacional}

Alguns passos têm sido dados no Brasil para promover as novas redes elétricas. Pode-se citar a geração distribuída de pequeno porte, regulamentada pela Resolução Normativa $\mathrm{n}^{\circ}$ 482/2012, recentemente atualizada para consolidar incentivos e procedimentos.

Adicionalmente, com o advento da Resolução Normativa $n^{\circ}$ 502/2012, a medição inteligente experimenta os passos iniciais em diretrizes oficiais, com suas primeiras funcionalidades. Além disso, nos próximos meses, deve se concretizar a aplicação da tarifa branca, que, por meio do estabelecimento de postos horários na baixa tensão, incentiva a redução da demanda de pico. Esse novo modelo tarifário tem previsão de disponibilização aos consumidores em 2018.

No que tange às iniciativas de governo, cita-se o grupo de trabalho criado pelo MME com o objetivo de avaliar políticas para a implantação das REI no Brasil (MME, 2011). Além disso, no Congresso Nacional tramitam projetos de lei concernentes ao tema. 
Ainda, a Agência Brasileira de Desenvolvimento Industrial (ABDI) tem investido na elaboração de políticas voltadas aos fornecedores das novas tecnologias, e o Ministério da Ciência, Tecnologia, Inovações e Comunicações (MCT) avalia perspectivas para a implantação das novas redes considerando a realidade brasileira (CGEE, 2012).

Quanto à Pesquisa e Desenvolvimento (P\&D), há, no Brasil, um considerável número de iniciativas sobre REI ou aspectos relacionados diretamente a elas. Um dos principais programas desenvolvidos vem da própria ANEEL, a partir da Chamada de Projeto Estratégico de P\&D n ${ }^{\circ}$ 011/2010. Essa chamada, além de incentivar diversos estudos de aplicabilidade desse novo sistema no Brasil, cria uma agenda para os próximos anos, com sugestões de temas a serem desenvolvidos nas diversas áreas que compõem a nova rede elétrica (Ferreira Filho et al., 2013).

No tocante às concessionárias, cita-se a Cemig, cujo projeto é, até o momento, o mais abrangente do país. Ele objetiva estabelecer um modelo funcional de referência para subsidiar futuras decisões de implantação em larga escala das REI. Neste projeto, os aspectos regulatórios, socioeconômicos, financeiros e de percepção dos clientes são avaliados (REDESINTELIGENTESBRASIL, 2016).

Outra iniciativa de destaque é a conduzida pela Light, que envolve a implantação de medição inteligente em 400.000 unidades consumidoras. Como resultado desta empreitada, tem-se a concepção e produção de um medidor direcionado para as necessidades brasileiras.

Adicionalmente, ressalta-se o projeto da EDP Bandeirante, InovCity, que tem sido desenvolvido na cidade de Aparecida, São Paulo. Ele replica a experiência do Grupo EDP em projeto similar na cidade de Évora, em Portugal.

Em universidades e em centros de pesquisa também se realizam trabalhos sobre as REI, como na Universidade Federal do Amazonas, na Universidade Estadual de Campinas, na Universidade Federal do Ceará, na Universidade de São Paulo e na Universidade de Brasília.

A Figura 2.4 apresenta a distribuição regional dos projetos sobre as REI no Brasil. 


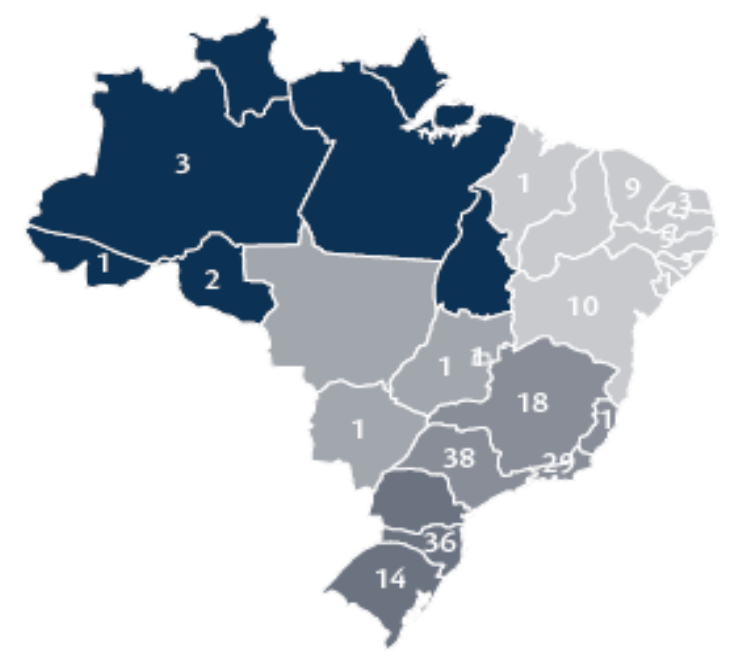

Figura 2.4 - Distribuição regional dos projetos sobre as REI no Brasil (CGEE, 2012).

Percebe-se na Figura 2.4 que existem projetos sobre as REI em todas as regiões do país, com maior concentração no Sudeste. Nota-se também que há um total de 178 iniciativas relativas às novas redes.

A Figura 2.5 expõe a distribuição regional do investimento realizado nesses projetos (em milhões).

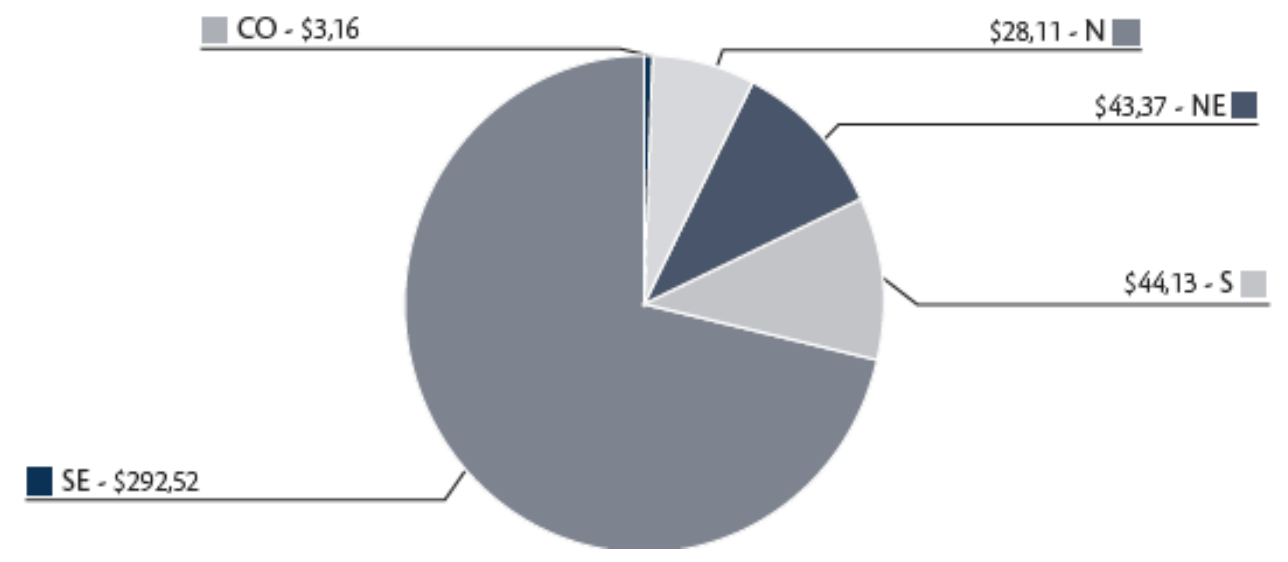

Figura 2.5 - Distribuição regional do investimento realizado em projetos sobre as REI no Brasil (CGEE, 2012).

Depreende-se da Figura 2.5 que os investimentos nesses projetos sobre as REI no Brasil totalizam mais de R 400 milhões, dos quais, mais de 70\% são alocados em iniciativas da região Sudeste. 
Apesar dessas inúmeras iniciativas, ainda são poucos os estudos que abordam o custobenefício da implantação das REI no país.

\section{2 - ANÁLISE DE CUSTO-BENEFÍCIO DA IMPLANTAÇÃO DAS REI}

\subsection{1 - Aspectos teóricos de análises de custo-benefício}

Classificada como uma metodologia de Análise de Impacto Regulatório, a análise de custobenefício é uma ferramenta que apresenta avaliação antecipada dos impactos de novas propostas ou alterações de normas (Lamin, 2013).

A análise de custo-benefício contempla o interesse de quem cria a regra com a necessidade de quem é atingido por ela. Por considerá-la uma técnica completa, as referências nacionais e internacionais sugerem que análises de impacto devam aplicar a metodologia de custobenefício para todas as decisões regulatórias e políticas (Lamin, 2013).

Dentre as métricas disponíveis para análise de custo-benefício, o Valor Presente Líquido (VPL) do fluxo de caixa dos custos e dos benefícios anuais aparece como uma das formas mais adequadas para situações em que os investimentos permeiam um número elevado de anos.

Algumas ferramentas de matemática financeira e engenharia econômica, tais como taxa de juros e período de capitalização, também são importantes para a realização de um estudo de custo-benefício que utilize a métrica de VPL (Camargo, 1998).

Algumas fases e requisitos são necessários para o processo de análise de custo-benefício. Entre as etapas, destaca-se a de coleta de dados, uma vez que a análise depende de informações que a suportem. A fase de coleta de dados pode ser a etapa mais cara e que demanda mais tempo na execução de custo-benefício (Lamin, 2013). Diferenças entre os dados utilizados para se quantificar os custos e os benefícios impactam significativamente no VPL resultante. 


\subsection{2 - Custo-benefício da implantação das REI}

Benefícios podem ser definidos como o impacto de um projeto que tem valor a uma concessionária, consumidor ou sociedade em geral, e devem ser quantificados sempre que possível. Adicionalmente, para facilitar comparações, eles devem ser expressos em termos monetários (EPRI, 2010).

Alguns exemplos de benefícios advindos da implantação das REI são:

1) Redução de perdas e interrupções;

2) Melhoria operacional;

3) Viabilização da inserção de geração distribuída de pequeno porte e veículos elétricos;

4) Eficiência energética; e

5) Facilitação do acesso a informações pelos consumidores.

Por outro lado, os custos referem-se ao investimento realizado para implementar o novo padrão das redes. Geralmente, a quantificação de custos é menos complexa do que de benefícios (EC, 2012).

Alguns exemplos de custo são:

1) Aquisição e instalação de medidores, equipamentos de telecomunicações e de TI;

2) Custos operacionais; e

3) Logística.

Segundo a Comissão Europeia, a estimação do custo-benefício da implantação das REI é dividida em três grandes etapas: i) caracterização do projeto, que envolve a descrição de tecnologias, objetivos e funcionalidades, ii) estimação dos benefícios, e iii) comparação de custos e benefícios (EC, 2012).

2.2.2.1 - Estudos de custo-benefício da implantação das REI no Brasil

Ainda são poucos os projetos conduzidos no Brasil sobre as REI que estimam o custobenefício da implantação das novas tecnologias. O primeiro deles, resultado do grupo de 
trabalho criado pelo MME para avaliar o tema, estima custos da ordem de R $\$ 19$ bilhões e benefícios superiores a $\mathrm{R} \$ 35$ bilhões.

Pode-se citar também o trabalho da Associação Brasileira de Distribuidores de Energia Elétrica (ABRADEE), realizado no âmbito de Projeto Estratégico de P\&D da ANEEL. Nesse projeto são considerados 3 cenários de implantação: acelerado, moderado e conservador. Os resultados são avaliados sob três óticas: da sociedade, do consumidor de energia elétrica e das distribuidoras (ABRADEE, 2011).

A Tabela 2.1 expõe os resultados sob a ótica da sociedade da análise de custo-benefício sobre a implantação das REI no Brasil conduzida pela ABRADEE.

Tabela 2.1 - Resultados, sob a ótica da sociedade, do custo-benefício da implantação das REI no Brasil. Adaptado de (ABRADEE, 2011).

\begin{tabular}{|c|c|c|c|c|c|c|c|c|c|}
\hline \multirow{3}{*}{$\begin{array}{c}\text { SOCIEDADE } \\
\text { (VPL em milhões) }\end{array}$} & \multicolumn{3}{|c|}{ ACELERADO } & \multicolumn{3}{|c|}{ MODERADO } & \multicolumn{3}{|c|}{ CONSERVADOR } \\
\hline & \multirow[t]{2}{*}{\begin{tabular}{|l|} 
CUSTOS \\
\end{tabular}} & \multicolumn{2}{|c|}{ BENEFÍCIOS } & \multirow[t]{2}{*}{ CUSTOS } & \multicolumn{2}{|c|}{ BENEFÍCIOS } & \multirow[t]{2}{*}{ CUSTOS } & \multicolumn{2}{|c|}{ BENEFÍCIOS } \\
\hline & & INFERIOR & SUPERIOR & & INFERIOR & SUPERIOR & & INFERIOR & SUPERIOR \\
\hline Medição & 18.533 & & & 11.300 & & & 8.407 & & \\
\hline Automação & 3.513 & & & 2.960 & & & 2.234 & & \\
\hline GD & 9.890 & & & 2.728 & & & 49 & & \\
\hline Redução END & & 11.864 & 17.773 & & 7.870 & 11.792 & & 3.589 & 5.377 \\
\hline Perdas NT & & 6.364 & 12.261 & & 4.870 & 9.394 & & 3.815 & 7.385 \\
\hline Custos Evitados Med & & 5.194 & 5.194 & & 3.690 & 3.690 & & 2.760 & 2.760 \\
\hline Eficiência Operacional & & 3.068 & 3.068 & & 1.829 & 1.829 & & 936 & 936 \\
\hline Custos Evitados Exp GD & & 15.796 & 15.796 & & 11.308 & 11.308 & & 6.808 & 6.808 \\
\hline Total & 31.936 & 42.286 & 54.092 & 16.988 & 29.567 & 38.013 & 10.690 & 17.908 & 23.266 \\
\hline Valor Presente Líquido & & 10.350 & 22.156 & & 12.578 & 21.024 & & 7.218 & 12.576 \\
\hline
\end{tabular}

Nota-se na Tabela 2.1 que, segundo a ABRADEE, sob a ótica da sociedade, a implantação das novas tecnologias no Brasil se viabiliza em todos os cenários, com maior ganho no caso acelerado. Percebe-se também que tantos os custos como os benefícios das novas redes atingem cifras da ordem de bilhões de reais.

O trabalho conduzido por Lamin (2013), que considera os graus de implantação tímido, intermediário e avançado, evolui na estimação dos benefícios ao segregá-los de acordo com o comportamento dos consumidores no novo ambiente do setor elétrico. Para tanto, cada 
cenário é avaliado com e sem a presença de mostradores digitais ${ }^{5}$ nas unidades consumidoras. A Tabela 2.2 expõe os resultados alcançados.

Tabela 2.2 - Resultados do custo-benefício da implantação das REI no Brasil. Adaptado de (Lamin, 2013).

\begin{tabular}{|c|c|c|c|c|c|c|c|}
\hline \multirow{2}{*}{ CENÁRIO } & \multirow{2}{*}{ IMPLANTAÇÃO } & \multirow{2}{*}{ IHD } & \multicolumn{3}{|c|}{ VPL EM R\$ BILHÕ̃S } & \multirow{2}{*}{ B/C } & \multirow{2}{*}{ TIR } \\
\cline { 4 - 6 } & & & CUSTOS (C) & BENEFÍCIOS (B) & SALDO (B-C) & & \\
\hline C1 & $50 \%$ & $0 \%$ & $-32,705$ & 41,029 & 8,324 & 1,2545 & $13,41 \%$ \\
\hline C2 & $80 \%$ & $0 \%$ & $-52,268$ & 65,647 & 13,379 & 1,2560 & $13,45 \%$ \\
\hline C3 & $100 \%$ & $0 \%$ & $-65,310$ & 82,059 & 16,749 & 1,2565 & $13,47 \%$ \\
\hline C4 & $50 \%$ & $10 \%$ & $-33,860$ & 43,152 & 9,292 & 1,2744 & $13,94 \%$ \\
\hline C5 & $80 \%$ & $16 \%$ & $-54,116$ & 69,044 & 14,928 & 1,2759 & $13,99 \%$ \\
\hline C6 & $100 \%$ & $20 \%$ & $-67,619$ & 86,305 & 18,686 & 1,2763 & $14,00 \%$ \\
\hline
\end{tabular}

Percebe-se na Tabela 2.2 que em todos os cenários avaliados por Lamin (2013), há viabilidade para implantação das REI no Brasil. Focando-se nos casos em que se considera a instalação do IHD, é possível notar que o resultado do custo-benefício é mais positivo do que nos demais.

Silva (2016) estima custos e benefícios da implantação das REI em 9 concessionárias de distribuição, considerando 3 cenários de penetração da medição eletrônica, 20\%, 50\% e 70\% das unidades consumidoras. Os resultados apontam para viabilização das novas tecnologias em todos os cenários para 8 empresas. A exceção é a COELBA, cuja implantação não é viável nos cenários de menor penetração.

Apesar desses trabalhos apontarem a viabilidade das novas tecnologias no país, não consta na literatura uma análise de custo-benefício da implantação das REI no Brasil que considere as diferenças entre todas as concessionárias de distribuição.

\subsubsection{2 - Motivadores para implantação das REI no Brasil}

Diferentemente do que se percebe no resto do mundo, no Brasil os principais motivadores não estão relacionados a questões ambientais, inserção de veículos elétricos ou segurança

\footnotetext{
${ }^{5}$ Os mostradores digitais ou In-Home-Display (IHD) no termo original em inglês dispõem ao consumidor, em tempo real, informações relativas a consumo, interrupções e tarifas, dentre outras.
} 
cibernética. Há, na verdade, uma certa convergência para aspectos ligados à redução do patamar de perdas, melhoria da qualidade do serviço e eficiência energética.

De acordo com CGEE (2012), os principais motivadores brasileiros são:

1) Redução das perdas técnicas e não técnicas;

2) Melhoria da qualidade do serviço;

3) Redução dos custos operacionais;

4) Melhoria do planejamento da expansão da rede;

5) Melhoria da gestão de ativos;

6) Promoção da eficiência energética; e

7) Fomento da inovação e da indústria tecnológica.

Segundo Ferreira Filho et al. (2013), a implantação das novas redes no Brasil encontra fundamento na redução de perdas, melhoria da qualidade do serviço e fomento da indústria.

Em sintonia com esses trabalhos, a análise de custo-benefício realizada pela ABRADEE (2011) aponta que os maiores benefícios da implantação das REI no Brasil são, respectivamente, redução da energia não distribuída ${ }^{6}$, custo evitados com a expansão das redes de distribuição ${ }^{7}$ e redução das perdas não técnicas.

Também alinhado com esses resultados, Lamin (2013) estima que os maiores benefícios decorrem da redução das perdas não técnicas, seguidos da redução do consumo ${ }^{8}$ e da redução da energia não distribuída.

\footnotetext{
${ }^{6}$ A energia não distribuída corresponde ao montante de energia que deixa de ser fornecido aos consumidores durante ocorrências no sistema. Assim, uma redução em interrupções implica em redução da energia não distribuída.

${ }^{7}$ Devido à redução da demanda de ponta.

${ }^{8}$ No trabalho de Lamin (2013) a redução do consumo é considerada como melhoria da eficiência energética.
} 
Silva (2016) menciona que as parcelas mais significativas de benefício decorrem, respectivamente, da redução do consumo, da redução das perdas não técnicas e da melhoria da qualidade do serviço.

Contudo, dadas as diferenças entre as concessões no Brasil, permanece a necessidade de uma avaliação se esses motivadores valem para todas as distribuidoras do país.

\section{3-CLUSTERIZAÇÃO}

\subsubsection{Conceituação}

Clusterização ${ }^{9}$ é o nome para um grupo de técnicas multivariadas cuja finalidade primária é agregar objetos com base em características que eles possuem (Hair et al., 2007).

Análises de clusterização têm se tornado cada vez mais importantes nos últimos tempos, uma vez que se vive em um mundo repleto de dados e informações. Uma das tarefas mais relevantes na análise de dados é a classificação, que busca identificar propriedades similares entre os objetos para agrupá-los (Xu e Wunsch, 2009).

O objetivo dos processos de agrupamento é reunir observações (ou objetos) em grupos tais que aqueles alocados no mesmo grupo são mais parecidos uns com os outros do que com os de outros grupos. A ideia é maximizar a homogeneidade dentro de grupos, ao mesmo tempo em que se maximiza a heterogeneidade entre eles (Hair et al., 2007).

Dentro desse conceito, um cluster, ou grupo, pode ser descrito como um conjunto de objetos que possuem similaridades. Da mesma forma, observações de clusters diferentes são dissimilares (Timm, 2002). Algoritmos de clusterização agrupam os objetos em análise em uma determinada quantidade de clusters.

Nos processos de agrupamento, as observações são descritas por seus atributos, ou seja, por suas características. A partir deles, com base em uma técnica de cálculo de proximidade,

\footnotetext{
${ }^{9}$ Processos de clusterização também são conhecidos como processos de agrupamento.
} 
obtém-se a distância entre os elementos e, assim, definem-se similaridades e dissimilaridades.

Em geral, utiliza-se a distância euclidiana para calcular a proximidade entre os objetos, conforme a equação (1) (Timm, 2002).

$$
d_{(i, j)}=\sqrt{\left(x_{i 1}-x_{j 1}\right)^{2}+\left(x_{i 2}-x_{j 2}\right)^{2}+\cdots+\left(x_{i p}-x_{j p}\right)^{2}}
$$

Onde $i$ e $j$ são dois objetos analisados e $p$ é a quantidade de atributos que os caracteriza.

Outras técnicas previstas na literatura são "Métrica de Canberra", "Coeficiente de Czekanowski" e "Distância de Manhattan" (Timm, 2002) (Kaufman e Rousseeuw, 2005).

\subsubsection{Métodos de clusterização}

Existem dois métodos principais de algoritmos de clusterização, a saber, o particional e o hierárquico. O primeiro método pressupõe a definição inicial da quantidade de clusters que se deseja no processo de agrupamento, ao passo que o segundo permite a escolha posterior da quantidade de clusters. Nesse último, constrói-se a árvore de agrupamentos (ou dendrograma), o que permite a visualização de cada etapa do processo.

O método hierárquico pode ser do tipo divisivo ou aglomerativo. No primeiro caso, parte-se de um único grupo com todos as $n$ observações analisadas para a formação de $n$ grupos com uma observação cada. Por outro lado, o método hierárquico aglomerativo parte de $n$ grupos com um objeto cada para a formação de um grande grupo com todos eles (Kaufman e Rousseeuw, 2005).

A Figura 2.6 exibe um exemplo de dendrograma de um processo de clusterização hierárquica aglomerativa de 5 observações. 


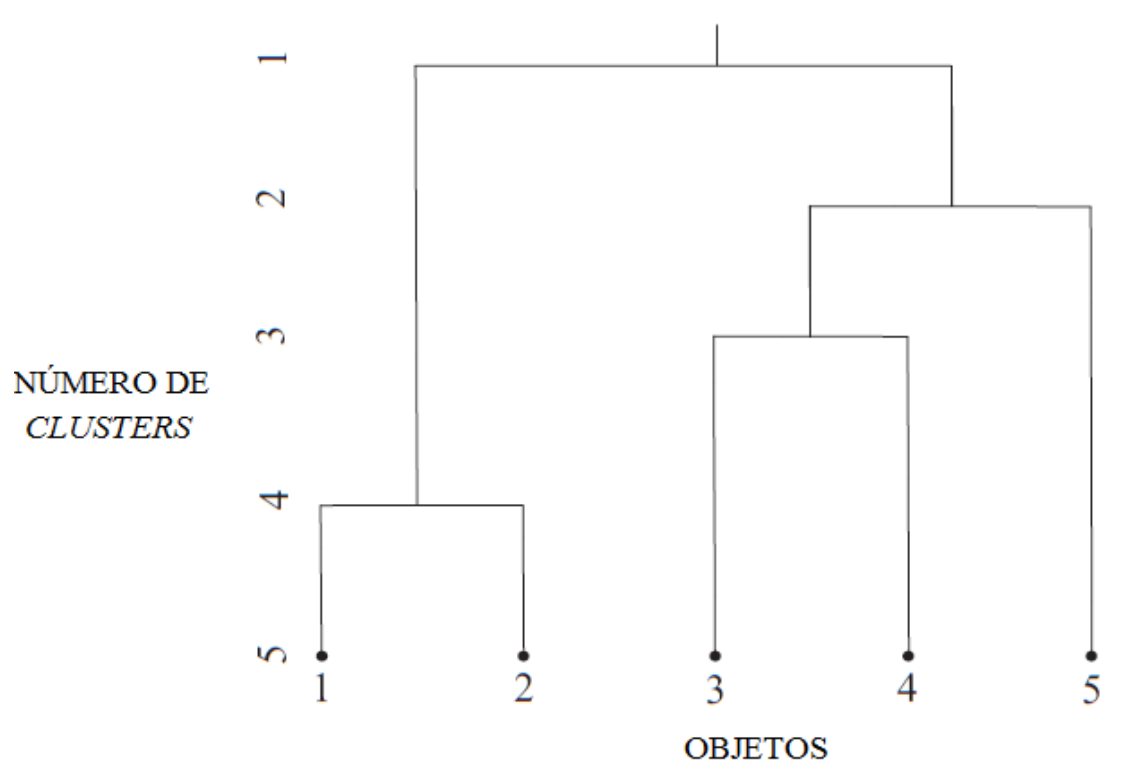

Figura 2.6 - Dendrograma de um processo de clusterização hierárquica aglomerativa de 5 observações. Adaptado de (Timm, 2002).

Da análise da Figura 2.6, nota-se que o dendrograma apresenta cada etapa do processo de cluterização e os grupos formados em cada uma. Percebe-se que as linhas verticais indicam os clusters formados e as linhas horizontais apontam os elementos pertencentes a cada grupo.

Assim, o primeiro agrupamento é constituído pelas observações 1 e 2, o segundo abrange a 3 e a 4 , e o terceiro aglutina o cluster que contém os objetos 3 e 4 com o objeto 5. Por fim, ocorre a junção de todos eles em um único grupo.

No processo ilustrado na Figura 2.6 ao se desejar 4 grupos, obtém-se um cluster com os objetos 1 e 2. Neste caso, os demais objetos são classificados individualmente. Para a formação de 3 grupos, os elementos 3 e 4 são juntados. No passo seguinte, esse cluster recebe o objeto 5. Por fim, chega-se a um único grupo com todos os 5 elementos.

\subsubsection{Algoritmos de clusterização}

No método aglomerativo de clusterização hierárquica, após a representação de cada elemento como um único cluster, calcula-se a matriz de proximidade com base em uma função de distância. Na sequência, os objetos e clusters vão sendo agrupados a partir das menores distâncias calculadas com base em um algoritmo específico. 
Alguns exemplos de algoritmos de clusterização são: i) média das distâncias entre as observações, ii) distância dos centroides, e iii) Ward.

2.3.3.1 Algoritmo de média das distâncias entre os objetos

De acordo com (Timm, 2002), o algoritmo de média das distâncias calcula a distância entre dois clusters por meio da equação (2).

$$
d_{(R)(S)}=\frac{\sum_{r} \sum_{s} d_{r S}}{n_{R} n_{S}}
$$

Onde $\mathrm{r}$ pertence ao cluster $\mathrm{R}$, s pertence ao cluster $\mathrm{S}, \mathrm{d}_{\mathrm{rs}}$ representa a medida de proximidade entre r e s calculada pela distância euclidiana, e $n_{\mathrm{R}}$ e $n_{\mathrm{S}}$ representam o número de objetos em cada cluster.

\subsubsection{Algoritmo da distância dos centroides}

Partindo da matriz de proximidades, o algoritmo da distância dos centroides executa a primeira combinação usando a média ponderada dos dois clusters mais similares, formando um novo cluster $T$ (Timm, 2002).

Os centroides dos clusters R e S são apresentados na equação (3).

$$
\overline{y_{r}}=\frac{\sum_{r} y_{r}}{n_{R}} \quad \text { e } \quad \overline{y_{s}}=\frac{\sum_{\mathrm{s}} y_{s}}{n_{S}}
$$

Onde $y_{r}$ representa os objetos do cluster $\mathrm{R}$ e $y_{s}$ representa os objetos do cluster $\mathrm{S}$.

A distância entre dois clusters é dada pela equação (4).

$$
d_{r s}=\left\|\overline{y_{r}}-\overline{y_{s}}\right\|
$$

O centroide do novo cluster é dado pela equação (5).

$$
\overline{y_{t}}=\frac{\left(n_{R} \overline{y_{r}}+n_{S} \overline{y_{s}}\right)}{\left(n_{R}+n_{S}\right)}
$$


Onde $\overline{y_{r}}$ e $\overline{y_{s}}$ representam os centroides dos clusters $\mathrm{R}$ e S, respectivamente.

Na sequência, a distância para um terceiro cluster é dada pelo quadrado da distância euclidiana de T para o centroide do terceiro cluster, U, por meio da equação (6).

$$
d_{t u}^{2}=\left(\frac{n_{R}}{n_{R}+n_{S}}\right) d_{r S}^{2}+\left(\frac{n_{S}}{n_{R}+n_{S}}\right) d_{r u}^{2}-\left(\frac{n_{R} n_{S}}{n_{R}+n_{S}}\right) d_{r S}^{2}
$$

\subsubsection{Algoritmo de Ward}

O terceiro algoritmo, Ward ou soma incremental dos quadrados, baseia-se no menor incremento da soma dos quadrados dos erros, sendo essa definida para um único cluster com todas as observações conforme equação (7) (Timm, 2002):

$$
S S E=\sum_{i=1}^{n}\left(y_{i}-\bar{y}\right)^{\prime}\left(y_{i}-\bar{y}\right)=\sum_{i=1}^{n}\left\|y_{i}-\bar{y}\right\|^{2}=T
$$

Onde $\bar{y}$ é o centroide de um dado cluster e $y_{i}$ seus elementos.

Assim, na combinação dos clusters $\mathrm{R}$ e $\mathrm{S}$ formando o cluster $T$, o quadrado da soma dos erros de $T$ é, equação (8).

$$
S S E_{t}=\sum_{t}\left\|y_{t}-\bar{y}\right\|^{2}, t \in T
$$

Busca-se, então, o menor valor do incremento do quadrado da soma dos erros, conforme representado pela equação (9).

$$
S S E_{t}-\left(S S E_{r}+S S E_{s}\right)
$$

Tendo apresentado os algoritmos, passa-se a considerar os conceitos e métricas dos parâmetros de homogeneidade e heterogeneidade, que são importantes para a avaliação dos algoritmos e para definição do número de clusters.

\subsubsection{Homogeneidade e Heterogeneidade}

A homogeneidade representa a similaridade ou proximidade entre dois elementos, ao passo que a heterogeneidade indica a dissimilaridade ou distância entre eles. Esses conceitos 
podem ser estendidos para o estudo de clusters, indicando a similaridade dos elementos nos grupos. A seguir, apresenta-se uma métrica para cálculo da homogeneidade e heterogeneidade de clusters.

O parâmetro de homogeneidade, $\mathrm{R}^{2}$, é definido pela equação (10) (Timm, 2002).

$$
R_{k}^{2}=\frac{T-\sum_{k} S S E_{k}}{T}
$$

Onde, equação (11).

$$
T=\sum_{i=1}^{n}\left\|y_{i}-\bar{y}\right\|^{2}
$$

E, equação (12).

$$
S S E_{k}=\sum_{i}\left\|y_{i}-\overline{y_{k}}\right\|^{2}
$$

Portanto, para $R^{2}=1$, tem-se o máximo de homogeneidade dentro dos clusters e de heterogeneidade entre eles. No caso contrário, quanto mais $R^{2}$ se aproxima de 0 , mais se perde em homogeneidade dentro dos clusters e heterogeneidade entre eles.

$S R^{2}$ é definido de acordo com a equação (13).

$$
S R^{2}=R_{k}^{2}-R_{k-1}^{2}
$$

Assim, quanto maior $S R^{2}$, maior é a diferença entre $R^{2}$ de um agrupamento e o $R^{2}$ do estágio seguinte. Portanto, maior a perda de homogeneidade dentro dos clusters. 


\section{3 - MATERIAIS E MÉTODOS}

Este capítulo tem como objetivo apresentar os materiais e os métodos utilizados i) para a estimação dos custos e dos benefícios da implantação das REI nas concessionárias de distribuição de energia elétrica brasileiras, e ii) para a investigação dos principais motivadores para essas redes no país.

Para tanto, inicialmente caracterizam-se os equipamentos, as tecnologias, as funcionalidades e o nível de penetração da medição eletrônica inteligente e dos dispositivos de telecomunicações e automação. Na sequência, expõem-se os dados empregados.

Posteriormente, descreve-se a metodologia utilizada para estimação dos custos e dos benefícios da implantação das REI nas distribuidoras. Cabe destacar que no tocante à análise de custo-benefício da implantação das REI em cada uma das concessionárias brasileiras de distribuição de energia elétrica, emprega-se como referência a tese de doutorado de Lamin (2013). Em função disso, no presente trabalho, faz-se uso da metodologia e dos parâmetros mencionados na citada referência.

Em seguida, trata-se dos algoritmos avaliados para a clusterização das concessionárias. Fechando o capítulo, aborda-se o método de correlação adotado para a identificação dos principais motivadores para implantação das REI no Brasil.

\section{1 - EQUIPAMENTOS, TECNOLOGIAS, FUNCIONALIDADES E NÍVEL DE PENETRAÇÃO}

Conforme adotado em Lamin (2013), a seleção dos equipamentos, das tecnologias e das funcionalidades aqui empregados baseia-se no que vem sendo praticado em projetos nacionais e internacionais sobre as REI.

\subsection{1 - Medição Eletrônica Inteligente}

Os medidores eletrônicos inteligentes permitem a comunicação bidirecional para operação remota. Eles possuem as seguintes funcionalidades: 
1) Medição de energia ativa e reativa;

2) Relógio interno para aplicação da tarifação horária na baixa tensão;

3) Demanda programável;

4) Possibilidade de aplicação do pré e pós-pagamento;

5) Medição de fluxo invertido para a utilização da geração distribuída de pequeno porte;

6) Registros de eventos relacionados à qualidade do serviço e cálculo dos indicadores de continuidade;

7) Medição de neutro, sensor de abertura da tampa e alertas anti-fraude;

8) Corte e religamento remotos; e

9) Saídas ou entradas de pulsos (ou saída serial) e porta ótica de comunicação local.

Para a análise realizada neste trabalho, assume-se que essa medição é instalada em 100\% das unidades consumidoras das concessionárias, inclusive nas faturadas com a Tarifa Social de Energia Elétrica (TSEE) ${ }^{10}$, na proporção de ligações monofásicas, bifásicas e trifásicas.

Ressalta-se que a opção pela instalação da medição eletrônica inteligente em todas as UC tem fundamento nos trabalhos da ABRADEE (2011), Lamin (2013) e Silva (2016), cujos resultados apontam para um melhor custo-benefício em cenários com maior nível de penetração das tecnologias.

A Figura 3.1 exibe alguns exemplos de medidores eletrônicos inteligentes.
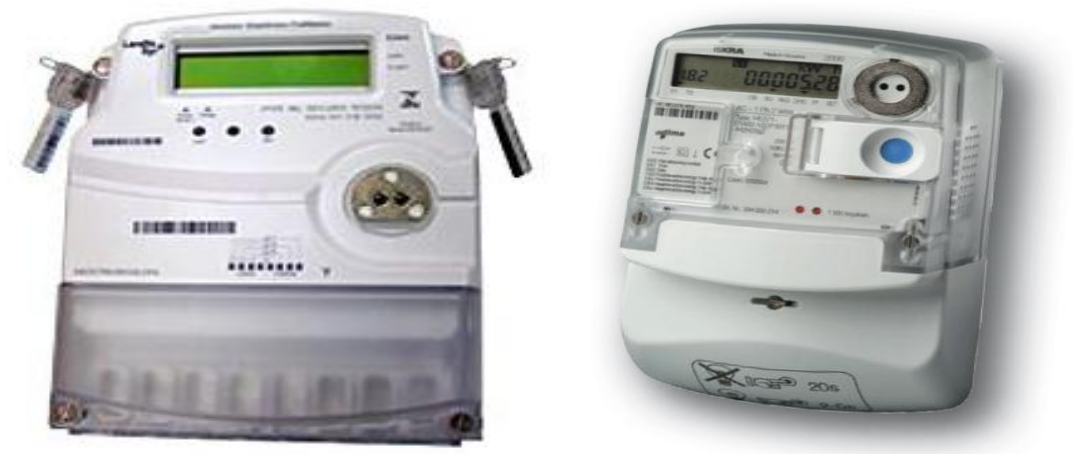

Figura 3.1 - Exemplos de medidores eletrônicos inteligentes. Fonte: (Lamin, 2013).

\footnotetext{
${ }^{10}$ Segundo a ANEEL, a Tarifa Social de Energia Elétrica (TSEE) é caracterizada por descontos incidentes sobre a tarifa aplicável à classe residencial das distribuidoras.
} 


\subsubsection{1 - Mostradores Digitais (In Home Display)}

Os mostradores digitais são instalados em $20 \%$ das unidades consumidoras, o que caracteriza o cenário mais avançado de Lamin (2013). Com esses equipamentos, as principais informações dos medidores eletrônicos inteligentes ficam disponíveis em tempo real aos consumidores. Dentre elas, destacam-se:

1) Tarifa aplicável em cada momento do dia;

2) Energia consumida e exportada;

3) Faturamento; e

4) Indicadores de continuidade individuais e coletivos.

O acesso a essas informações pode incentivar o consumidor a adotar hábitos mais eficientes e potencializar benefícios relacionados à redução da demanda de ponta e do consumo. Além disso, pode induzi-lo a exigir das distribuidoras uma melhor prestação do serviço.

A Figura 3.2 apresenta alguns exemplos de mostradores digitais.
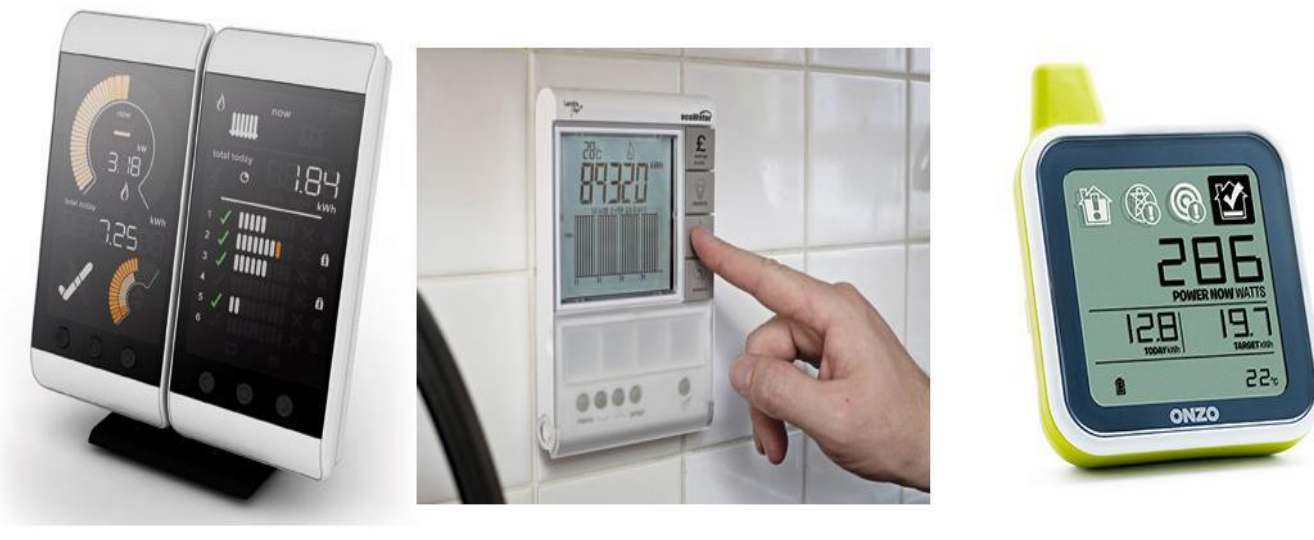

Figura 3.2 - Exemplos de mostradores digitais. Fonte: (Lamin, 2013).

\subsection{2 - Infraestrutura de telecomunicações}

Na parte interna das unidades consumidoras (Home Area Network-HAN), a comunicação de dados é viabilizada pelas tecnologias Zigbee e PLC. Para links de curtíssima distância, a exemplo da conexão entre o medidor e o mostrador digital, faz-se uso de Bluetooth ou WiFi. 
Quanto à comunicação entre os medidores e os concentradores (Local Area Network-LAN), que abrangem várias unidades consumidoras, adota-se Zigbee, PLC, Wimax, Mesh, ADSL, ou Rádio Frequência-RF. Esses links cumprem pequenas distâncias.

Para a comunicação entre os concentradores e os centros de operação e faturamento das distribuidoras (Wide Area Network-WAN), considera-se que são utilizados GSM, GPRS, ADSL ou links por satélite. Entre a WAN e a LAN, também pode existir uma rede intermediária, chamada de Region Area Network-RAN ou Backhaul, com interligação dos concentradores a pontos mais amplos. As tecnologias utilizadas nessa rede são Wimax, Mesh com conexões sem fio ou suportadas por fibra ótica.

A Figura 3.3 ilustra a infraestrutura de telecomunicações considerada neste trabalho.

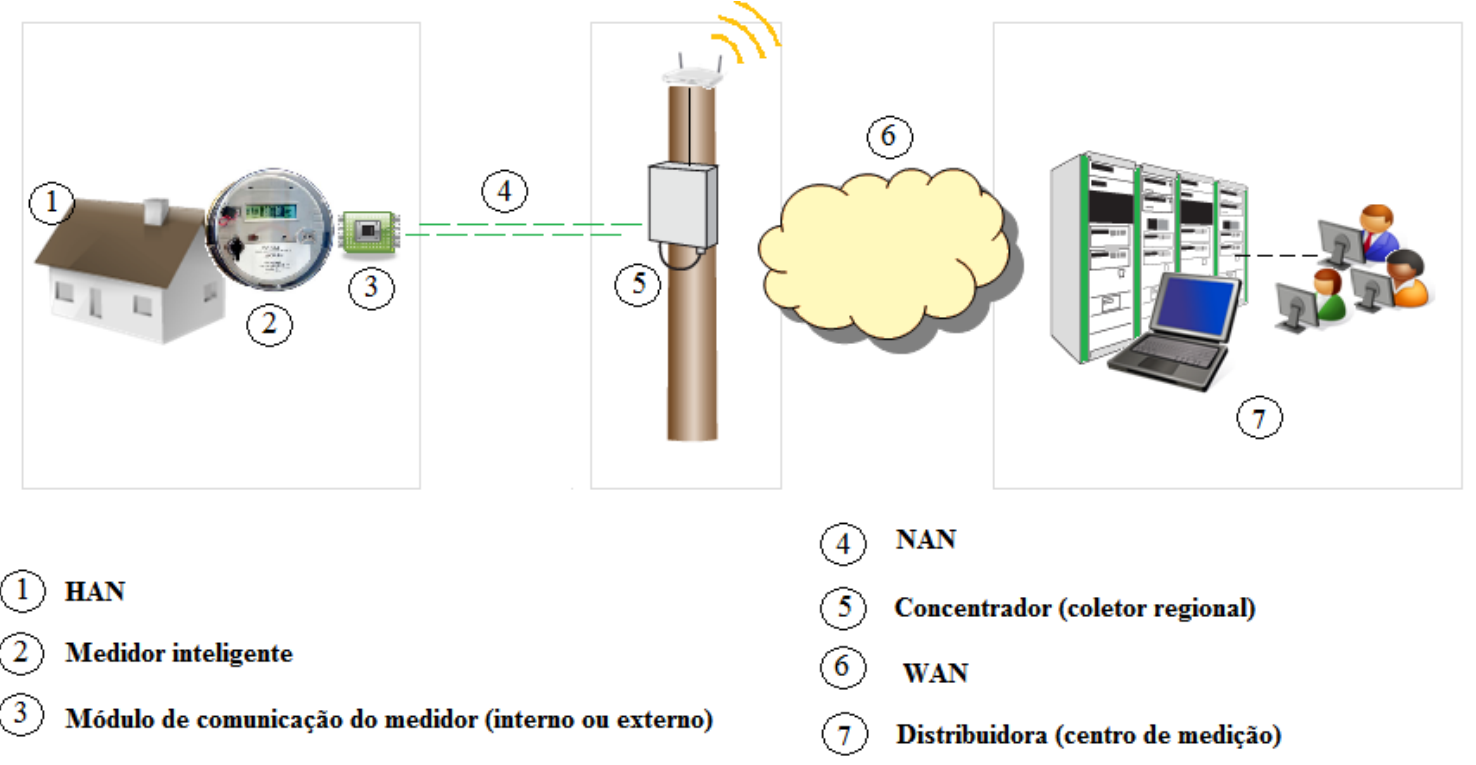

Figura 3.3 - Estrutura de telecomunicações considerada. Fonte: (Lamin, 2013).

\subsection{3 - Automação}

Quanto à automação, considera-se que são instalados controladores Volt/Var, chaves e religadores. Além disso, trabalha-se com o cenário em que são implantados novos equipamentos de monitoramento. Dessa forma, possibilita-se restauração automática ou remota, e self-healing (capacidade de autorrestabelecimento). Com estes equipamentos, 
intensifica-se a possibilidade de remanejamento de cargas e reconfiguração de circuitos sem necessidade de atuação humana.

Com esse novo padrão de rede, é possível melhorar os níveis de qualidade do serviço, e reduzir as perdas técnicas e não técnicas. Essa estrutura também permite uma melhor gestão de ativos, em virtude do monitoramento da condição de operação dos equipamentos em tempo real. Espera-se ainda uma otimização operacional, considerando que o trabalho das equipes de campo pode ser aperfeiçoado.

\subsection{4 - Tecnologia da Informação}

Nesse grupo está incluída a nova infraestrutura computacional, caracterizada pelo aumento das capacidades de hardware e de software. Considera-se que os centros de operação e faturamento das distribuidoras são dotados das ferramentas adequadas para atuar no novo ambiente. Além disso, eles devem ser capazes de receber e manipular corretamente o maior volume de informações fornecidas pela rede.

\section{2 -DADOS UTILIZADOS}

\subsubsection{Levantamento dos Dados}

Conforme exposto, este trabalho tem como referência a metodologia desenvolvida por Lamin (2013) para realização de análise de custo-benefício da implantação das REI considerando-se todo o território nacional.

Obviamente, para a sua aplicação em cada concessionária de distribuição de energia elétrica brasileira, faz-se necessária a identificação das informações de cada empresa. Neste estudo, este intenso trabalho de captação de informações passa pela consulta nos bancos de dados da ANEEL.

A Tabela 3.1 apresenta a lista dos dados das concessionárias de distribuição utilizados neste trabalho e os respectivos períodos de referência. 
Tabela 3.1 - Dados utilizados.

\begin{tabular}{|c|c|c|}
\hline DADO & UNIDADE & PERÍODO DE REFERÊNCIA \\
\hline Número de Unidades Consumidoras (UC) & - & 2015 \\
\hline Crescimento médio do número de UC & $\%$ & $2003-2015$ \\
\hline Mercado & MWh & 2015 \\
\hline Crescimento médio do mercado & $\%$ & $2003-2015$ \\
\hline WACC real depois de impostos & $\%$ & 2015 \\
\hline Receita de Fornecimento & $\mathrm{R} \$$ & 2015 \\
\hline Tarifa Média de Fornecimento & $\mathrm{R} \$ / \mathrm{MWh}$ & 2015 \\
\hline Custo dos Medidores & $\mathrm{R} \$$ & 2013 \\
\hline Gastos com Logística & $\mathrm{R} \$ /$ medidor & 2013 \\
\hline Gastos Legais & $\mathrm{R} \$ / \mathrm{UC}$ & 2013 \\
\hline Gastos com campanhas de comunicação & $\mathrm{R} \$ / \mathrm{UC}$ & 2013 \\
\hline DEC apurado & horas & 2015 \\
\hline Valor da energia não distribuída & $\mathrm{R} \$ / \mathrm{kWh}$ & 2013 \\
\hline Compensações pela continuidade & $\mathrm{R} \$$ & 2015 \\
\hline Custo de leitura & $\mathrm{R} \$ / \mathrm{mês}$ & 2015 \\
\hline Custo da religação normal & $\mathrm{R} \$ / \mathrm{UC}$ & 2015 \\
\hline Custo da religação de emergência & $\mathrm{R} \$ / \mathrm{UC}$ & 2015 \\
\hline Custo do desligamento programado & $\mathrm{R} \$ / \mathrm{UC}$ & 2015 \\
\hline Valor da compra de energia & $\mathrm{R} \$ / \mathrm{MWh}$ & 2015 \\
\hline Gasto com a expansão da rede & $\mathrm{R} \$$ & $2010-2015$ \\
\hline Crescimento médio da demanda de ponta & $\%$ & $2010-2015$ \\
\hline Demanda de ponta & MW & 2015 \\
\hline Custo da geração & $\mathrm{R} \$ / \mathrm{kW}$ & 2013 \\
\hline Perdas técnicas apuradas & $\%$ & 2014 \\
\hline Perdas não técnicas apuradas & $\%$ & 2014 \\
\hline $\mathrm{CO} 2$ emitido & ton/MWh & 2013 \\
\hline Valor do CO2 não emitido & $\mathrm{R} \$ /$ ton & 2016 \\
\hline Gastos com Call Center & $\mathrm{R} \$$ & 2013 \\
\hline Inadimplência & $\%$ & 2015 \\
\hline Custos de Faturas de Papel & $\mathrm{R} \$ / \mathrm{UC}$ & 2013 \\
\hline
\end{tabular}

Depreende-se da análise da Tabela 3.1, que os dados empregados se referem, em grande parte, ao ano de 2015, demonstrando a atualidade deste trabalho. Ressalta-se que são utilizadas as informações mais recentes disponíveis para todas as concessionárias, o que implica em anos de referência diferentes em alguns casos.

Os dados específicos das distribuidoras analisadas e as respectivas fontes são exibidos no Apêndice A.

Destaca-se que há uma grande carência de informações relativas à Companhia Energética de Roraima (CERR), impedindo a realização da análise de custo-benefício para essa distribuidora. Por esse motivo, apesar de atuarem no Brasil 63 concessionárias de distribuição, executa-se a análise de custo-benefício para as 62 empresas que são exibidas na Tabela 3.2. 
Tabela 3.2 - Concessionárias analisadas.

\begin{tabular}{|c|c|}
\hline CONCESSIONÁRIA & SIGLA \\
\hline Aes Sul Distribuidora Gaúcha de Energia S/A & AES-SUL \\
\hline Amazonas Distribuidora de Energia S/A & AME \\
\hline Ampla Energia e Serviços S/A & AMPLA \\
\hline Bandeirante Energia S/A & BANDEIRANTE \\
\hline Boa Vista Energia S/A & BOA VISTA \\
\hline Caiuá Distribuição de Energia S/A & CAIUÁ \\
\hline Companhia de Eletricidade do Amapá & CEA \\
\hline Companhia Energética de Alagoas & CEAL \\
\hline Ceb Distribuição S/A & CEB \\
\hline Companhia Estadual de Distribuição de Energia Elétrica & CEEE \\
\hline Celesc Distribuição S.A. & CELESC \\
\hline Celg Distribuição S.A. & CELG \\
\hline Centrais Elétricas do Pará S/A & CELPA \\
\hline Companhia Energética de Pernambuco & CELPE \\
\hline Companhia Energética do Maranhão & CEMAR \\
\hline Cemig Distribuição S/A & CEMIG \\
\hline Companhia Energética do Piauí & CEPISA \\
\hline Centrais Elétricas de Rondônia S/A & CERON \\
\hline Companhia Força e Luz do Oeste & CFLO \\
\hline Companhia Hidroelétrica São Patrício & CHESP \\
\hline Companhia Nacional de Energia Elétrica & CNEE \\
\hline Companhia Campolarguense de Energia & COCEL \\
\hline Companhia de Eletricidade do Estado da Bahia & COELBA \\
\hline Companhia Energética do Ceará & COELCE \\
\hline Cooperativa Aliança & COOPERALIANÇA \\
\hline Copel Distribuição S/A & COPEL \\
\hline Companhia Energética do Rio Grande do Norte & COSERN \\
\hline Companhia Jaguari de Energia & CPFL JAGUARI \\
\hline Companhia Leste Paulista de Energia & CPFL LESTEPAULISTA \\
\hline Companhia Luz e Força de Mococa & CPFL MOCOCA \\
\hline Companhia Paulista de Força e Luz & CPFL PAULISTA \\
\hline Companhia Piratininga de Força e Luz & CPFL PIRATININGA \\
\hline Companhia Luz e Força Santa Cruz & CPFL SANTACRUZ \\
\hline Companhia Sul Paulista de Energia & CPFL SULPAULISTA \\
\hline departamento Municipal de Energia de Ijuí & DEMEI \\
\hline Dme Distribuição S.A & DMED \\
\hline Distribuidora de Energia S.A. & $\mathrm{EBO}$ \\
\hline Empresa de Distribuição de Energia Vale Paranapanem & EDEVP \\
\hline Empresa Elétrica Bragantina S/A & EEB \\
\hline Empresa Força e Luz João Cesa Ltda & EFLJC \\
\hline Empresa Força e Luz Urussanga Ltda & EFLUL \\
\hline Elektro Eletricidade e Serviços S/A & ELEKTRO \\
\hline Companhia de Eletricidade do Acre & ELETROACRE \\
\hline Centrais Elétricas de Carazinho S/A & ELETROCAR \\
\hline Eletropaulo Metropolitana Eletricidade de São Paulo S/ & ELETROPAULO \\
\hline Empresa Luz e Força Santa Maria S/A & ELFSM \\
\hline Energisa Minas Gerais - Distribuidora de Energia S.A. & EMG \\
\hline Energisa Mato Grosso do Sul - Distribuidora de Energi & EMS \\
\hline Energisa Mato Grosso - Distribuidora de Energia S.A & EMT \\
\hline Energisa Nova Friburgo - Distribuidora de Energia S.A & ENF \\
\hline Energisa Paraiba - Distribuidora de Energia & EPB \\
\hline Espírito Santo Centrais Elétricas S/A & ESCELSA \\
\hline Energisa Sergipe - Distribuidora de Energia S.A. & ESE \\
\hline Energisa Tocantins - Distribuidora de Energia S.A. & ETO \\
\hline Força e Luz Coronel Vivida Ltda & FORCEL \\
\hline Hidroelétrica Panambi S/A & HIDROPAN \\
\hline Iguaçu Distribuidora de Energia Elétrica Ltda & IENERGIA \\
\hline Light Serviços de Eletricidade S/A & LIGHT \\
\hline Muxfeldt Marin \& Cia. Ltda & MUX \\
\hline Rio Grande Energia S/A & RGE \\
\hline Companhia Sul Sergipana de Eletricidade & SULGIPE \\
\hline Usina Hidroelétrica Nova Palma Ltda & UHENPAL \\
\hline
\end{tabular}




\subsubsection{Custos e benefícios}

Utilizam-se neste trabalho as componentes e percentuais de custos e benefícios estimados por Lamin (2013). A Tabela 3.3 exibe os valores e percentuais de custos para implantação das REI considerados neste trabalho.

Ressalta-se que a percepção de custos e benefícios entre os agentes do setor elétrico e da sociedade é a mesma descrita por Lamin (2013), conforme exposto na seção A.20 do Apêndice A.

Tabela 3.3 - Componentes e valores dos custos.

\begin{tabular}{|c|c|}
\hline COMPONENTE DE CUSTO & VALOR/PERCENTUAL \\
\hline \multicolumn{2}{|l|}{ AQUISIÇÃO E INSTALAÇÃO } \\
\hline Medidor Eletrônico Inteligente & $\mathrm{R} \$ 355,00$ \\
\hline Instalação do Medidor & $\mathrm{R} \$ 20,00$ \\
\hline Mostrador Digital & $\mathrm{R} \$ 125,00$ \\
\hline Instalação do Mostrador Digital & $\mathrm{R} \$ 20,00$ \\
\hline Aquisição e instalação da Infraestrutura de Telecomunicações & $40 \%$ do valor do medidor \\
\hline Aquisição e instalação da Infraestrutura de Automação & $15 \%$ do valor do medidor \\
\hline Aquisição e instalação da Infraestrutura de Tecnologia da Informação & $15 \%$ do valor do medidor \\
\hline \multicolumn{2}{|l|}{ O\&M E SUBSCRIÇÃO } \\
\hline Gastos de O\&M para Infraestrutura de Telecomunicações & $2,5 \%$ do valor do medidor \\
\hline Subscrição dos serviços de Telecomunições & $3,0 \%$ do valor do medidor \\
\hline Gastos de O\&M para Infraestrutura de Automação & $1,5 \%$ do valor do medidor \\
\hline Gastos de O\&M para Infraestrutura de Tecnologia da Informação & $1,5 \%$ do valor do medidor \\
\hline \multicolumn{2}{|c|}{ LOGÍSTICA, ADMINISTRAÇÃO E COMUNICAÇÃO } \\
\hline Logística do programa & $12,5 \mathrm{R} \$ /$ medidor \\
\hline Custos Administrativos & $0,5 \mathrm{R} \$ / \mathrm{UC}$ \\
\hline Campanhas de Comunicação & $1,0 \mathrm{R} \$ / \mathrm{UC}$ \\
\hline
\end{tabular}

Percebe-se na Tabela 3.3 que as componentes de custos são divididas em 3 categorias:

1) Aquisição e Instalação;

2) O\&M e Subscrição; e

3) Logística, Administração e Comunicação.

A Tabela 3.4 exibe os valores e percentuais de benefícios decorrentes da implantação das REI. 
Tabela 3.4 - Componentes, valores e percentuais de benefícios.

\begin{tabular}{|c|c|c|}
\hline COMPONENTE DE BENEFÍCIO & $\begin{array}{l}\text { REDUÇÃO } \\
\text { ESPERADA }\end{array}$ & OBSERVAÇÕES \\
\hline \multicolumn{3}{|c|}{ EFICIÊNCIA ENERGÉTICA } \\
\hline Demanda de Ponta & $5,00 \%$ & \multirow{3}{*}{$\begin{array}{l}\text { Estima-se que a implantação das REI induz uma redução de } 5 \% \text { da demanda de ponta e } \\
\text { do consumo total das distribuidoras. Em decorrência desses dois itens, também diminui a } \\
\text { necessidade de novas plantas de geração. }\end{array}$} \\
\hline Consumo de energia & $5,00 \%$ & \\
\hline Novas plantas de geração & $5,00 \%$ & \\
\hline \multicolumn{3}{|r|}{ CONTINUIDADE } \\
\hline Energia Não Distribuída & $5,10 \mathrm{R} \$ / \mathrm{kWh}$ & \multirow{3}{*}{$\begin{array}{l}\text { Adota-se uma redução de } 40,00 \% \text { no indicador DEC, o que indica que os consumidores } \\
\text { ficam menos horas sem suprimento. Como consequência, aumenta a quantidade de energia } \\
\text { distribuída pelas concessionárias (que é valorada em 5,10 R } \$ / \mathrm{kWh} \text { ), há queda de } 50 \% \text { no } \\
\text { montante compensado por violação de indicadores de qualidade e há recuperação de } \\
\text { receita em virtude de um maior tempo de prestação do serviço. }\end{array}$} \\
\hline Compensações por violação de indicadores & $50,00 \%$ & \\
\hline Recuperação de Receita & Receita/h & \\
\hline \multicolumn{3}{|r|}{ PERDAS } \\
\hline Perdas Não Técnicas & $33,30 \%$ & $\begin{array}{l}\text { Considera-se uma queda de 33,30\% das Perdas Não Técnicas em decorrência da } \\
\text { implantação das REI. Com essa redução, estima-se que, além da maior quantidade de } \\
\text { energia faturada, também há racionalização do consumo por parte dos consumidores. Do } \\
\text { benefício resultante, } 85 \% \text { do se deve à energia que passa a ser faturada e 15\% à } \\
\text { racionalização do consumo. }\end{array}$ \\
\hline Perdas Técnicas & $2,00 \%$ & $\begin{array}{l}\text { Assume-se que a redução de demanda e de consumo promovida pelas REI acarreta em } \\
\text { menor carregamento das redes distribuição, diminuindo a Perdas Técnicas em 2,00\%. }\end{array}$ \\
\hline \multicolumn{3}{|r|}{ CUSTOS OPERACIONAIS } \\
\hline Leitura Remota & $95,00 \%$ & \multirow{3}{*}{$\begin{array}{l}\text { Entende-se que as REI permitem que grande parte dos serviços de leitura, corte, religação } \\
\text { e desligamento programado sejam executados remotamente, reduzindo o custo operacional } \\
\text { relativo a esses itens. Adota-se uma queda de } 95 \% \text { na quantidade atualmente realizada } \\
\text { desses serviços. }\end{array}$} \\
\hline Corte e Religação & $95,00 \%$ & \\
\hline Desligamento Programado & $95,00 \%$ & \\
\hline \multicolumn{3}{|r|}{ EMISSÕES } \\
\hline Consumo & $2,50 \%$ & \multirow{3}{*}{$\begin{array}{l}\text { Estima-se que a redução do consumo de } \\
\text { de emissões de } \mathrm{CO}_{2} \text {, que somada a dim } \\
\text { patamares de Perdas Técnicas e Não Té } \\
\text { das emissões de } \mathrm{CO}_{2} \text { do setor elétrico. }\end{array}$} \\
\hline Perdas Técnicas & $1,00 \%$ & \\
\hline Perdas Não Técnicas & $5,00 \%$ & \\
\hline \multicolumn{3}{|c|}{ CALL CENTER E INADIMPLÊNCIA } \\
\hline Call Center & $30,00 \%$ & \multirow{2}{*}{$\begin{array}{l}\text { Considera-se que as REI permitem uma redução de 35,00\% na inadimplência. Quanto ao } \\
\text { serviço de teleatendimento, ou Call Center, estima-se que haja um aumento de 10,00\% } \\
\text { no primeiro ciclo de implantação das tecnologias (custo) e uma redução posterior de 30\% } \\
\text { dos gastos com esse serviço (benefício). }\end{array}$} \\
\hline Inadimplência & $35,00 \%$ & \\
\hline \multicolumn{3}{|r|}{ FATURAS DE PAPEL } \\
\hline Faturas de Papel & $20,00 \%$ & $\begin{array}{l}\text { Entende-se que o novo padrão de atendimento comercial, viabilizado pelas REI, induz a } \\
\text { disponibilização da fatura de energia por e-mail ou em ambiente da rede mundial de } \\
\text { computadores, reduzindo o custo com emissão e envio da fatura em papel. Em função } \\
\text { disso, adota-se uma redução de } 20,00 \% \text {. }\end{array}$ \\
\hline \multicolumn{3}{|r|}{ CUSTOS EVITADOS } \\
\hline Custos Evitados & 25,00 R $\$$ /medidor & $\begin{array}{l}\text { A instalação dos medidores eletrônicos inteligentes implica na redução dos custos com a } \\
\text { instalação de medidores básicos, que são valorados a } 25,00 \mathrm{R} \$ \text { /medidor. }\end{array}$ \\
\hline
\end{tabular}

Depreende-se da Tabela 3.4 que as componentes de benefícios são divididas em 8 categorias:

1) Eficiência Energética; 
2) Continuidade;

3) Perdas;

4) Custos Operacionais;

5) Emissões;

6) Call Center e Inadimplência;

7) Faturas de Papel; e

8) Custos Evitados.

Ressalta-se que são esperados outros benefícios não quantificados neste trabalho. A título de exemplo, pode-se citar o fomento da indústria nacional e a preparação da rede para a conexão da geração distribuída de pequeno porte.

As 3 componentes de custos e as 8 de benefícios, expostas nas Tabelas 3.3 e 3.4, e o saldo da implantação das $\mathrm{REI}^{11}$ caracterizam-se como os atributos das concessionárias nos processos de clusterização executados neste trabalho.

Destaca-se que, conforme pode ser visualizado na Tabela 3.4, a redução do indicador DEC acarreta em 3 itens de benefício: i) redução da energia não distribuída; ii) redução das compensações pela transgressão dos limites de continuidade; e iii) recuperação de receita devido ao maior período de fornecimento.

Nota-se também na Tabela 3.4, que essa divisão em itens de benefícios ocorre com as componentes de eficiência energética, redução de perdas, de custos operacionais e de emissões.

\subsubsection{Prazos e taxas considerados}

Para a execução da análise de custo-benefício da implantação das REI em cada concessionária, fazem-se necessárias informações relativas a prazos e taxas, exibidas na Tabela 3.5.

${ }^{11} \mathrm{O}$ saldo da implantação das REI é resultado da subtração da soma dos benefícios pela soma dos custos. Assim, um saldo positivo significa que os benefícios são maiores do que os custos. Por outro lado, um saldo negativo implica que os custos suplantam os benefícios. 
Tabela 3.5 - Prazos e taxas considerados.

\begin{tabular}{|c|c|c|}
\hline ITEM & VALOR & OBSERVAÇÕES \\
\hline Tempo de Análise & 30 anos & $\begin{array}{l}\text { Valor equivalente ao prazo de concessão da distriuição. } \\
\text { Tanto para as distribuidoras cuja concessão já foi prorrogada } \\
\text { no útimo ano quanto para as demais. }\end{array}$ \\
\hline $\begin{array}{l}\text { Vida útil de medidores e equipamentos de } \\
\text { telecomunicações e automação }\end{array}$ & 13 anos & \multirow{2}{*}{$\begin{array}{l}\text { Foram consideradas as taxas de depreciação regulatórias } \\
\text { adotadas pela ANEEL no Manual de Controle Patrimonial } \\
\text { do Setor Elétrico -MCPSE. }\end{array}$} \\
\hline Vida útil de hardwares e softwares de TI & 5 anos & \\
\hline $\begin{array}{l}\text { Ciclo de implantação de medidores e } \\
\text { equipamentos de telecomunicações e } \\
\text { automação }\end{array}$ & 13 anos & $\begin{array}{l}\text { Valor equivalente à vida útil considerada para os } \\
\text { equipamentos. }\end{array}$ \\
\hline Ciclo de implantação de TI & 2 anos & $\begin{array}{l}\text { A vida útil de hardwares e softwares é mais curta. Além } \\
\text { disso, entende-se que a infraestrutura de TI deve ser } \\
\text { instalada de forma mais rápida, de modo que esteja pronta } \\
\text { previamente à instalação dos outros equipamentos. }\end{array}$ \\
\hline Taxa de desconto (anual) & $8,09 \%$ & Valor equiavealente ao $W A C C$ líquido. \\
\hline $\begin{array}{l}\text { Redução Anual dos Custos (ganhos de escala e } \\
\text { evolução tecnológica) }\end{array}$ & $1,50 \%$ & $\begin{array}{l}\text { A redução anual ocorre até um determinado limite, de modo } \\
\text { que o valor final do equipamento ao longo dos anos satura } \\
\text { em } 70 \% \text { do valor original. }\end{array}$ \\
\hline Inflação & $0 \%$ & \multirow[b]{2}{*}{ Não considerados. } \\
\hline $\begin{array}{l}\text { Variação da Tarifa e da Receita de } \\
\text { Fornecimento }\end{array}$ & $0 \%$ & \\
\hline
\end{tabular}

\subsubsection{Perfil de Implantação}

O perfil de implantação das tecnologias que caracterizam as REI define a quantidade de medidores e equipamentos comprados e instalados por ano. Ele tem como referência o ciclo de implantação, que, conforme exibido na Tabela 3.5, é igual a 13 anos para medidores e equipamentos de telecomunicações e automação.

Com respeito aos equipamentos de TI, entende-se que eles dão suporte para as atividades das distribuidoras e, assim, devem ser instalados em prazo menor. Por esse motivo, adota-se um ciclo de implantação de 2 anos.

Nesse contexto, utiliza-se o mesmo perfil definido por Lamin (2013), quer seja, a implantação não uniforme ao longo dos anos e com folga nas pontas para os medidores e equipamentos de telecomunicações e automação. Essa escolha assume que há mais complexidade da logística no início do ciclo, e que são deixadas para o fím as unidades consumidoras de instalação e de acesso mais difíceis. Para equipamentos de TI, considerase um perfil uniforme de instalação.

A Figura 3.4 apresenta, sem especificar as quantidades instaladas, o perfil de implantação dos medidores e equipamentos de telecomunicações e automação adotado neste trabalho. Caso fosse utilizado o perfil uniforme, as barras teriam uma projeção com valor de 1,0. 


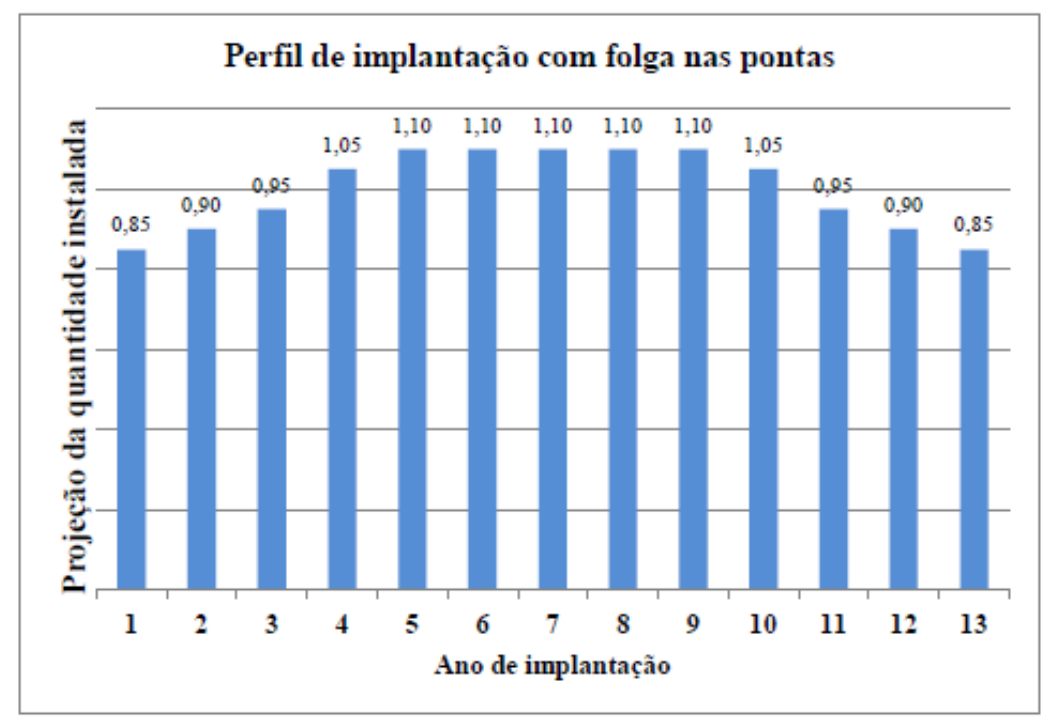

Figura 3.4 - Perfil de implantação dos medidores e equipamentos de telecomunicações e automação. Fonte: (Lamin, 2013).

Com base nos dados e informações apresentados nesta seção, é possível calcular o Valor Presente (VP) de cada um dos custos e dos benefícios da implantação das REI nas 62 concessionárias. Adota-se 2017 como o primeiro ano de implantação das REI.

Por meio desses resultados, somando-se o VP dos benefícios e subtraindo-se desse total a soma do VP dos custos, chega-se ao saldo da implantação das tecnologias, que equivale ao VPL do custo-benefício da implantação das REI no Brasil.

\subsection{5 - Normalização dos Resultados}

Os resultados de VP em 2017 dos custos e dos benefícios das 62 concessionárias avaliadas são normalizados pela receita de 2015 das empresas. Esse procedimento tem o objetivo de retirar da análise o efeito do tamanho delas ${ }^{12}$ nos processos de clusterização.

Caso se utilizassem os valores nominais, em reais, as empresas com maiores números de consumidores e que, assim, apresentam maiores custos e benefícios da implantação das REI, seriam alocadas no mesmo cluster. Da mesma forma, as menores empresas seriam agrupadas em conjunto. Como resultado, a análise dos motivadores para implantação das novas tecnologias nas diferentes concessões ficaria prejudicada.

\footnotetext{
${ }^{12}$ Neste trabalho o tamanho de uma concessionária é definido pela quantidade de UC por ela atendidas.
} 
Considerando que o VP dos custos e dos benefícios é calculado em reais e que as receitas das concessionárias também estão nessa unidade, o processo de normalização resulta em valores adimensionais, que, ao serem multiplicados por 100, podem ser entendidos como percentuais da receita das distribuidoras.

\section{3 - CLUSTERIZAÇÃO}

Conforme apresentado no Capítulo 2, os processos de clusterização têm como objetivo reunir objetos semelhantes em grupos. A ideia é maximizar a homogeneidade dentro dos grupos e a heterogeneidade entre eles. Nesses processos, os objetos são descritos por seus atributos, ou seja, por suas características.

Neste trabalho, as observações são as 62 concessionárias de distribuição analisadas, que são ordenadas conforme exposto na Tabela 3.6.

Tabela 3.6 - Ordenação das concessionárias nos processos de clusterização.

\begin{tabular}{|l|c|}
\hline CONCESSIONÁRIA & CLUSTERIZAÇÃO \\
\hline EBO & OB 1 \\
\hline COSERN & OB 2 \\
\hline EPB & OB 3 \\
\hline ESE & OB 4 \\
\hline COELBA & OB 5 \\
\hline SULGIPE & OB 6 \\
\hline COELCE & OB 7 \\
\hline ENF & OB 8 \\
\hline CEMIG & OB 9 \\
\hline EEB & OB 10 \\
\hline CPFLSULPAULISTA & OB 11 \\
\hline DMED & OB 12 \\
\hline CFLO & OB 13 \\
\hline CEMAR & OB 14 \\
\hline RGE & OB 15 \\
\hline CHESP & OB 16 \\
\hline CPFLSANTACRUZ & OB 17 \\
\hline ELETROCAR & OB 18 \\
\hline EDEVP & OB 19 \\
\hline CNEE & OB 20 \\
\hline BANDEIRANTE & OB 21 \\
\hline CAIUA & OB 22 \\
\hline CPFLPAULISTA & OB 23 \\
\hline CPFLMOCOCA & OB 24 \\
\hline UHENPAL & OB 25 \\
\hline AES-SUL & OB 26 \\
\hline CELPE & OB 27 \\
\hline HIDROPAN & OB 28 \\
\hline CPFLJAGUARI & OB 29 \\
\hline CELESC & OB 30 \\
\hline COPEL & OB 31 \\
\hline
\end{tabular}

\begin{tabular}{|l|c|}
\hline CONCESSIONÁRIA & CLUSTERIZAÇÃO \\
\hline ELEKTRO & OB 32 \\
\hline COOPERALIANÇA & OB 33 \\
\hline CPFLPIRATININGA & OB 34 \\
\hline DEMEI & OB 35 \\
\hline ELETROPAULO & OB 36 \\
\hline EFLUL & OB 37 \\
\hline EMS & OB 38 \\
\hline EMG & OB 39 \\
\hline MUXENERGIA & OB 40 \\
\hline COCEL & OB 41 \\
\hline ELFSM & OB 42 \\
\hline ESCELSA & OB 43 \\
\hline CPFLLESTEPAULISTA & OB 44 \\
\hline IENERGIA & OB 45 \\
\hline CELG & OB 46 \\
\hline CEB & OB 47 \\
\hline ETO & OB 48 \\
\hline FORCEL & OB 49 \\
\hline EFLJC & OB 50 \\
\hline AMPLA & OB 51 \\
\hline EMT & OB 52 \\
\hline CEEE & OB 53 \\
\hline CEPISA & OB 54 \\
\hline LIGHT & OB 55 \\
\hline CEAL & OB 56 \\
\hline CELPA & OB 57 \\
\hline ELETROACRE & OB 58 \\
\hline CERON & OB 59 \\
\hline BOA VISTA & OB 60 \\
\hline CEA & OB 61 \\
\hline AME & OB 62 \\
\hline
\end{tabular}


Os atributos que caracterizam as empresas são i) o VPL em 2017 do custo-benefício da implantação das REI, e ii) as 3 componentes de custos e as 8 de benefícios da implantação dessas redes. Com o objetivo de facilitar a apresentação dos resultados, os atributos são representados pelas abreviações exibidas na Tabela 3.7 .

Tabela 3.7 - Representação dos atributos de custos e de benefícios utilizados nos processos de clusterização.

\begin{tabular}{|c|c|}
\hline ATRIBUTO & ABREVIAÇÃO \\
\hline \multicolumn{2}{|l|}{ CUSTOS } \\
\hline Aquisição e Instalação & AQ_INST \\
\hline O\&M e Subscrição & O\&M_SUBSC \\
\hline Logística, Administração e Comunicação & LOG_ADM_COM \\
\hline \multicolumn{2}{|l|}{ BENEFÍCIOS } \\
\hline Eficiência Energética & EFI_ENER \\
\hline Continuidade & CONTIN \\
\hline Perdas & PERDAS \\
\hline Custos Operacionais & CUS_OPERA \\
\hline Emissões & EMISSOES \\
\hline Call Center e Inadimplência & CALLCEN_INADIM \\
\hline Faturas de Papel & FAT_PAPEL \\
\hline Custos Evitados & CUS_EVITADOS \\
\hline
\end{tabular}

Com base no resultado da clusterização, é possível identificar as componentes com maior peso no resultado de custo-benefício da implantação das REI e, assim, elucidar quais os motivadores para essas redes no Brasil.

Neste trabalho, os processos de clusterização são executados por meio do software $\mathrm{SAS}^{\circledR}$ Enterprise Guide 6.1.

\subsubsection{Algoritmos de clusterização}

A definição da quantidade de clusters é uma das etapas deste trabalho. Assim, com base no que foi apresentado no capítulo 2, utiliza-se o método aglomerativo hierárquico de clusterização. Esse método também tem a vantagem de permitir a construção da árvore de agrupamentos, que apresenta, a cada estágio, os clusters formados.

O software $\mathrm{SAS}^{\circledR}$ Enterprise Guide 6.1 possui três algoritmos de clusterização hierárquica aglomerativa: i) média das distâncias entre os objetos, ii) distância dos centroides, e iii) Ward. Neste trabalho avalia-se qual dessas opções apresenta o melhor resultado. 


\section{4 - CORRELAÇÃ̃o}

A identificação dos motivadores brasileiros para as REI se divide em duas etapas: i) execução da clusterização com base no resultado do custo-benefício da implantação das novas tecnologias e nas 3 componentes de custos e 8 de benefícios consideradas, e ii) correlação dessas 11 componentes com o saldo final.

Os processos de clusterização permitem avaliar quais componentes de custos e de benefícios têm maior representatividade no saldo da implantação dessas redes nas 62 concessionárias analisadas. Por outro lado, a correlação elucida, entre as empresas, quais atributos têm comportamento mais similar ao do saldo.

Nesse contexto, as componentes de benefício que tiverem, conjuntamente, grandes representatividade e correlação com o saldo são as que mais explicam o custo-benefício da implantação das REI. Assim, essas componentes representam os motivadores para utilização dessas tecnologias no Brasil.

Neste trabalho, a correlação entre os atributos de custos e de benefícios e o saldo da implantação das REI é avaliada por meio dos coeficientes de correlação de Pearson e diagramas de dispersão. 


\section{4 - APRESENTAÇÃO E ANÁLISE DOS RESULTADOS}

Neste capítulo, são apresentados e analisados, inicialmente, os 3 custos, os 8 benefícios e o saldo da implantação das REI em 62 concessionárias de distribuição de energia elétrica brasileiras, os quais constituem os atributos avaliados neste trabalho.

Na sequência, passa-se à exposição dos resultados dos dois processos de clusterização executados, que são baseados i) no VPL em 2017 do custo-benefício das REI, e ii) nos demais 11 atributos acima citados.

Em seguida, é exibido e discutido o resultado da investigação dos motivadores para a aplicação das novas tecnologias no Brasil. Essa etapa é baseada nos processos de clusterização e na análise de correlações entre os 12 atributos considerados.

Finalizando o capítulo, expõe-se a análise de sensibilidade do valor de compra dos medidores para o custo-benefício das novas tecnologias em cada um dos grupos de distribuidoras resultantes dos processos de clusterização.

\subsection{CUSTOS E BENEFÍCIOS DA IMPLANTAÇÃO DAS REI}

Conforme citado no capítulo 3, os resultados do Valor Presente (VP) em 2017 dos custos e dos benefícios da implantação das REI são normalizados pela receita de 2015 da empresa em avaliação. Esse procedimento tem como objetivo evitar que o processo de agrupamento seja afetado pelo tamanho das distribuidoras.

A Tabela 4.1 apresenta o VP normalizado dos 3 custos e dos 8 benefícios decorrentes da implantação das REI nas 62 concessionárias de distribuição analisadas neste trabalho. 
Tabela 4.1 - VP normalizado dos custos e dos benefícios da implantação das REI nas 62

concessionárias.

\begin{tabular}{|c|c|c|c|c|c|c|c|c|c|c|c|}
\hline \multirow[b]{3}{*}{ CONCESSIONÁRIA } & \multicolumn{11}{|c|}{ ATRIBUTOS NORMALIZADOS } \\
\hline & \multicolumn{3}{|c|}{ CUSTOS } & \multicolumn{8}{|c|}{ BENEFÍCIOS } \\
\hline & LOG_ADM_COM & O\&M_SUBSC & AQ_INST & EMISSOES & CALLCEN_INADIM & FAT_PAPEL & CUS_OPERA & CUS_EVITADOS & CONTIN & EFI_ENER & PERDAS \\
\hline AES-SUL & 0,008 & 0,086 & 0,311 & 0,009 & 0,018 & 0,018 & 0,053 & 0,005 & 0,099 & 0,158 & 0,050 \\
\hline AME & 0,014 & 0,153 & 0,571 & 0,086 & 0,024 & 0,033 & 0,098 & 0,011 & 0,297 & 0,791 & 5,796 \\
\hline AMPLA & 0,011 & 0,122 & 0,441 & 0,014 & 0,045 & 0,026 & 0,074 & 0,007 & 0,143 & 0,175 & 0,631 \\
\hline BANDEIRANTE & 0,011 & 0,116 & 0,425 & 0,009 & 0,001 & 0,025 & 0,080 & 0,008 & 0,036 & 0,179 & 0,158 \\
\hline BOA VISTA & 0,015 & 0,165 & 0,618 & 0,179 & 0,060 & 0,036 & 0,106 & 0,012 & 0,167 & 1,073 & 1,745 \\
\hline CAIUA & 0,011 & 0,127 & 0,460 & 0,090 & 0,008 & 0,027 & 0,084 & 0,008 & 0,066 & 0,207 & 0,080 \\
\hline CEA & 0,017 & 0,183 & 0,682 & 0,119 & 0,294 & 0,040 & 0,118 & 0,013 & 0,486 & 0,575 & 3,893 \\
\hline CEAL & 0,021 & 0,225 & 0,833 & 0,032 & 0,010 & 0,049 & 0,146 & 0,016 & 0,154 & 0,283 & 1,499 \\
\hline CEB & 0,010 & 0,109 & 0,402 & 0,020 & 0,018 & 0,024 & 0,072 & 0,007 & 0,083 & 0,318 & 0,237 \\
\hline CEEE & 0,009 & 0,097 & 0,347 & 0,015 & 0,024 & 0,021 & 0,061 & 0,005 & 0,084 & 0,181 & 0,864 \\
\hline CELESC & 0,010 & 0,113 & 0,411 & 0,012 & 0,014 & 0,024 & 0,069 & 0,007 & 0,074 & 0,214 & 0,160 \\
\hline CELG & 0,014 & 0,155 & 0,570 & 0,022 & 0,097 & 0,033 & 0,102 & 0,010 & 0,256 & 0,280 & 0,181 \\
\hline CELPA & 0,024 & 0,249 & 0,948 & 0,038 & 0,039 & 0,054 & 0,160 & 0,020 & 0,167 & 0,373 & 2,193 \\
\hline CELPE & 0,022 & 0,242 & 0,889 & 0,023 & 0,056 & 0,052 & 0,136 & 0,016 & 0,115 & 0,287 & 0,489 \\
\hline CEMAR & 0,040 & 0,418 & 1,602 & 0,047 & 0,008 & 0,091 & 0,242 & 0,035 & 0,082 & 0,457 & 1,003 \\
\hline CEMIG & 0,015 & 0,168 & 0,610 & 0,014 & 0,019 & 0,036 & 0,115 & 0,011 & 0,058 & 0,227 & 0,114 \\
\hline CEPISA & 0,026 & 0,279 & 1,044 & 0,038 & 0,016 & 0,061 & 0,187 & 0,021 & 0,119 & 0,358 & 1,366 \\
\hline CERON & 0,011 & 0,117 & 0,438 & 0,037 & 0,080 & 0,025 & 0,080 & 0,009 & 0,171 & 0,486 & 2,189 \\
\hline CFLO & 0,010 & 0,106 & 0,387 & 0,012 & 0,002 & 0,023 & 0,067 & 0,007 & 0,023 & 0,233 & 0,021 \\
\hline CHESP & 0,013 & 0,143 & 0,520 & 0,016 & 0,005 & 0,031 & 0,085 & 0,009 & 0,074 & 0,309 & 0,054 \\
\hline CNEE & 0,009 & 0,097 & 0,351 & 0,016 & 0,007 & 0,021 & 0,066 & 0,006 & 0,037 & 0,229 & 0,007 \\
\hline COCEL & 0,009 & 0,104 & 0,383 & 0,021 & 0,003 & 0,022 & 0,066 & 0,007 & 0,045 & 0,393 & 0,091 \\
\hline COELBA & 0,032 & 0,341 & 1,274 & 0,031 & 0,029 & 0,074 & 0,195 & 0,025 & 0,164 & 0,349 & 0,347 \\
\hline COELCE & 0,023 & 0,249 & 0,922 & 0,027 & 0,018 & 0,054 & 0,140 & 0,017 & 0,064 & 0,352 & 0,193 \\
\hline COOPERALIANÇA & 0,009 & 0,105 & 0,383 & 0,017 & 0,007 & 0,023 & 0,064 & 0,007 & 0,021 & 0,278 & 0,145 \\
\hline COPEL & 0,009 & 0,101 & 0,368 & 0,014 & 0,006 & 0,022 & 0,065 & 0,006 & 0,064 & 0,222 & 0,120 \\
\hline COSERN & 0,026 & 0,279 & 1,041 & 0,023 & 0,009 & 0,060 & 0,170 & 0,020 & 0,089 & 0,308 & 0,064 \\
\hline CPFLJAGUARI & 0,005 & 0,057 & 0,208 & 0,014 & 0,002 & 0,012 & 0,039 & 0,004 & 0,036 & 0,162 & 0,033 \\
\hline CPFLLESTEPAULISTA & 0,009 & 0,104 & 0,375 & 0,012 & 0,029 & 0,022 & 0,071 & 0,006 & 0,044 & 0,392 & 0,107 \\
\hline CPFLMOCOCA & 0,010 & 0,113 & 0,406 & 0,011 & 0,005 & 0,024 & 0,076 & 0,007 & 0,036 & 0,286 & 0,065 \\
\hline CPFLPAULISTA & 0,009 & 0,102 & 0,371 & 0,011 & 0,018 & 0,022 & 0,066 & 0,006 & 0,038 & 0,183 & 0,118 \\
\hline CPFLPIRATININGA & 0,009 & 0,096 & 0,349 & 0,012 & 0,026 & 0,021 & 0,065 & 0,006 & 0,033 & 0,211 & 0,148 \\
\hline CPFLSANTACRUZ & 0,009 & 0,102 & 0,370 & 0,011 & 0,007 & 0,022 & 0,066 & 0,006 & 0,040 & 0,186 & 0,056 \\
\hline CPFLSULPAULISTA & 0,011 & 0,121 & 0,439 & 0,012 & 0,010 & 0,026 & 0,078 & 0,007 & 0,063 & 0,199 & 0,021 \\
\hline DEMEI & 0,011 & 0,127 & 0,457 & 0,016 & 0,050 & 0,027 & 0,074 & 0,007 & 0,048 & 0,247 & 0,208 \\
\hline DMED & 0,010 & 0,112 & 0,405 & 0,016 & 0,010 & 0,024 & 0,074 & 0,007 & 0,006 & 0,246 & 0,021 \\
\hline EBO & 0,024 & 0,261 & 0,963 & 0,018 & 0,006 & 0,056 & 0,150 & 0,018 & 0,030 & 0,265 & 0,013 \\
\hline EDEVP & 0,010 & 0,113 & 0,408 & 0,015 & 0,012 & 0,024 & 0,070 & 0,006 & 0,036 & 0,237 & 0,057 \\
\hline EEB & 0,013 & 0,138 & 0,509 & 0,011 & 0,004 & 0,030 & 0,096 & 0,009 & 0,082 & 0,214 & 0,034 \\
\hline EFLJC & 0,013 & 0,143 & 0,535 & 0,009 & 0,004 & 0,031 & 0,090 & 0,010 & 0,005 & 1,015 & 0,002 \\
\hline EFLUL & 0,006 & 0,063 & 0,234 & 0,016 & 0,001 & 0,014 & 0,044 & 0,005 & 0,024 & 0,306 & 0,000 \\
\hline ELEKTRO & 0,009 & 0,103 & 0,372 & 0,011 & 0,017 & 0,022 & 0,067 & 0,006 & 0,043 & 0,211 & 0,157 \\
\hline ELETROACRE & 0,023 & 0,238 & 0,905 & 0,054 & 0,028 & 0,052 & 0,154 & 0,019 & 0,307 & 0,385 & 2,264 \\
\hline ELETROCAR & 0,008 & 0,088 & 0,317 & 0,010 & 0,004 & 0,019 & 0,054 & 0,005 & 0,054 & 0,178 & 0,004 \\
\hline ELETROPAULO & 0,009 & 0,104 & 0,375 & 0,011 & 0,028 & 0,022 & 0,062 & 0,006 & 0,137 & 0,190 & 0,128 \\
\hline ELFSM & 0,012 & 0,132 & 0,489 & 0,023 & 0,003 & 0,029 & 0,103 & 0,009 & 0,036 & 0,370 & 0,234 \\
\hline EMG & 0,017 & 0,194 & 0,703 & 0,050 & 0,008 & 0,042 & 0,112 & 0,012 & 0,049 & 0,627 & 0,136 \\
\hline EMS & 0,013 & 0,147 & 0,543 & 0,020 & 0,027 & 0,032 & 0,096 & 0,010 & 0,077 & 0,276 & 0,285 \\
\hline EMT & 0,010 & 0,110 & 0,415 & 0,028 & 0,026 & 0,024 & 0,071 & 0,008 & 0,123 & 0,391 & 0,511 \\
\hline ENF & 0,013 & 0,145 & 0,522 & 0,008 & 0,005 & 0,031 & 0,089 & 0,008 & 0,039 & 0,262 & 0,003 \\
\hline EPB & 0,029 & 0,320 & 1,185 & 0,035 & 0,017 & 0,069 & 0,186 & 0,022 & 0,107 & 0,325 & 0,204 \\
\hline ESCELSA & 0,013 & 0,143 & 0,524 & 0,015 & 0,051 & 0,031 & 0,090 & 0,009 & 0,044 & 0,208 & 0,425 \\
\hline ESE & 0,025 & 0,267 & 0,990 & 0,022 & 0,009 & 0,058 & 0,156 & 0,019 & 0,076 & 0,248 & 0,196 \\
\hline ETO & 0,024 & 0,252 & 0,965 & 0,049 & 0,013 & 0,055 & 0,148 & 0,021 & 0,145 & 0,580 & 0,521 \\
\hline FORCEL & 0,006 & 0,071 & 0,255 & 0,033 & 0,004 & 0,015 & 0,048 & 0,004 & 0,003 & 0,630 & 0,008 \\
\hline HIDROPAN & 0,008 & 0,090 & 0,329 & 0,016 & 0,001 & 0,019 & 0,061 & 0,006 & 0,024 & 0,274 & 0,050 \\
\hline IENERGIA & 0,010 & 0,109 & 0,396 & 0,021 & 0,003 & 0,023 & 0,069 & 0,007 & 0,106 & 0,282 & 0,212 \\
\hline LIGHT & 0,008 & 0,092 & 0,334 & 0,016 & 0,038 & 0,020 & 0,064 & 0,005 & 0,070 & 0,252 & 0,989 \\
\hline MUXENERGIA & 0,011 & 0,123 & 0,460 & 0,029 & 0,037 & 0,027 & 0,073 & 0,009 & 0,019 & 0,433 & 0,096 \\
\hline RGE & 0,010 & 0,112 & 0,407 & 0,009 & 0,013 & 0,024 & 0,068 & 0,007 & 0,082 & 0,194 & 0,040 \\
\hline SULGIPE & 0,031 & 0,333 & 1,234 & 0,031 & 0,026 & 0,072 & 0,196 & 0,023 & 0,062 & 0,411 & 0,427 \\
\hline UHENPAL & 0,009 & 0,097 & 0,348 & 0,010 & 0,007 & 0,021 & 0,062 & 0,005 & 0,058 & 0,226 & 0,064 \\
\hline
\end{tabular}


É possível observar na Tabela 4.1 que os atributos "LOG_ADM_COM", "EMISSÕES", "CALLCENTER_INADIM", "FAT_PAPEL" e "CUS_EVITADOS" possuem valores inferiores a 0,3 em todas as empresas. No caso de "PERDAS", atinge-se o patamar de até 5,796 (na concessionária AME), muito embora constate-se o valor 0 para a EFLUL.

Percebe-se também que o requisito “AQ_INST" varia entre 0,208 na CPFL JAGUARI e 1,602 na CEMAR. Esses resultados indicam que alguns custos e benefícios têm maior peso na receita das distribuidoras do que outros.

Com o objetivo de permitir a identificação dos atributos com maiores pesos na receita das concessionárias, bem como as respectivas dispersões, a Tabela 4.2 exibe a média e o desvio padrão das 3 componentes de custos e das 8 de benefícios decorrentes da implantação das REI nas 62 empresas analisadas.

Tabela 4.2 - Média e desvio padrão das 3 componentes de custos e 8 de benefícios da implantação das REI nas 62 empresas analisadas.

\begin{tabular}{|l|c|c|c|c|c|c|c|c|c|c|c|}
\cline { 2 - 12 } \multicolumn{1}{c|}{} & \multicolumn{9}{c|}{ CUSTOS } & \multicolumn{7}{c|}{ BENEFICIOS } \\
\cline { 2 - 12 } \multicolumn{1}{c|}{} & LOG_ADM_COM & 0\&M_SUBSC & AQ_INST & EMISSOES & CALLCEN_INADIM & FAT_PAPEL & CUS_OPERA & CUS_EVITADOS & CONTIN & EFI_ENER & PERDAS \\
\hline MÉDIA & 0,014 & 0,154 & 0,570 & 0,027 & 0,024 & 0,033 & 0,097 & 0,011 & 0,087 & 0,329 & 0,509 \\
\hline DESVIO PADRÃO0 & 0,007 & 0,078 & 0,297 & 0,028 & 0,040 & 0,017 & 0,045 & 0,006 & 0,082 & 0,184 & 0,989 \\
\hline
\end{tabular}

Depreende-se da análise da Tabela 4.2, que o atributo "AQ_INST" possui o maior valor de média, 0,570, indicando maior peso na receita das distribuidoras. Na sequência, ficam "PERDAS" (0,509) e "EFI_ENER" (0,329). Percebe-se também que "CUS_EVITADOS" $(0,011)$, “LOG_ADM_COM" $(0,014)$ e “CALLCEN_INADIM" $(0,024)$ apresentam as menores médias e, assim, os menores pesos na receita das empresas.

Observando-se os resultados de desvio padrão na Tabela 4.2, nota-se que o benefício relativo a "PERDAS" apresenta o maior valor, 0,989, seguido por “AQ_INST", 0,297, e "EFI_ENER", 0,184. Os atributos "CUS_EVITADOS" (0,006), "LOG_ADM_COM" $(0,007)$ e "FAT_PAPEL" $(0,017)$ possuem os menores valores de desvio padrão. 
A Figura 4.1 exibe o VPL em 2017 do custo-benefício da implantação das REI nas 62 distribuidoras. Trata-se do saldo (diferença entre as somas do VP dos benefícios e dos custos) calculado considerando-se os 11 atributos de custos e de benefícios considerados.

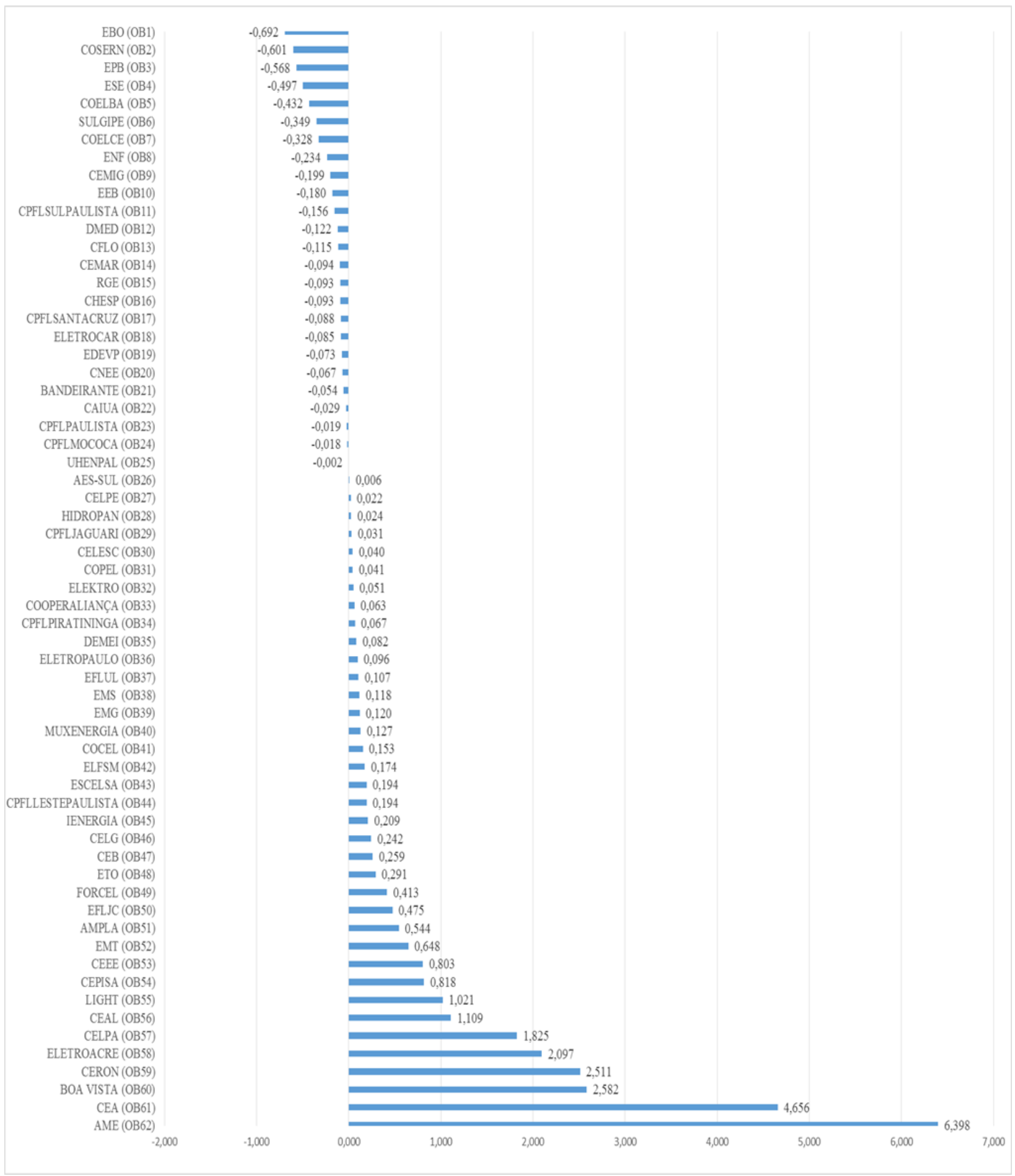

Figura 4.1 - VPL normalizado do custo-benefício da implantação das REI nas 62 distribuidoras. 
Infere-se da Figura 4.1 que, em 25 concessionárias, o VPL do custo-benefício da implantação das REI é negativo, indicando custos maiores do que os benefícios. Nesses casos, não há, atualmente, atratividade econômica para a aquisição das novas tecnologias. Quanto a esses resultados, ressalta-se que uma parte dessas empresas já iniciou a implantação das REI e que, uma vez que elas já podem estar percebendo os benefícios do novo padrão tecnológico, essa situação pode ter influenciado o resultado.

Por outro lado, em 37 distribuidoras, mais da metade do total analisado, os benefícios são maiores do que os custos. Nessas empresas, já se verifica viabilidade econômica para essas redes.

Pela análise da Figura 4.1, também é possível notar que nas distribuidoras AME $(6,398)$, CEA $(4,656)$, BOA VISTA $(2,582)$, CERON $(2,511)$, ELETROACRE $(2,097)$ e CELPA $(1,825)$, a magnitude do resultado é maior do que o valor individual das demais 31 concessionárias com saldo positivo. Nesses 6 casos, apenas uma grande variação nos atributos de custos e de benefícios pode modificar o cenário ora exposto.

Contudo, há um grupo com 56 distribuidoras cujo custo-benefício situa no intervalo de 0,692 a 1,109. Nestes casos, uma pequena alteração nos atributos pode modificar a atratividade dessas tecnologias.

Com base nesses resultados, é oportuno analisar as similaridades e as diferenças das concessionárias quanto à atratividade das REI por meio de processos de clusterização. Para tanto, inicialmente define-se o algoritmo mais adequado para tal aplicação.

Posteriormente à clusterização, avalia-se, por meio de técnica de correlação, quais custos e quais benefícios possuem comportamentos mais semelhantes ao do saldo da implantação das REI, o que permite identificar os motivadores para aplicação das novas redes nas diferentes áreas de concessão de distribuição no Brasil.

\subsection{CLUSTERIZAÇÃO}

A clusterização aglomerativa hierárquica calcula os parâmetros de homogeneidade entre objetos analisados e, por meio de um algoritmo específico, os agrupa seguidamente até a formação de um único cluster. Nesse processo, os objetos são descritos por seus atributos. 
A execução desse procedimento nos resultados exibidos anteriormente permite elucidar as semelhanças e as diferenças das concessionárias quanto à viabilidade econômica das novas tecnologias. Essa etapa constitui o primeiro passo para a identificação dos motivadores para a implantação das REI no Brasil.

Inicialmente, executa-se o processo de clusterização fazendo-se uso dos algoritmos de média das distâncias, distância dos centroides e Ward. Em seguida, efetua-se uma análise comparativa entre os seus respectivos resultados de forma a definir aquele que será empregado nas demais etapas deste estudo.

\subsubsection{Definição do algoritmo a ser aplicado}

As Tabelas 4.3, 4.4 e 4.5 apresentam os resultados da clusterização das 62 distribuidoras com base no VPL do custo-benefício das REI, empregando-se, respectivamente, os algoritmos de média das distâncias, distância dos centroides e Ward.

Tabela 4.3 - Resultados da clusterização das 62 distribuidoras empregando-se o algoritmo de média das distâncias.

\begin{tabular}{|c|c|c|c|c|}
\hline $\begin{array}{c}\text { Número de } \\
\text { Clusters }\end{array}$ & \multicolumn{2}{|l|}{ Agrupamentos } & $\mathbf{R}^{2}$ & SR $^{2}$ \\
\hline 61 & OB15 & OB16 & 1,000 & 0,000 \\
\hline 60 & OB43 & OB44 & 1,000 & 0,000 \\
\hline 59 & OB30 & OB31 & 1,000 & 0,000 \\
\hline 58 & OB14 & CL61 & 1,000 & 0,000 \\
\hline 57 & OB23 & OB24 & 1,000 & 0,000 \\
\hline 56 & OB27 & OB28 & 1,000 & 0,000 \\
\hline 55 & OB38 & OB39 & 1,000 & 0,000 \\
\hline 54 & OB17 & OB18 & 1,000 & 0,000 \\
\hline 53 & OB33 & OB34 & 1,000 & 0,000 \\
\hline 52 & OB19 & OB20 & 1,000 & 0,000 \\
\hline 51 & OB12 & OB13 & 1,000 & 0,000 \\
\hline 50 & OB25 & OB26 & 1,000 & 0,000 \\
\hline 49 & CL58 & CL54 & 1,000 & 0,000 \\
\hline 48 & CL56 & OB29 & 1,000 & 0,000 \\
\hline 47 & CL55 & OB40 & 1,000 & 0,000 \\
\hline 46 & OB22 & CL57 & 1,000 & 0,000 \\
\hline 45 & OB36 & OB37 & 1,000 & 0,000 \\
\hline 44 & CL59 & OB32 & 1,000 & 0,000 \\
\hline 43 & OB53 & OB54 & 1,000 & 0,000 \\
\hline 42 & CL60 & OB45 & 1,000 & 0,000 \\
\hline 41 & CL52 & OB21 & 1,000 & 0,000 \\
\hline & & & & \\
\hline
\end{tabular}

\begin{tabular}{|c|c|c|c|c|}
\hline $\begin{array}{c}\text { Número de } \\
\text { Clusters }\end{array}$ & \multicolumn{2}{|l|}{ Agrupamentos } & $\mathbf{R}^{\mathbf{2}}$ & SR $^{\mathbf{2}}$ \\
\hline 40 & OB46 & OB47 & 1,000 & 0,000 \\
\hline 39 & CL53 & OB35 & 1,000 & 0,000 \\
\hline 38 & OB9 & OB10 & 1,000 & 0,000 \\
\hline 37 & CL48 & CL44 & 1,000 & 0,000 \\
\hline 36 & OB6 & OB7 & 1,000 & 0,000 \\
\hline 35 & OB41 & OB42 & 1,000 & 0,000 \\
\hline 34 & CL45 & CL47 & 1,000 & 0,000 \\
\hline 33 & CL46 & CL50 & 1,000 & 0,000 \\
\hline 32 & CL49 & CL41 & 1,000 & 0,000 \\
\hline 31 & OB2 & OB3 & 1,000 & 0,000 \\
\hline 30 & CL38 & OB11 & 1,000 & 0,000 \\
\hline 29 & CL35 & CL42 & 1,000 & 0,000 \\
\hline 28 & CL37 & CL39 & 1,000 & 0,000 \\
\hline 27 & CL51 & CL32 & 1,000 & 0,000 \\
\hline 26 & CL40 & OB48 & 1,000 & 0,000 \\
\hline 25 & OB8 & CL30 & 1,000 & 0,000 \\
\hline 24 & OB49 & OB50 & 1,000 & 0,000 \\
\hline 23 & CL33 & CL28 & 1,000 & 0,000 \\
\hline 22 & OB4 & OB5 & 1,000 & 0,000 \\
\hline 21 & OB59 & OB60 & 1,000 & 0,000 \\
\hline & & & & \\
\hline & & & & \\
\hline
\end{tabular}

\begin{tabular}{|c|c|c|c|c|}
\hline $\begin{array}{c}\text { Número de } \\
\text { Clusters }\end{array}$ & \multicolumn{2}{|l|}{ Agrupamentos } & $\mathbf{R}^{2}$ & SR $^{\mathbf{2}}$ \\
\hline 20 & CL34 & CL29 & 0,999 & 0,000 \\
\hline 19 & OB55 & OB56 & 0,999 & 0,000 \\
\hline 18 & OB51 & OB52 & 0,999 & 0,000 \\
\hline 17 & OB1 & CL31 & 0,999 & 0,000 \\
\hline 16 & CL25 & CL27 & 0,999 & 0,000 \\
\hline 15 & CL20 & CL26 & 0,998 & 0,000 \\
\hline 14 & CL22 & CL36 & 0,998 & 0,000 \\
\hline 13 & CL16 & CL23 & 0,997 & 0,002 \\
\hline 12 & CL24 & CL18 & 0,996 & 0,000 \\
\hline 11 & CL17 & CL14 & 0,995 & 0,001 \\
\hline 10 & CL13 & CL15 & 0,990 & 0,005 \\
\hline 9 & CL43 & CL19 & 0,989 & 0,001 \\
\hline 8 & OB57 & OB58 & 0,989 & 0,001 \\
\hline 7 & CL12 & CL9 & 0,984 & 0,004 \\
\hline 6 & CL11 & CL10 & 0,965 & 0,020 \\
\hline 5 & CL8 & CL21 & 0,960 & 0,004 \\
\hline 4 & CL6 & CL7 & 0,909 & 0,051 \\
\hline 3 & OB61 & OB62 & 0,891 & 0,019 \\
\hline 2 & CL4 & CL5 & 0,671 & 0,220 \\
\hline 1 & CL2 & CL3 & 0,000 & 0,671 \\
\hline & & & & \\
\hline
\end{tabular}


Tabela 4.4 - Resultados da clusterização das 62 distribuidoras empregando-se o algoritmo de distância dos centroides.

\begin{tabular}{|c|c|c|c|c|}
\hline $\begin{array}{c}\text { Número de } \\
\text { Clusters }\end{array}$ & \multicolumn{2}{|c|}{ Agrupamentos } & $\mathbf{R}^{\mathbf{2}}$ & $\mathbf{S R}^{\mathbf{2}}$ \\
\hline 61 & OB15 & OB16 & 1,000 & 0,000 \\
\hline 60 & OB43 & OB44 & 1,000 & 0,000 \\
\hline 59 & OB30 & OB31 & 1,000 & 0,000 \\
\hline 58 & OB14 & CL61 & 1,000 & 0,000 \\
\hline 57 & OB23 & OB24 & 1,000 & 0,000 \\
\hline 56 & OB27 & OB28 & 1,000 & 0,000 \\
\hline 55 & OB38 & OB39 & 1,000 & 0,000 \\
\hline 54 & OB17 & OB18 & 1,000 & 0,000 \\
\hline 53 & OB33 & OB34 & 1,000 & 0,000 \\
\hline 52 & OB19 & OB20 & 1,000 & 0,000 \\
\hline 51 & OB12 & OB13 & 1,000 & 0,000 \\
\hline 50 & CL58 & CL54 & 1,000 & 0,000 \\
\hline 49 & OB25 & OB26 & 1,000 & 0,000 \\
\hline 48 & CL56 & OB29 & 1,000 & 0,000 \\
\hline 47 & CL55 & OB40 & 1,000 & 0,000 \\
\hline 46 & OB22 & CL57 & 1,000 & 0,000 \\
\hline 45 & OB36 & OB37 & 1,000 & 0,000 \\
\hline 44 & CL59 & OB32 & 1,000 & 0,000 \\
\hline 43 & OB53 & OB54 & 1,000 & 0,000 \\
\hline 42 & CL60 & OB45 & 1,000 & 0,000 \\
\hline 41 & CL52 & OB21 & 1,000 & 0,000 \\
\hline
\end{tabular}

\begin{tabular}{|c|c|c|c|c|}
\hline $\begin{array}{c}\text { Número de } \\
\text { Clusters }\end{array}$ & \multicolumn{2}{|c|}{ Agrupamentos } & $\mathbf{R}^{\mathbf{2}}$ & SR $^{\mathbf{2}}$ \\
\hline 40 & OB46 & OB47 & 1,000 & 0,000 \\
\hline 39 & CL53 & OB35 & 1,000 & 0,000 \\
\hline 38 & CL48 & CL44 & 1,000 & 0,000 \\
\hline 37 & OB9 & OB10 & 1,000 & 0,000 \\
\hline 36 & CL45 & CL47 & 1,000 & 0,000 \\
\hline 35 & OB6 & OB7 & 1,000 & 0,000 \\
\hline 34 & OB41 & OB42 & 1,000 & 0,000 \\
\hline 33 & CL46 & CL49 & 1,000 & 0,000 \\
\hline 32 & CL50 & CL41 & 1,000 & 0,000 \\
\hline 31 & OB2 & OB3 & 1,000 & 0,000 \\
\hline 30 & CL37 & OB11 & 1,000 & 0,000 \\
\hline 29 & CL34 & CL42 & 1,000 & 0,000 \\
\hline 28 & CL38 & CL39 & 1,000 & 0,000 \\
\hline 27 & CL51 & CL32 & 1,000 & 0,000 \\
\hline 26 & CL40 & OB48 & 1,000 & 0,000 \\
\hline 25 & OB8 & CL30 & 1,000 & 0,000 \\
\hline 24 & CL33 & CL28 & 1,000 & 0,000 \\
\hline 23 & OB49 & OB50 & 1,000 & 0,000 \\
\hline 22 & OB4 & OB5 & 1,000 & 0,000 \\
\hline 21 & OB59 & OB60 & 1,000 & 0,000 \\
\hline \multicolumn{5}{|r}{} \\
\hline
\end{tabular}

\begin{tabular}{|c|c|c|c|c|}
\hline $\begin{array}{c}\text { Número de } \\
\text { Clusters }\end{array}$ & Agrupamentos & $\mathbf{R}^{2}$ & SR $^{2}$ \\
\hline 20 & CL36 & CL29 & 0,999 & 0,000 \\
\hline 19 & OB55 & OB56 & 0,999 & 0,000 \\
\hline 18 & CL23 & OB51 & 0,999 & 0,000 \\
\hline 17 & CL25 & CL27 & 0,999 & 0,000 \\
\hline 16 & OB1 & CL31 & 0,999 & 0,000 \\
\hline 15 & CL20 & CL26 & 0,998 & 0,000 \\
\hline 14 & CL22 & CL35 & 0,998 & 0,000 \\
\hline 13 & CL17 & CL24 & 0,996 & 0,002 \\
\hline 12 & OB52 & CL43 & 0,996 & 0,000 \\
\hline 11 & CL16 & CL14 & 0,995 & 0,001 \\
\hline 10 & CL13 & CL15 & 0,990 & 0,005 \\
\hline 9 & OB57 & OB58 & 0,989 & 0,001 \\
\hline 8 & CL18 & CL12 & 0,988 & 0,001 \\
\hline 7 & CL8 & CL19 & 0,984 & 0,004 \\
\hline 6 & CL11 & CL10 & 0,965 & 0,020 \\
\hline 5 & CL9 & CL21 & 0,960 & 0,004 \\
\hline 4 & CL6 & CL7 & 0,909 & 0,051 \\
\hline 3 & OB61 & OB62 & 0,891 & 0,019 \\
\hline 2 & CL4 & CL5 & 0,671 & 0,220 \\
\hline 1 & CL2 & CL3 & 0,000 & 0,671 \\
\hline
\end{tabular}

Tabela 4.5 - Resultados da clusterização das 62 distribuidoras empregando-se o algoritmo de Ward.

\begin{tabular}{|c|c|c|c|c|}
\hline $\begin{array}{c}\text { Número de } \\
\text { Clusters }\end{array}$ & Agrupamentos & $\mathbf{R}^{\mathbf{2}}$ & $\mathbf{S R}^{\mathbf{2}}$ \\
\hline 61 & OB15 & OB16 & 1,000 & 0,000 \\
\hline 60 & OB43 & OB44 & 1,000 & 0,000 \\
\hline 59 & OB30 & OB31 & 1,000 & 0,000 \\
\hline 58 & OB23 & OB24 & 1,000 & 0,000 \\
\hline 57 & OB14 & CL61 & 1,000 & 0,000 \\
\hline 56 & OB27 & OB28 & 1,000 & 0,000 \\
\hline 55 & OB38 & OB39 & 1,000 & 0,000 \\
\hline 54 & OB17 & OB18 & 1,000 & 0,000 \\
\hline 53 & OB33 & OB34 & 1,000 & 0,000 \\
\hline 52 & OB19 & OB20 & 1,000 & 0,000 \\
\hline 51 & OB12 & OB13 & 1,000 & 0,000 \\
\hline 50 & OB25 & OB26 & 1,000 & 0,000 \\
\hline 49 & CL56 & OB29 & 1,000 & 0,000 \\
\hline 48 & CL55 & OB40 & 1,000 & 0,000 \\
\hline 47 & OB36 & OB37 & 1,000 & 0,000 \\
\hline 46 & CL57 & CL54 & 1,000 & 0,000 \\
\hline 45 & OB22 & CL58 & 1,000 & 0,000 \\
\hline 44 & CL59 & OB32 & 1,000 & 0,000 \\
\hline 43 & OB53 & OB54 & 1,000 & 0,000 \\
\hline 42 & OB46 & OB47 & 1,000 & 0,000 \\
\hline 41 & CL60 & OB45 & 1,000 & 0,000 \\
\hline
\end{tabular}

\begin{tabular}{|c|c|c|c|c|}
\hline $\begin{array}{c}\text { Número de } \\
\text { Clusters }\end{array}$ & Agrupamentos & $\mathbf{R}^{2}$ & SR $^{2}$ \\
\hline 40 & CL52 & OB21 & 1,000 & 0,000 \\
\hline 39 & OB9 & OB10 & 1,000 & 0,000 \\
\hline 38 & CL53 & OB35 & 1,000 & 0,000 \\
\hline 37 & OB6 & OB7 & 1,000 & 0,000 \\
\hline 36 & OB41 & OB42 & 1,000 & 0,000 \\
\hline 35 & CL47 & CL48 & 1,000 & 0,000 \\
\hline 34 & CL49 & CL44 & 1,000 & 0,000 \\
\hline 33 & OB2 & OB3 & 1,000 & 0,000 \\
\hline 32 & CL45 & CL50 & 1,000 & 0,000 \\
\hline 31 & CL39 & OB11 & 1,000 & 0,000 \\
\hline 30 & CL42 & OB48 & 1,000 & 0,000 \\
\hline 29 & CL51 & CL46 & 1,000 & 0,000 \\
\hline 28 & CL36 & CL41 & 1,000 & 0,000 \\
\hline 27 & OB49 & OB50 & 1,000 & 0,000 \\
\hline 26 & OB4 & OB5 & 1,000 & 0,000 \\
\hline 25 & OB8 & CL31 & 1,000 & 0,000 \\
\hline 24 & CL29 & CL40 & 1,000 & 0,000 \\
\hline 23 & OB59 & OB60 & 1,000 & 0,000 \\
\hline 22 & CL34 & CL38 & 1,000 & 0,000 \\
\hline 21 & OB55 & OB56 & 1,000 & 0,000 \\
\hline \multicolumn{5}{|r}{} \\
\hline
\end{tabular}

\begin{tabular}{|c|c|c|c|c|}
\hline $\begin{array}{c}\text { Número de } \\
\text { Clusters }\end{array}$ & \multicolumn{2}{|c|}{ Agrupamentos } & $\mathbf{R}^{2}$ & SR $^{\mathbf{2}}$ \\
\hline 20 & OB51 & OB52 & 1,000 & 0,000 \\
\hline 19 & OB1 & CL33 & 1,000 & 0,000 \\
\hline 18 & CL32 & CL22 & 0,999 & 0,000 \\
\hline 17 & CL28 & CL30 & 0,999 & 0,000 \\
\hline 16 & CL26 & CL37 & 0,999 & 0,000 \\
\hline 15 & CL27 & CL20 & 0,999 & 0,000 \\
\hline 14 & CL18 & CL35 & 0,998 & 0,000 \\
\hline 13 & CL25 & CL24 & 0,998 & 0,000 \\
\hline 12 & OB57 & OB58 & 0,998 & 0,001 \\
\hline 11 & CL43 & CL21 & 0,997 & 0,001 \\
\hline 10 & CL19 & CL16 & 0,996 & 0,001 \\
\hline 9 & CL14 & CL17 & 0,994 & 0,002 \\
\hline 8 & CL12 & CL23 & 0,990 & 0,004 \\
\hline 7 & CL15 & CL11 & 0,985 & 0,004 \\
\hline 6 & CL13 & CL9 & 0,980 & 0,005 \\
\hline 5 & OB61 & OB62 & 0,962 & 0,019 \\
\hline 4 & CL10 & CL6 & 0,942 & 0,020 \\
\hline 3 & CL4 & CL7 & 0,891 & 0,051 \\
\hline 2 & CL8 & CL5 & 0,716 & 0,175 \\
\hline 1 & CL3 & CL2 & 0,000 & 0,716 \\
\hline
\end{tabular}

Percebe-se nas Tabelas 4.3 e 4.4, que o parâmetro de homogeneidade $\mathrm{R}^{2}$ tem valor igual a 1,000 até a formação de 21 clusters, indicando máxima homogeneidade nos agrupamentos. Nota-se também que, a partir do estágio de formação de 6 clusters, o $\mathrm{R}^{2}$ apresenta redução mais intensa. No estágio de 4 grupos, o parâmetro torna-se 0,909 . 
Analisando-se a Tabela 4.5, depreende-se que $\mathrm{R}^{2}$ apresenta a primeira redução no estágio de 18 clusters. Na formação de 4 grupos, esse parâmetro torna-se 0,942 . Portanto, os resultados de $\mathrm{R}^{2}$ decorrentes do processo de clusterização com base no VPL do custo-benefício da implantação das REI empregando-se Ward apresentam os maiores patamares. Logo, trata-se do método que culmina na mais elevada homogeneidade.

Com base nesse resultado, conclui-se que o algoritmo de Ward é o mais adequado para ser aplicado nos processos de clusterização executados neste trabalho.

\subsubsection{Clusterização das distribuidoras com base no VPL do custo-benefício da implantação das REI}

A Tabela 4.6 apresenta os parâmetros de homogeneidade $\mathrm{R}^{2}$ e $\mathrm{R}^{2}$ semi-parcial $\left(\mathrm{SR}^{2}\right)$ do processo de clusterização das 62 concessionárias com base no VPL do custo-benefício da implantação das REI ${ }^{13}$.

Tabela 4.6 - $\mathrm{R}^{2}$ e $\mathrm{SR}^{2}$ da clusterização das distribuidoras com base no VPL do custobenefício da implantação das REI.

\begin{tabular}{|c|c|c|c|c|}
\hline $\begin{array}{c}\text { Número de } \\
\text { Clusters }\end{array}$ & \multicolumn{2}{|l|}{ Agrupamentos } & $\mathbf{R}^{2}$ & SR $^{\mathbf{2}}$ \\
\hline 61 & OB15 & OB16 & 1,000 & 0,000 \\
\hline 60 & OB43 & OB44 & 1,000 & 0,000 \\
\hline 59 & OB30 & OB31 & 1,000 & 0,000 \\
\hline 58 & OB23 & OB24 & 1,000 & 0,000 \\
\hline 57 & OB14 & CL61 & 1,000 & 0,000 \\
\hline 56 & OB27 & OB28 & 1,000 & 0,000 \\
\hline 55 & OB38 & OB39 & 1,000 & 0,000 \\
\hline 54 & OB17 & OB18 & 1,000 & 0,000 \\
\hline 53 & OB33 & OB34 & 1,000 & 0,000 \\
\hline 52 & OB19 & OB20 & 1,000 & 0,000 \\
\hline 51 & OB12 & OB13 & 1,000 & 0,000 \\
\hline 50 & OB25 & OB26 & 1,000 & 0,000 \\
\hline 49 & CL56 & OB29 & 1,000 & 0,000 \\
\hline 48 & CL55 & OB40 & 1,000 & 0,000 \\
\hline 47 & OB36 & OB37 & 1,000 & 0,000 \\
\hline 46 & CL57 & CL54 & 1,000 & 0,000 \\
\hline 45 & OB22 & CL58 & 1,000 & 0,000 \\
\hline 44 & CL59 & OB32 & 1,000 & 0,000 \\
\hline 43 & OB53 & OB54 & 1,000 & 0,000 \\
\hline 42 & OB46 & OB47 & 1,000 & 0,000 \\
\hline 41 & CL60 & OB45 & 1,000 & 0,000 \\
\hline
\end{tabular}

\begin{tabular}{|c|c|c|c|c|}
\hline $\begin{array}{c}\text { Número de } \\
\text { Clusters }\end{array}$ & \multicolumn{2}{|c|}{ Agrupamentos } & $\mathbf{R}^{2}$ & SR $^{2}$ \\
\hline 40 & CL52 & OB21 & 1,000 & 0,000 \\
\hline 39 & OB9 & OB10 & 1,000 & 0,000 \\
\hline 38 & CL53 & OB35 & 1,000 & 0,000 \\
\hline 37 & OB6 & OB7 & 1,000 & 0,000 \\
\hline 36 & OB41 & OB42 & 1,000 & 0,000 \\
\hline 35 & CL47 & CL48 & 1,000 & 0,000 \\
\hline 34 & CL49 & CL44 & 1,000 & 0,000 \\
\hline 33 & OB2 & OB3 & 1,000 & 0,000 \\
\hline 32 & CL45 & CL50 & 1,000 & 0,000 \\
\hline 31 & CL39 & OB11 & 1,000 & 0,000 \\
\hline 30 & CL42 & OB48 & 1,000 & 0,000 \\
\hline 29 & CL51 & CL46 & 1,000 & 0,000 \\
\hline 28 & CL36 & CL41 & 1,000 & 0,000 \\
\hline 27 & OB49 & OB50 & 1,000 & 0,000 \\
\hline 26 & OB4 & OB5 & 1,000 & 0,000 \\
\hline 25 & OB8 & CL31 & 1,000 & 0,000 \\
\hline 24 & CL29 & CL40 & 1,000 & 0,000 \\
\hline 23 & OB59 & OB60 & 1,000 & 0,000 \\
\hline 22 & CL34 & CL38 & 1,000 & 0,000 \\
\hline 21 & OB55 & OB56 & 1,000 & 0,000 \\
\hline & & & &
\end{tabular}

\begin{tabular}{|c|c|c|c|c|}
\hline $\begin{array}{c}\text { Número de } \\
\text { Clusters }\end{array}$ & \multicolumn{2}{|c|}{ Agrupamentos } & $\mathbf{R}^{\mathbf{2}}$ & SR $^{\mathbf{2}}$ \\
\hline 20 & OB51 & OB52 & 1,000 & 0,000 \\
\hline 19 & OB1 & CL33 & 1,000 & 0,000 \\
\hline 18 & CL32 & CL22 & 0,999 & 0,000 \\
\hline 17 & CL28 & CL30 & 0,999 & 0,000 \\
\hline 16 & CL26 & CL37 & 0,999 & 0,000 \\
\hline 15 & CL27 & CL20 & 0,999 & 0,000 \\
\hline 14 & CL18 & CL35 & 0,998 & 0,000 \\
\hline 13 & CL25 & CL24 & 0,998 & 0,000 \\
\hline 12 & OB57 & OB58 & 0,998 & 0,001 \\
\hline 11 & CL43 & CL21 & 0,997 & 0,001 \\
\hline 10 & CL19 & CL16 & 0,996 & 0,001 \\
\hline 9 & CL14 & CL17 & 0,994 & 0,002 \\
\hline 8 & CL12 & CL23 & 0,990 & 0,004 \\
\hline 7 & CL15 & CL11 & 0,985 & 0,004 \\
\hline 6 & CL13 & CL9 & 0,980 & 0,005 \\
\hline 5 & OB61 & OB62 & 0,962 & 0,019 \\
\hline 4 & CL10 & CL6 & 0,942 & 0,020 \\
\hline 3 & CL4 & CL7 & 0,891 & 0,051 \\
\hline 2 & CL8 & CL5 & 0,716 & 0,175 \\
\hline 1 & CL3 & CL2 & 0,000 & 0,716 \\
\hline
\end{tabular}

\footnotetext{
${ }^{13}$ Conforme comentado no capítulo 3 , nos processos de clusterização, as distribuidoras são tratadas como observações, cuja abreviação é “OB”. A ordem das observações é a mesma apresentada na Figura 4.1. Portanto, a "OB” 1 indica a distribuidora EBO, a "OB” 2 representa a COSERN e, assim, sucessivamente, até a "OB” 62, que equivale à AME.
} 
Infere-se da análise da Tabela 4.6 que no estágio de redução de 19 para 18 clusters, o parâmetro $\mathrm{R}^{2}$ exibe o primeiro decrescimento, de 1,000 para 0,999 , indicando perda de homogeneidade. Ele permanece nesse patamar até a composição de 15 grupos e na etapa seguinte se torna 0,998. Tal parâmetro apresenta nova redução em 11 clusters, para 0,997, e, a partir desse ponto, ele decresce de forma intensa, até chegar a zero na formação de um único grupo.

A Figura 4.2 apresenta a evolução do parâmetro $\mathrm{SR}^{2}$, que representa a variação de $\mathrm{R}^{2}$, em relação à quantidade de clusters formados no processo de agrupamento.

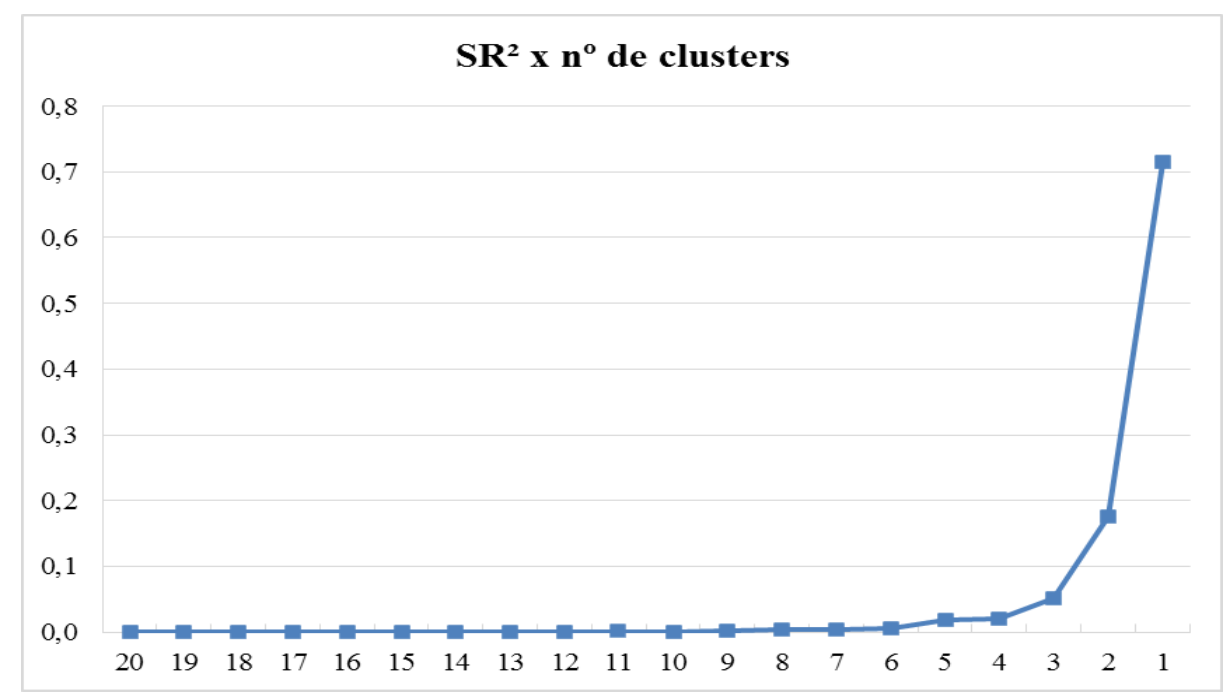

Figura 4.2 - Evolução do parâmetro $\mathrm{SR}^{2}$ em relação à quantidade de clusters formados no processo de agrupamento.

Depreende-se da análise da Figura 4.2, que $\mathrm{SR}^{2}$ se mantém muito próximo de zero até a constituição de 3 clusters, ocasião em que ele aumenta para próximo de 0,05. Esse comportamento aponta para uma grande homogeneidade até essa etapa do processo de agrupamento. Nota-se que há, nos estágios seguintes, um crescimento acentuado desse parâmetro.

Portanto, conclui-se que, nas clusterizações executadas neste trabalho, a divisão das concessionárias em 3 grupos representa a menor quantidade de clusters com garantia de elevada homogeneidade entres seus componentes. Essa quantidade é utilizada como referência para as análises seguintes. 
Expõem-se, na Tabela 4.7, os 3 grupos formados no processo de clusterização das distribuidoras com base no VPL do custo-benefício da implantação das REI.

Tabela 4.7 - Grupos formados na clusterização das distribuidoras com base no VPL do custo-benefício da implantação das REI.

\begin{tabular}{|l|l|l|}
\hline \multicolumn{2}{|c|}{ Clusters } \\
\hline \multicolumn{1}{|c|}{$\mathbf{2}$} & \multicolumn{1}{|c|}{$\mathbf{3}$} \\
\hline EBO & CELPA & CEA \\
\hline COSERN & ELETROACRE & AME \\
\hline EPB & CERON & \\
\hline ESE & BOA VISTA & \\
\hline COELBA & & \\
\hline SULGIPE & & \\
\hline COELCE & & \\
\hline ENF & & \\
\hline CEMIG & & \\
\hline EEB & & \\
\hline CPFLSULPAULISTA & & \\
\hline DMED & & \\
\hline CFLO & & \\
\hline CEMAR & & \\
\hline RGE & & \\
\hline CHESP & & \\
\hline CPFLSANTACRUZ & & \\
\hline ELETROCAR & & \\
\hline EDEVP & & \\
\hline CNEE & & \\
\hline BANDEIRANTE & & \\
\hline CAIUA & & \\
\hline CPFLPAULISTA & & \\
\hline CPFLMOCOCA & & \\
\hline UHENPAL & & \\
\hline AES-SUL & & \\
\hline CELPE & & \\
\hline HIDROPAN & & \\
\hline CPFLJAGUARI & & \\
\hline CELESC & & \\
\hline COPEL & & \\
\hline ELEKTRO & & \\
\hline COOPERALIANÇA & & \\
\hline CPFLPIRATININGA & & \\
\hline DEMEI & & \\
\hline ELETROPAULO & & \\
\hline EFLUL & & \\
\hline EMS & & \\
\hline EMG & & \\
\hline MUXENERGIA & & \\
\hline COCEL & & \\
\hline ELFSM & & \\
\hline ESCELSA & & \\
\hline CPFLLESTEPAULISTA & & \\
\hline IENERGIA & & \\
\hline CELG & & \\
\hline EEB & & \\
\hline FORCEL & & \\
\hline AMPLA & & \\
\hline EMT & & \\
\hline CEPISA & & \\
\hline
\end{tabular}


Nota-se na Tabela 4.7 que as empresas CEA e AME formam um único cluster, o que também ocorre com a CELPA, a ELETROACRE, a CERON e a BOA VISTA. Percebe-se ainda que existe um grande cluster de distribuidoras semelhantes.

Comparando-se a Tabela 4.7 e a Figura 4.1, constata-se que o cluster 1 contém as empresas cujo custo-benefício fica próximo a zero. Os clusters 2 e 3 contemplam as distribuidoras nas quais há maior atratividade econômica para a implantação das novas tecnologias.

A Figura 4.3 apresenta o dendrograma do processo de clusterização com base no VPL do custo-benefício da implantação das REI. Nessa figura, o eixo vertical contém a magnitude do $\mathrm{SR}^{2}$ e o horizontal apresenta as empresas ${ }^{14}$. As linhas horizontais mais finas destacam os agrupamentos e a horizontal mais grossa indica o valor de $\mathrm{SR}^{2}$ no estágio de formação de 3 clusters. As linhas verticais apontam os grupos formados em cada etapa do processo.

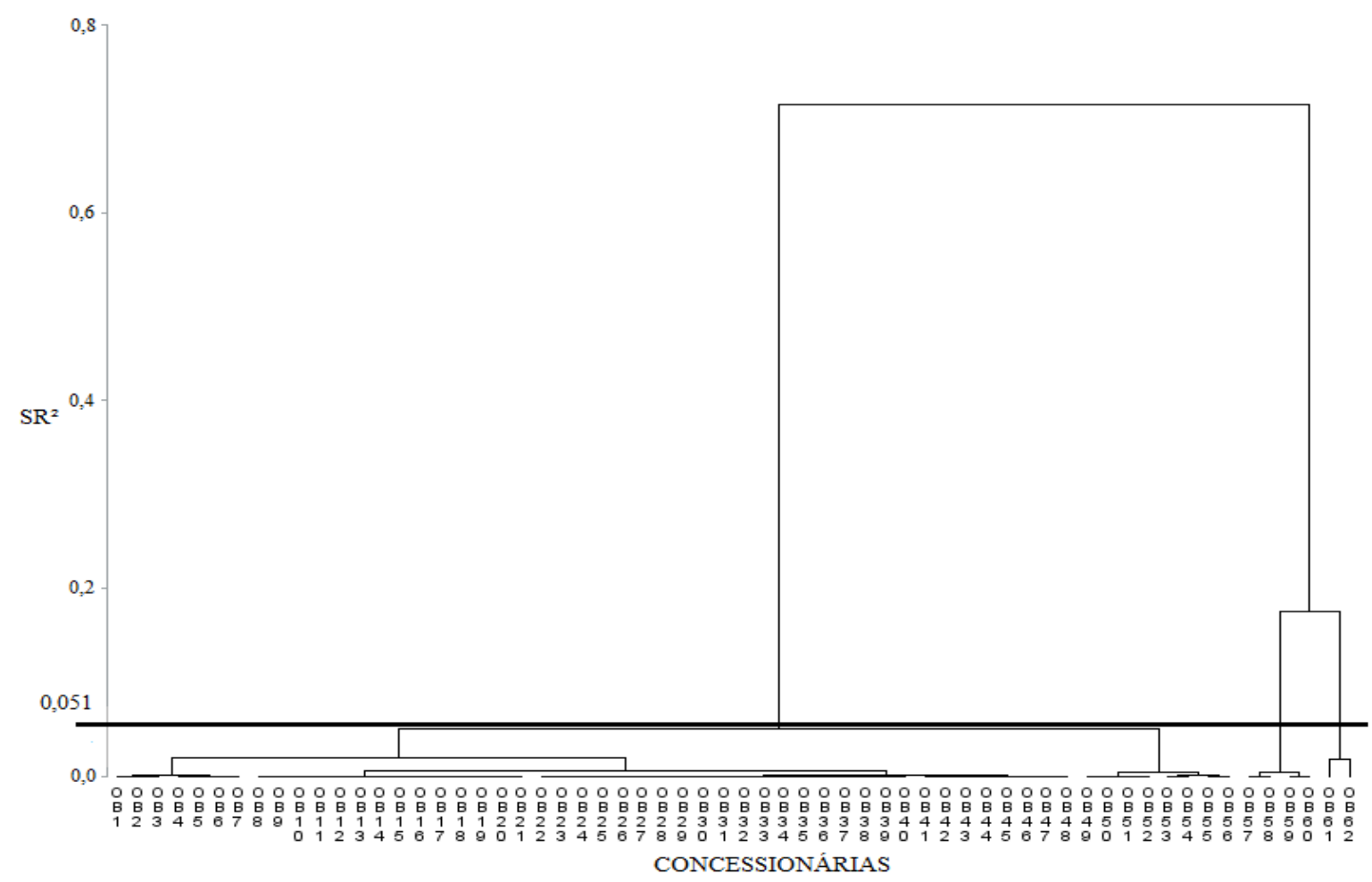

Figura 4.3 - Dendrograma da clusterização com base no VPL do custo-benefício da implantação das REI nas 62 concessionárias.

\footnotetext{
${ }^{14}$ No dendrograma, as distribuidoras também são tratadas como observações, “OB”. A ordem é a mesma apresentada na Figura 4.1.
} 
Percebe-se na Figura 4.3 que os grupos com menor magnitude de $\mathrm{SR}^{2}$, ou seja, menor perda de homogeneidade, ocorrem com as distribuidoras que possuem VPL do custo-benefício próximo a zero, a saber, "OB 1" a "OB 56" 15 . O cluster dessas empresas segue crescendo até $\mathrm{SR}^{2}$ atingir 0,051 , estágio no qual as observações 49 a $56^{16}$ são agrupadas às demais concessionárias.

Pela análise da Figura 4.3 também é possível notar que, na formação de 2 grupos, a magnitude de $\mathrm{SR}^{2}$ aumenta para um patamar próximo a 0,2, indicando maior perda de homogeneidade nessa etapa do processo.

Ainda, nota-se na Figura 4.3 que as concessionárias CELPA, ELETROACRE, CERON, BOA VISTA, CEA e AME possuem a maior diferença em relação às demais, uma vez que elas são as últimas a serem agrupadas. No estágio do processo em que elas são agregadas às outras 56 empresas, formando um único cluster, o parâmetro $\mathrm{SR}^{2}$ atinge o seu máximo valor, próximo a 0,8 .

Após a discussão sobre as similaridades e diferenças das 62 concessionárias quanto ao VPL do custo-benefício da implantação das REI, expõe-se, na sequência, os resultados do processo de clusterização com base nos demais 11 atributos.

\subsubsection{Clusterização das distribuidoras com base nos 11 atributos de custos e de benefícios}

A Tabela 4.8 exibe os parâmetros $\mathrm{R}^{2}$ e $\mathrm{SR}^{2}$ da clusterização das 62 concessionárias com base nos 11 atributos de custos e de benefícios apresentados na Tabela 4.1.

\footnotetext{
${ }^{15}$ A “OB 1" representa a concessionária EBO e a “OB 56" a CEAL.

${ }^{16}$ As observações 49 a 56 representam, na ordem, as concessionárias: FORCEL, EFLJC, AMPLA, EMT, CEEE, CEPISA, LIGHT e CEAL.
} 
Tabela 4.8 - $\mathrm{R}^{2}$ e $\mathrm{SR}^{2}$ da clusterização das distribuidoras com base no VP dos 11 atributos de custos e benefícios da implantação das REI.

\begin{tabular}{|c|c|c|c|c|}
\hline $\begin{array}{c}\text { Número de } \\
\text { Clusters }\end{array}$ & Agrupamentos & $\mathbf{R}^{\mathbf{2}}$ & SR$^{\mathbf{2}}$ \\
\hline 61 & OB32 & OB34 & 1,000 & 0,000 \\
\hline 60 & OB12 & OB13 & 1,000 & 0,000 \\
\hline 59 & OB41 & OB44 & 1,000 & 0,000 \\
\hline 58 & OB11 & OB15 & 1,000 & 0,000 \\
\hline 57 & OB23 & OB31 & 1,000 & 0,000 \\
\hline 56 & OB17 & OB25 & 1,000 & 0,000 \\
\hline 55 & OB19 & OB24 & 1,000 & 0,000 \\
\hline 54 & OB45 & OB47 & 1,000 & 0,000 \\
\hline 53 & CL57 & CL61 & 1,000 & 0,000 \\
\hline 52 & OB21 & OB30 & 1,000 & 0,000 \\
\hline 51 & CL60 & OB20 & 1,000 & 0,000 \\
\hline 50 & OB18 & OB26 & 1,000 & 0,000 \\
\hline 49 & OB8 & OB10 & 1,000 & 0,000 \\
\hline 48 & CL51 & OB28 & 1,000 & 0,000 \\
\hline 47 & CL49 & OB16 & 1,000 & 0,000 \\
\hline 46 & CL48 & CL55 & 1,000 & 0,000 \\
\hline 45 & CL53 & OB33 & 0,999 & 0,000 \\
\hline 44 & CL46 & CL56 & 0,999 & 0,000 \\
\hline 43 & CL52 & OB35 & 0,999 & 0,000 \\
\hline 42 & OB40 & CL59 & 0,999 & 0,000 \\
\hline 41 & CL58 & OB22 & 0,999 & 0,000 \\
\hline
\end{tabular}

\begin{tabular}{|c|c|c|c|c|}
\hline $\begin{array}{c}\text { Número de } \\
\text { Clusters }\end{array}$ & Agrupamentos & $\mathbf{R}^{\mathbf{2}}$ & SR $^{\mathbf{2}}$ \\
\hline 40 & OB1 & OB2 & 0,999 & 0,000 \\
\hline 39 & OB4 & OB7 & 0,999 & 0,000 \\
\hline 38 & OB38 & OB42 & 0,999 & 0,000 \\
\hline 37 & CL45 & OB36 & 0,999 & 0,000 \\
\hline 36 & CL50 & OB29 & 0,998 & 0,000 \\
\hline 35 & OB53 & OB55 & 0,998 & 0,000 \\
\hline 34 & OB5 & OB6 & 0,998 & 0,000 \\
\hline 33 & CL43 & CL37 & 0,998 & 0,000 \\
\hline 32 & OB57 & OB58 & 0,998 & 0,000 \\
\hline 31 & CL47 & OB9 & 0,998 & 0,000 \\
\hline 30 & CL41 & CL44 & 0,997 & 0,000 \\
\hline 29 & CL36 & OB37 & 0,997 & 0,000 \\
\hline 28 & CL38 & CL54 & 0,997 & 0,000 \\
\hline 27 & CL40 & CL39 & 0,996 & 0,000 \\
\hline 26 & OB3 & CL34 & 0,996 & 0,000 \\
\hline 25 & OB43 & OB51 & 0,996 & 0,000 \\
\hline 24 & CL25 & OB52 & 0,995 & 0,001 \\
\hline 23 & OB54 & OB56 & 0,995 & 0,001 \\
\hline 22 & CL28 & OB46 & 0,994 & 0,001 \\
\hline 21 & OB27 & OB48 & 0,993 & 0,001 \\
\hline
\end{tabular}

\begin{tabular}{|c|c|c|c|c|}
\hline $\begin{array}{c}\text { Número de } \\
\text { Clusters }\end{array}$ & \multicolumn{1}{|c|}{ Agrupamentos } & $\mathbf{R}^{2}$ & SR $^{2}$ \\
\hline 20 & CL30 & CL29 & 0,992 & 0,001 \\
\hline 19 & CL42 & OB49 & 0,991 & 0,001 \\
\hline 18 & CL20 & CL33 & 0,990 & 0,001 \\
\hline 17 & CL31 & CL22 & 0,989 & 0,001 \\
\hline 16 & OB39 & OB50 & 0,987 & 0,002 \\
\hline 15 & CL26 & CL21 & 0,985 & 0,003 \\
\hline 14 & CL17 & CL19 & 0,982 & 0,003 \\
\hline 13 & CL32 & OB59 & 0,980 & 0,003 \\
\hline 12 & CL24 & CL35 & 0,976 & 0,003 \\
\hline 11 & CL14 & CL18 & 0,973 & 0,003 \\
\hline 10 & CL27 & CL15 & 0,970 & 0,004 \\
\hline 9 & OB14 & CL23 & 0,963 & 0,007 \\
\hline 8 & CL13 & OB60 & 0,955 & 0,008 \\
\hline 7 & CL11 & CL16 & 0,945 & 0,010 \\
\hline 6 & CL7 & CL12 & 0,922 & 0,023 \\
\hline 5 & CL9 & CL8 & 0,899 & 0,023 \\
\hline 4 & OB61 & OB62 & 0,871 & 0,028 \\
\hline 3 & CL10 & CL6 & 0,821 & 0,051 \\
\hline 2 & CL5 & CL4 & 0,598 & 0,223 \\
\hline 1 & CL3 & CL2 & 0,000 & 0,598 \\
\hline
\end{tabular}

Percebe-se na Tabela 4.8 que o parâmetro $\mathrm{R}^{2}$ permanece em patamar elevado, próximo a 1 , até a formação de 5 grupos, quando ele atinge 0,899 . Focando-se no $\mathrm{SR}^{2}$, nota-se que há inicialmente um lento crescimento. Isso ocorre até a passagem de 3 para 2 clusters, estágio no qual ele mais do que quadruplica, de 0,051 para 0,223.

Comparando-se as Tabelas 4.8 e 4.6, e tendo como referência o estágio de 3 grupos definido anteriormente, nota-se que a clusterização com base no VPL do custo-benefício da implantação das REI apresenta um valor maior de $\mathrm{R}^{2}(0,891)$ do que no presente caso $(0,821)$, indicando maior homogeneidade nos clusters formados. Todavia, conclui-se que os patamares são próximos entre si, com diferença de 0,07 .

A Tabela 4.9 apresenta os 3 grupos do processo de clusterização das distribuidoras com base no VP dos 3 custos e dos 8 benefícios da implantação das REI. 
Tabela 4.9 - Grupos formados na clusterização das distribuidoras com base no VP dos 3 custos e 8 benefícios da implantação das REI.

\begin{tabular}{|l|l|l|}
\hline \multicolumn{2}{|c|}{ Clusters } \\
\hline & \multicolumn{1}{|c|}{$\mathbf{2}$} \\
\hline EBO & CEMAR & CEA \\
\hline COSERN & CEPISA & AME \\
\hline EPB & CEAL & \\
\hline ESE & CELPA & \\
\hline COELBA & ELETROACRE & \\
\hline SULGIPE & CERON & \\
\hline COELCE & BOA VISTA & \\
\hline ENF & & \\
\hline CEMIG & & \\
\hline EEB & & \\
\hline CPFLSULPAULISTA & & \\
\hline DMED & & \\
\hline CFLO & & \\
\hline RGE & & \\
\hline CHESP & & \\
\hline CPFLSANTACRUZ & & \\
\hline ELETROCAR & & \\
\hline EDEVP & & \\
\hline CNEE & & \\
\hline BANDEIRANTE & & \\
\hline CAIUA & & \\
\hline CPFLPAULISTA & & \\
\hline CPFLMOCOCA & & \\
\hline UHENPAL & & \\
\hline AES-SUL & & \\
\hline CELPE & & \\
\hline HIDROPAN & & \\
\hline CPFLJAGUARI & & \\
\hline CELESC & & \\
\hline COPEL & & \\
\hline ELEKTRO & & \\
\hline COOPERALIANÇA & & \\
\hline CPFLPIRATININGA & & \\
\hline DEMEI & & \\
\hline ELETROPAULO & & \\
\hline EFLUL & & \\
\hline EMS & & \\
\hline EMG & & \\
\hline MUXENERGIA & & \\
\hline COCEL & & \\
\hline ELFSM & & \\
\hline ESCELSA & & \\
\hline CPFLLESTEPAULISTA & & \\
\hline IENERGIA & & \\
\hline CELG & & \\
\hline CEB & & \\
\hline FORCEL & & \\
\hline EMLJC & & \\
\hline EMT & & \\
\hline
\end{tabular}


Depreende-se da comparação das Tabelas 4.9 e 4.7, que o cluster 3 é igual nos dois processos de clusterização. Nos demais grupos, é possível notar que há alteração apenas na CEMAR, CEPISA e CEAL. Portanto, do total de 62 empresas avaliadas, apenas 3, ou seja 4,8\% do total, são agrupadas de forma distinta.

A Figura 4.4 apresenta o dendrograma da clusterização baseada nas 3 componentes de custos e 8 de benefícios.

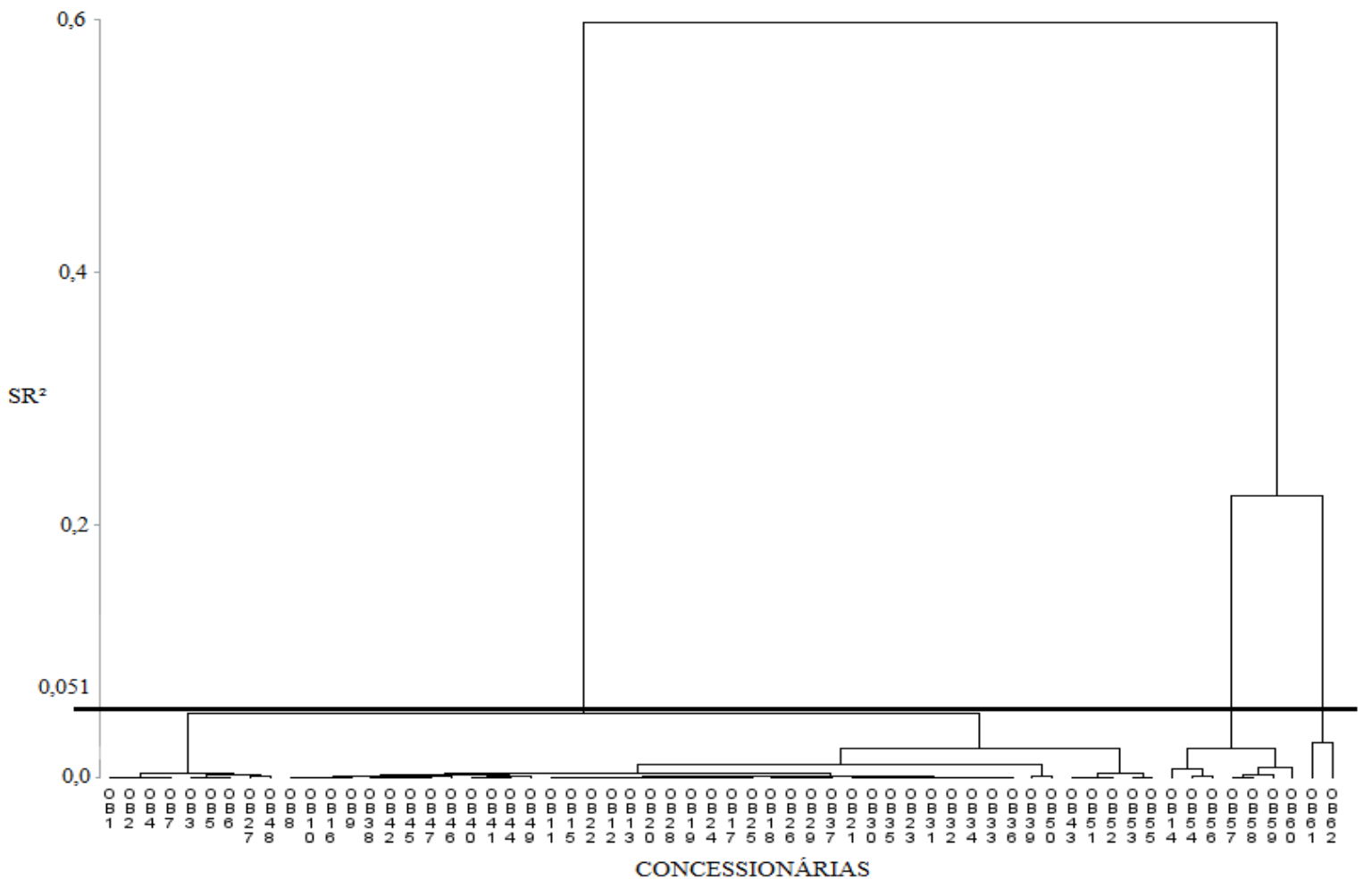

Figura 4.4 - Dendrograma da clusterização com base nas 3 componentes de custos e 8 de benefícios.

Comparando-se as Figuras 4.4 e 4.3, percebe-se que a sequência dos agrupamentos, indicada pelas linhas horizontais, é similar nos dois processos de clusterização. Ainda, no estágio de 3 clusters, a homogeneidade sofre redução idêntica nos dois casos, uma vez que o parâmetro $\mathrm{SR}^{2}$ atinge 0,051 .

Considerando os aspectos expostos, nota-se que os processos de agrupamento com base no VPL do custo-benefício da implantação das REI e no VP das 11 componentes de custos e de benefícios são similares. Portanto, é válida, para os dois casos, a análise de similaridades e diferenças quanto à viabilidade da implantação das REI nas 62 empresas. 


\subsection{INVESTIGAÇÃO SOBRE OS MOTIVADORES PARA IMPLANTAÇÃO DAS REI NO BRASIL}

\subsubsection{Avaliação da representatividade dos atributos para o VPL do custo-benefício da implantação das REI}

Nesta seção, apresenta-se o resultado da repetição do processo de clusterização retirando-se, um a um, os 3 custos e os 8 benefícios. A ordem de supressão dos atributos segue a disposição das colunas na Tabela 4.1. Assim, inicia-se o procedimento com a retirada do "LOG_ADM_COM", e finaliza-se com "PERDAS".

A execução desta prática está alicerçada no fato de que a retirada de componentes com alta representatividade no VPL do custo-benefício gera alteração nos agrupamentos. Por outro lado, a exclusão de atributos com baixa representatividade afeta pouco os resultados. A Figura 4.5 apresenta o dendrograma do processo de clusterização baseado, exclusivamente, nos atributos de "AQ_INST" e de "PERDAS".

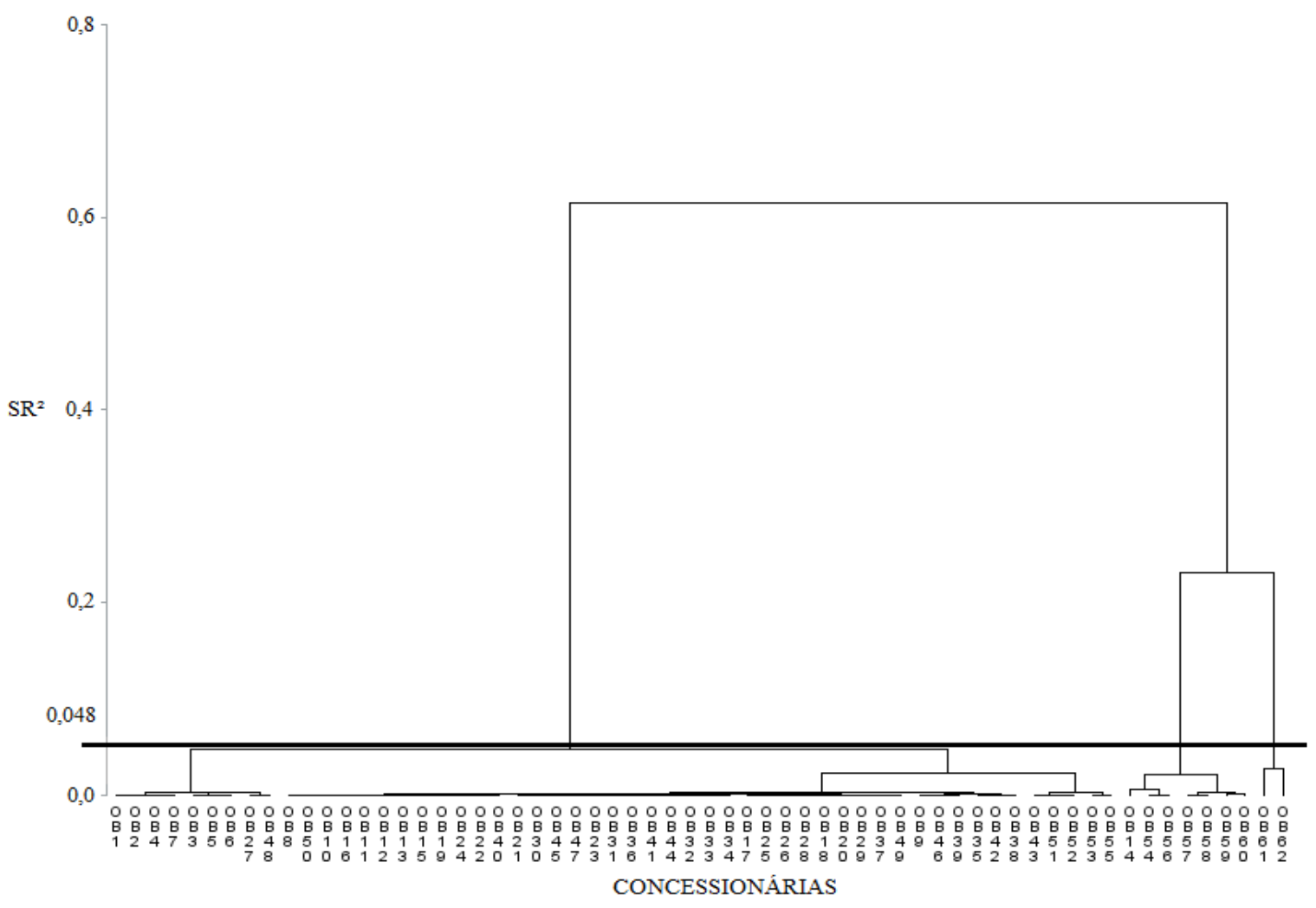

Figura 4.5 - Dendrograma da clusterização baseada nos atributos "AQ_INST" e "PERDAS". 
Infere-se da comparação das Figuras 4.5, 4.4 e 4.3 que o processo de clusterização com base nos atributos "AQ_INST" e "PERDAS" é semelhante ao baseado no VPL do custo-benefício e nos demais 11 atributos. É possível notar que os 3 grupos formados são similares e que, nessa quantidade de clusters, o parâmetro $\mathrm{SR}^{2}$ obtido em cada um dos citados processos de clusterização, atinge valores próximos (0,051 e 0,048), indicando perda equivalente de homogeneidade nesse estágio do agrupamento.

Portanto, a exclusão de 9 atributos não afeta expressivamente os resultados da clusterização, apontando que eles são menos representativos para o custo-benefício da implantação das novas tecnologias.

As Figuras 4.6 e 4.7 apresentam os resultados do processo de clusterização com base nos atributos considerados, excluindo-se, respectivamente, "AQ_INST" e "PERDAS".

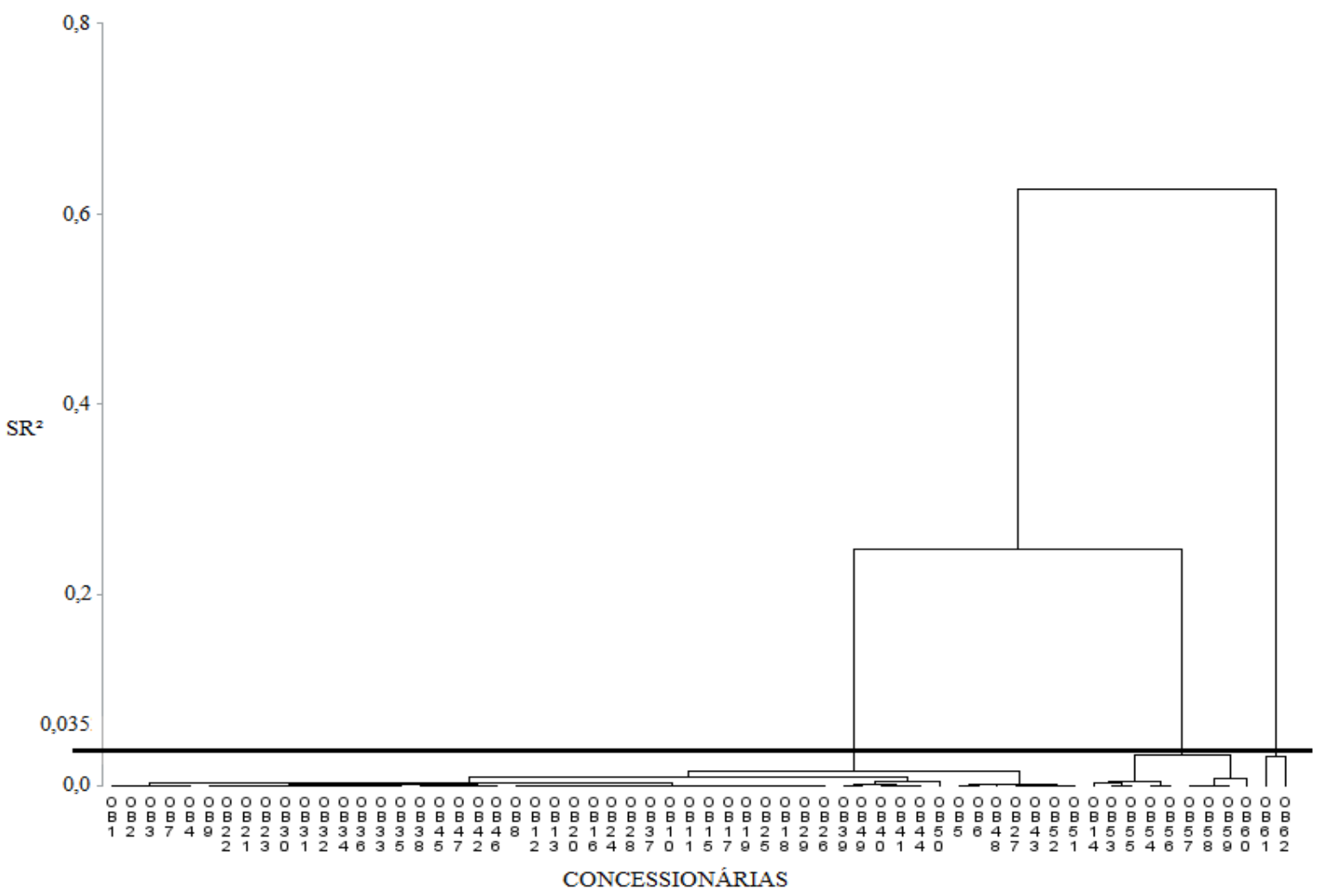

Figura 4.6 - Dendrograma da clusterização das distribuidoras excluindo-se, unicamente, o atributo "AQ_INST". 


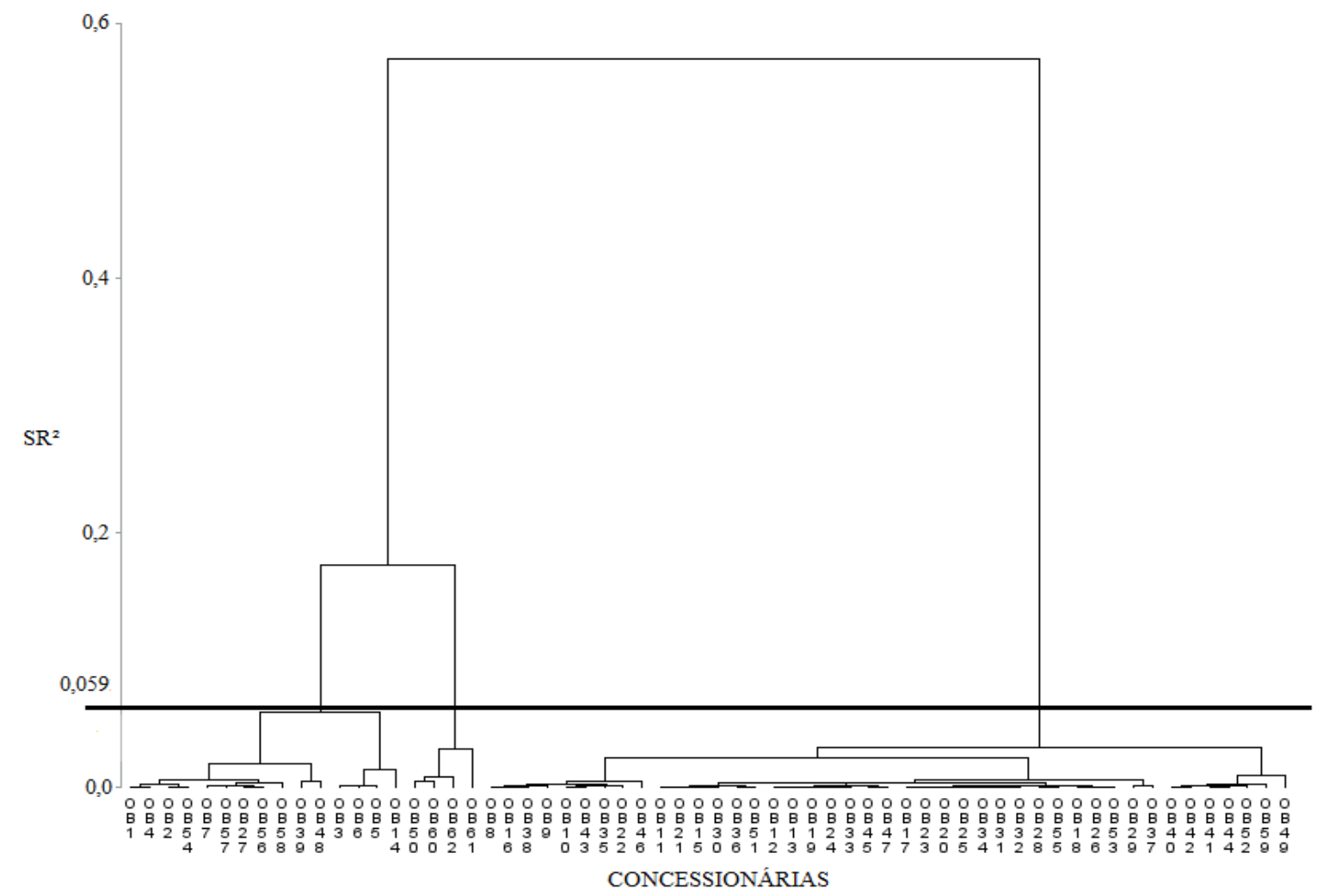

Figura 4.7 - Dendrograma da clusterização das distribuidoras excluindo-se, unicamente, o atributo "PERDAS".

Comparando-se as Figuras 4.6 e 4.5, infere-se que os estágios de agrupamento são diferentes ao se excluir o atributo "AQ_INST" do processo de clusterização. Os grupos formados também são distintos, uma vez que, no presente caso, as distribuidoras CEEE e LIGHT (“OB” 53 e 55) são alocadas no cluster 2, o que não se verifica no caso anterior.

De forma semelhante, comparando-se as Figuras 4.7 e 4.5, nota-se, pela disposição e tamanho das linhas verticais, que os estágios de agrupamento são diferentes ao se excluir "PERDAS". Também é possível perceber que há discrepâncias nos grupos formados. Por exemplo, no presente processo as empresas CEA e AME (“OB” 61 e 62) estão agrupadas em conjunto com as concessionárias EFLJC e BOA VISTA (“OB” 50 e 60).

Portanto, os atributos "AQ_INST" e "PERDAS" são os mais representativos para o VPL do custo-benefício da implantação das REI. Esse resultado é coerente com o cenário exibido na Tabela 4.2, uma vez que eles possuem os maiores valores de média. 
Além disso, conforme exposto no capítulo 2, os processos de clusterização se iniciam com a distância euclidiana das observações, calculada por meio da equação (1).

$$
d_{(i, j)}=\sqrt{\left(x_{i 1}-x_{j 1}\right)^{2}+\left(x_{i 2}-x_{j 2}\right)^{2}+\cdots+\left(x_{i p}-x_{j p}\right)^{2}}
$$

Da análise da equação, nota-se que quanto maior a dispersão de um atributo, representada pelo seu desvio padrão, maior a diferença entre as empresas. Assim, esse atributo tem mais peso na distância euclidiana e é mais representativo para a clusterização. Percebe-se na Tabela 4.2, que as componentes "AQ_INST" e "PERDAS" também apresentam os maiores valores de desvio padrão.

Com base nesses resultados, é oportuno avaliar a correlação dos 11 atributos de custos e de benefícios entre si, e destes com o VPL do custo-benefício (saldo) da implantação das REI nas concessionárias, o que permite hierarquizar aqueles que mais explicam a viabilidade da implantação das novas tecnologias. Para tanto, utilizam-se os coeficientes de correlação de Pearson e diagramas de dispersão.

\subsubsection{Correlação de Pearson e motivadores da implantação das REI no Brasil}

Expõem-se na Tabela 4.10 os coeficientes de correlação de Pearson dos 3 atributos de custos e 8 de benefícios, e destes com o saldo da implantação das REI. Adicionalmente, também são exibidos os indicadores de significância dos resultados da correlação.

Quanto maior o valor do coeficiente de Pearson, o qual varia de 0 a 1, maior a correlação entre os atributos. Além disso, quanto menor o indicador de significância, mais se pode confiar no resultado da correlação ${ }^{17}$.

\footnotetext{
${ }^{17}$ Quanto maior o valor do indicador de significância, maior a probabilidade de o coeficiente de correlação representar um resultado aleatório. Por outro lado, quanto menor o indicador de significância, mais se pode confiar no resultado da correlação.
} 
Tabela 4.10 - Coeficientes de correlação de Pearson.

\begin{tabular}{|c|c|c|c|c|c|c|c|c|c|c|c|c|}
\hline & LOG_ADM_COM & O\&M_SUBSC & AQ_INST & EMISSOES & CALLCEN_INADIM & FAT_PAPEL & CUS_OPERA & CUS_EVITADOS & CONTIN & EFI_ENER & PERDAS & SALDO \\
\hline \multirow{2}{*}{ LOG_ADM_COM } & 1,000 & 0,999 & 1,000 & 0,286 & 0,090 & 1,000 & 0,992 & 0,993 & 0,304 & 0,242 & 0,226 & $-0,008$ \\
\hline & & $<, 0001$ & $<, 0001$ & 0,024 & 0,489 & $<, 0001$ & $<, 0001$ & $<, 0001$ & 0,017 & 0,058 & 0,077 & 0,951 \\
\hline \multirow{2}{*}{ O\&M_SUBSC } & 0,999 & 1,000 & 1,000 & 0,278 & 0,088 & 1,000 & 0,991 & 0,988 & 0,296 & 0,231 & 0,215 & $-0,020$ \\
\hline & $<, 0001$ & & $<, 0001$ & 0,029 & 0,495 & $<, 0001$ & $<, 0001$ & $<, 0001$ & 0,020 & 0,071 & 0,093 & 0,876 \\
\hline \multirow{2}{*}{ AQ_INST } & 1,000 & 1,000 & 1,000 & 0,285 & 0,089 & 1,000 & 0,992 & 0,992 & 0,302 & 0,240 & 0,225 & $-0,010$ \\
\hline & $<, 0001$ & $<, 0001$ & & 0,025 & 0,490 & $<, 0001$ & $<, 0001$ & $<, 0001$ & 0,017 & 0,060 & 0,079 & 0,940 \\
\hline \multirow{2}{*}{ EMISSOES } & 0,286 & 0,278 & 0,285 & 1,000 & 0,487 & 0,280 & 0,301 & 0,313 & 0,591 & 0,670 & 0,624 & 0,647 \\
\hline & 0,024 & 0,029 & 0,025 & & $<, 0001$ & 0,028 & 0,017 & 0,013 & $<, 0001$ & $<, 0001$ & $<, 0001$ & $<, 0001$ \\
\hline \multirow{2}{*}{ CALLCEN_INADIM } & 0,090 & 0,088 & 0,089 & 0,487 & 1,000 & 0,089 & 0,102 & 0,094 & 0,751 & 0,224 & 0,526 & 0,562 \\
\hline & 0,489 & 0,495 & 0,490 & $<, 0001$ & & 0,493 & 0,430 & 0,467 & $<, 0001$ & 0,080 & $<, 0001$ & $<, 0001$ \\
\hline \multirow{2}{*}{ FAT_PAPEL } & 1,000 & 1,000 & 1,000 & 0,280 & 0,089 & 1,000 & 0,991 & 0,989 & 0,298 & 0,234 & 0,218 & $-0,017$ \\
\hline & $<, 0001$ & $<, 0001$ & $<, 0001$ & 0,028 & 0,493 & & $<, 0001$ & $<, 0001$ & 0,019 & 0,067 & 0,089 & 0,896 \\
\hline \multirow{2}{*}{ CUS_OPERA } & 0,992 & 0,991 & 0,992 & 0,301 & 0,102 & 0,991 & 1,000 & 0,985 & 0,326 & 0,241 & 0,257 & 0,023 \\
\hline & $<, 0001$ & $<, 0001$ & $<, 0001$ & 0,017 & 0,430 & $<, 0001$ & & $<, 0001$ & 0,010 & 0,059 & 0,044 & 0,857 \\
\hline \multirow{2}{*}{ CUS_EVITADOS } & 0,993 & 0,988 & 0,992 & 0,313 & 0,094 & 0,989 & 0,985 & 1,000 & 0,329 & 0,280 & 0,264 & 0,036 \\
\hline & $<, 0001$ & $<, 0001$ & $<, 0001$ & 0,013 & 0,467 & $<, 0001$ & $<, 0001$ & & 0,009 & 0,028 & 0,038 & 0,784 \\
\hline \multirow{2}{*}{ CONTIN } & 0,304 & 0,296 & 0,302 & 0,591 & 0,751 & 0,298 & 0,326 & 0,329 & 1,000 & 0,300 & 0,787 & 0,751 \\
\hline & 0,017 & 0,020 & 0,017 & $<, 0001$ & $<, 0001$ & 0,019 & 0,010 & 0,009 & & 0,018 & $<, 0001$ & $<, 0001$ \\
\hline \multirow{2}{*}{ EFI_ENER } & 0,242 & 0,231 & 0,240 & 0,670 & 0,224 & 0,234 & 0,241 & 0,280 & 0,300 & 1,000 & 0,471 & 0,543 \\
\hline & 0,058 & 0,071 & 0,060 & $<, 0001$ & 0,080 & 0,067 & 0,059 & 0,028 & 0,018 & & 0,000 & $<, 0001$ \\
\hline \multirow{2}{*}{ PERDAS } & 0,226 & 0,215 & 0,225 & 0,624 & 0,526 & 0,218 & 0,257 & 0,264 & 0,787 & 0,471 & 1,000 & 0,960 \\
\hline & 0,077 & 0,093 & 0,079 & $<, 0001$ & $<, 0001$ & 0,089 & 0,044 & 0,038 & $<, 0001$ & 0,000 & & $<, 0001$ \\
\hline \multirow{2}{*}{ SALDO } & $-0,008$ & $-0,020$ & $-0,010$ & 0,647 & 0,562 & $-0,017$ & 0,023 & 0,036 & 0,751 & 0,543 & 0,960 & 1,000 \\
\hline & 0,951 & 0,876 & 0,940 & $<, 0001$ & $<, 0001$ & 0,896 & 0,857 & 0,784 & $<, 0001$ & $<, 0001$ & $<, 0001$ & \\
\hline
\end{tabular}

Percebe-se na Tabela 4.10 que as três componentes de custo, "LOG_ADM_COM", “AQ_INST” e “O\&M_SUBSC”, são altamente correlacionadas, com coeficiente de Pearson próximo a 1. No que tange aos benefícios, o mesmo ocorre com "FAT_PAPEL", “CUS_OPERA" e "CUS_EVITADOS". Além disso, esses 6 atributos possuem forte correlação entre si.

Quanto aos custos, depreende-se da análise da Tabela 4.10, que todos os atributos, com 0,008, - $-0,010$ e -0,020, possuem baixa correlação com o saldo da implantação das novas tecnologias. No que tange aos benefícios, infere-se que "PERDAS", "CONTIN" e “EMISSÕES", com 0,960, 0,751 e 0,647, são, nessa ordem, os mais correlacionados com o saldo.

Nesse ponto, cabe ressaltar que a correlação indica se a variação dos atributos é equivalente entre as empresas observadas. Por outro lado, a representatividade de um componente está relacionada à sua magnitude e, dessa forma, ao seu peso no saldo do custo-benefício. Portanto, com vistas à avaliação do quanto um atributo explica o custo-benefício, deve-se considerar sua correlação e sua representatividade para o resultado do saldo. 
Nesse contexto, com base na discussão apresentada na seção anterior, os atributos "CONTIN" e "EMISSÕES" possuem pouca representatividade para o custo-benefício. Portanto, esses atributos não têm um alto peso na explicação do custo-benefício da implantação das REI nas 62 concessionárias.

Por outro lado, conforme exposto na Tabela 4.2, o "EFI_ENER" possui a terceira maior média entre todos os atributos e a quinta maior correlação com o saldo, 0,543. Assim, essa componente de benefício possui significativo peso na explicação do resultado do custobenefício.

Ressalta-se que esse atributo apresentou baixo impacto na clusterização, consoante ao que foi discutido na seção 4.3.1, em virtude da presença de "AQ_INST" e "PERDAS", que são os mais representativos para o resultado dos agrupamentos.

A Figura 4.8 exibe os diagramas de dispersão de parte dos atributos considerados. Nos gráficos, quanto mais a distribuição dos pontos se aproximar de uma reta, maior é a correlação dos atributos analisados.

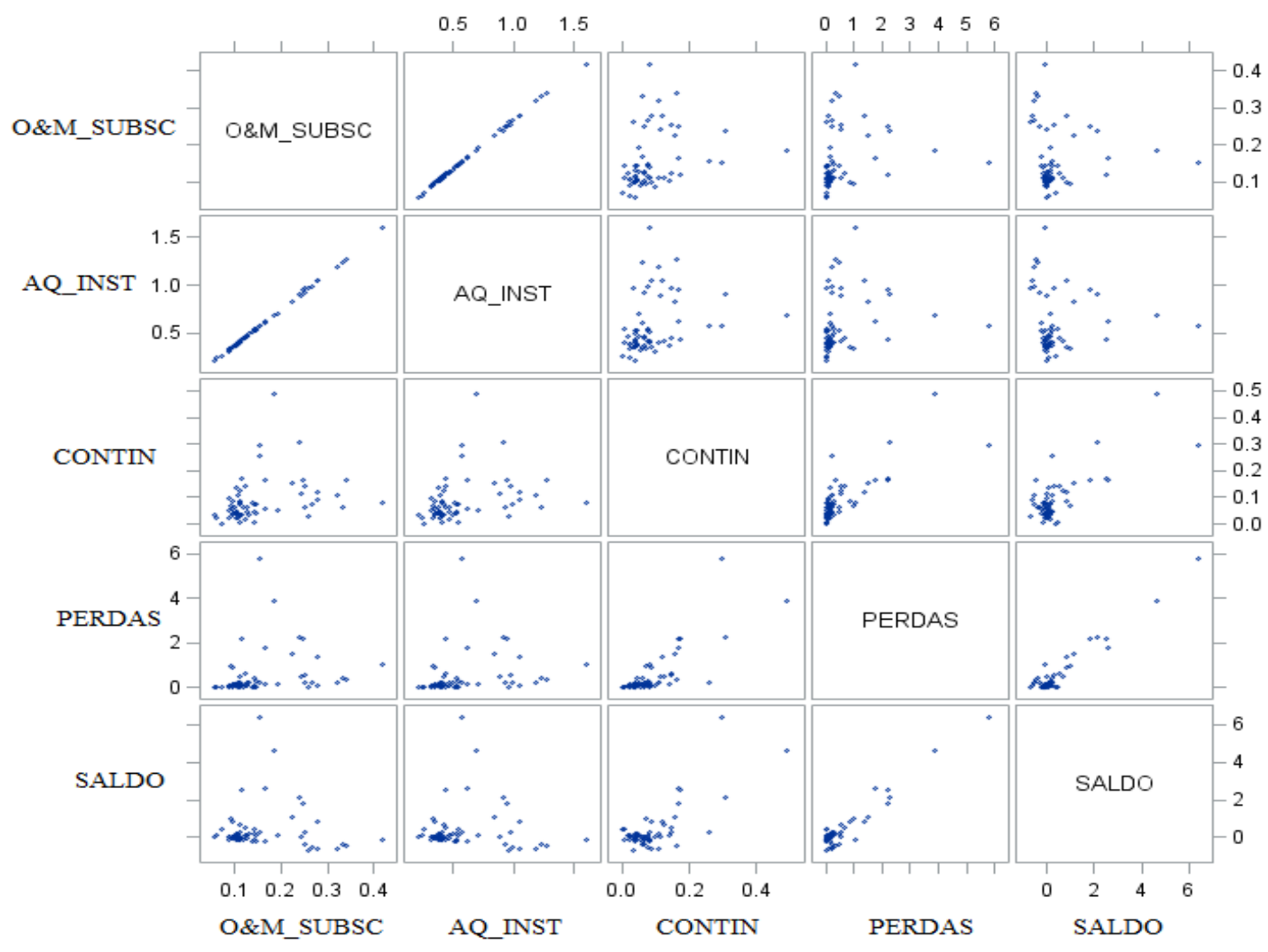

Figura 4.8 - Diagramas de dispersão de parte dos atributos considerados. 
Depreende-se da Figura 4.8 que a distribuição dos pontos no gráfico dos atributos "AQ_INST" e "O\&M_SUBSC" possui um formato similar a uma reta, indicando que existe, de fato, uma forte correlação entre eles. Também é possível perceber na Figura 4.8 que, quando se comparam os atributos de custos e de benefícios com o saldo da implantação das REI, a maior semelhança com uma reta ocorre com o atributo de "PERDAS".

Dessa forma, da análise da Tabela 4.7 e da Figura 4.8 e da avaliação da representatividade dos atributos realizada anteriormente, conclui-se que o atributo de "PERDAS" é o mais importante para a análise da viabilidade da implantação das REI no Brasil.

O atributo "EFI_ENER", que possui significativo peso na explicação do custo-benefício, e o "CONTIN", com alta correlação com o saldo, também são importantes para a viabilidade dessas redes no país.

Com base nesses resultados, e considerando-se que o atributo de "PERDAS" indica as perdas técnicas e não técnicas apuradas nas redes de distribuição, é oportuno avaliar qual o peso de cada uma dessas componentes na explicação do resultado do custo-benefício.

4.3.2.1 Correlação de Pearson das perdas técnicas e não técnicas com o saldo da implantação das REI

A Tabela 4.11 apresenta os coeficientes de correlação de Pearson das componentes de perdas técnicas e não técnicas com o atributo de "PERDAS", e destes com o saldo da implantação das REI nas 62 concessionárias.

Tabela 4.11 - Coeficientes de correlação de Pearson das componentes de perdas técnicas e não técnicas com o atributo de "PERDAS" e destes com o saldo da implantação das REI.

\begin{tabular}{|c|c|c|c|c|}
\cline { 2 - 5 } \multicolumn{1}{c|}{} & PERDAS & PERDAS TÉCNICAS & PERDAS NÃO TÉCNICAS & SALDO \\
\hline \multirow{2}{*}{ PERDAS } & $\mathbf{1 , 0 0 0}$ & $\mathbf{0 , 6 8 0}$ & $\mathbf{1 , 0 0 0}$ & $\mathbf{0 , 9 6 0}$ \\
\cline { 2 - 5 } & & $<, 0001$ & $<, 0001$ & $<, 0001$ \\
\hline \multirow{2}{*}{ PERDAS TÉCNICAS } & $\mathbf{0 , 6 8 0}$ & $\mathbf{1 , 0 0 0}$ & $\mathbf{0 , 6 7 5}$ & $\mathbf{0 , 6 5 3}$ \\
\cline { 2 - 5 } & $<, 0001$ & & $<, 0001$ & $<, 0001$ \\
\hline \multirow{2}{*}{ PERDAS NÃO TÉCNICAS } & $\mathbf{1 , 0 0 0}$ & $\mathbf{0 , 6 7 5}$ & $\mathbf{1 , 0 0 0}$ & $\mathbf{0 , 9 6 0}$ \\
\cline { 2 - 5 } & $<, 0001$ & $<, 0001$ & & $<, 0001$ \\
\hline \multirow{2}{*}{ SALDO } & $\mathbf{0 , 9 6 0}$ & $\mathbf{0 , 6 5 3}$ & $\mathbf{0 , 9 6 0}$ & $\mathbf{1 , 0 0 0}$ \\
\cline { 2 - 5 } & $<, 0001$ & $<, 0001$ & $<, 0001$ & \\
\hline
\end{tabular}

Percebe-se na Tabela 4.11 que a componente de perdas não técnicas é mais correlacionada com o atributo de "PERDAS", com coeficiente igual a 1,0000, do que o de perdas técnicas, 
com 0,680. Da mesma forma, destaca-se que as perdas não técnicas exibem uma maior correlação com o saldo da implantação das REI $(0,960$ contra 0,653$)$.

Todavia, além da análise de correlação, também é necessário avaliar a representatividade das duas componentes para o valor final do atributo, o que é apresentado na Tabela 4.12.

Tabela 4.12 - VP normalizado das duas componentes do atributo de "PERDAS".

\begin{tabular}{|c|c|c|c|c|}
\hline CONCESSIONÁRIA & PERDAS & PERDAS TÉCNICAS & PERDAS NÃO TÉCNICAS & SALDO \\
\hline EBO & 0,013 & 0,004 & 0,008 & $-0,692$ \\
\hline COSERN & 0,064 & 0,012 & 0,052 & $-0,601$ \\
\hline EPB & 0,204 & 0,017 & 0,187 & $-0,568$ \\
\hline ESE & 0,196 & 0,007 & 0,189 & $-0,497$ \\
\hline COELBA & 0,347 & 0,013 & 0,334 & $-0,432$ \\
\hline SULGIPE & 0,427 & 0,013 & 0,413 & $-0,349$ \\
\hline COELCE & 0,193 & 0,016 & 0,178 & $-0,328$ \\
\hline ENF & 0,003 & 0,003 & 0,000 & $-0,234$ \\
\hline CEMIG & 0,114 & 0,011 & 0,103 & $-0,199$ \\
\hline EEB & 0,034 & 0,003 & 0,031 & $-0,180$ \\
\hline CPFLSULPAULISTA & 0,021 & 0,004 & 0,017 & $-0,156$ \\
\hline DMED & 0,021 & 0,004 & 0,017 & $-0,122$ \\
\hline CFLO & 0,021 & 0,002 & 0,019 & $-0,115$ \\
\hline CEMAR & 1,003 & 0,018 & 0,985 & $-0,094$ \\
\hline CHESP & 0,054 & 0,011 & 0,043 & $-0,093$ \\
\hline RGE & 0,040 & 0,005 & 0,035 & $-0,093$ \\
\hline CPFLSANTACRUZ & 0,056 & 0,005 & 0,051 & $-0,088$ \\
\hline ELETROCAR & 0,004 & 0,004 & 0,000 & $-0,085$ \\
\hline EDEVP & 0,057 & 0,006 & 0,052 & $-0,073$ \\
\hline CNEE & 0,007 & 0,007 & 0,000 & $-0,067$ \\
\hline BANDEIRANTE & 0,158 & 0,004 & 0,154 & $-0,054$ \\
\hline CAIUA & 0,080 & 0,004 & 0,076 & $-0,029$ \\
\hline CPFLPAULISTA & 0,118 & 0,005 & 0,113 & $-0,019$ \\
\hline CPFLMOCOCA & 0,065 & 0,003 & 0,062 & $-0,018$ \\
\hline UHENPAL & 0,064 & 0,010 & 0,054 & $-0,002$ \\
\hline AES-SUL & 0,050 & 0,004 & 0,046 & 0,006 \\
\hline CELPE & 0,489 & 0,011 & 0,478 & 0,022 \\
\hline HIDROPAN & 0,050 & 0,004 & 0,047 & 0,024 \\
\hline CPFLJAGUARI & 0,033 & 0,002 & 0,031 & 0,031 \\
\hline CELESC & 0,160 & 0,006 & 0,154 & 0,040 \\
\hline COPEL & 0,120 & 0,005 & 0,115 & 0,041 \\
\hline ELEKTRO & 0,157 & 0,005 & 0,153 & 0,051 \\
\hline COOPERALIANÇA & 0,145 & 0,010 & 0,134 & 0,063 \\
\hline CPFLPIRATININGA & 0,148 & 0,004 & 0,144 & 0,067 \\
\hline DEMEI & 0,208 & 0,005 & 0,204 & 0,082 \\
\hline ELETROPAULO & 0,128 & 0,004 & 0,124 & 0,096 \\
\hline EFLUL & 0,000 & 0,000 & 0,000 & 0,107 \\
\hline EMS & 0,285 & 0,010 & 0,274 & 0,118 \\
\hline EMG & 0,136 & 0,030 & 0,105 & 0,120 \\
\hline MUXENERGIA & 0,096 & 0,006 & 0,089 & 0,127 \\
\hline COCEL & 0,091 & 0,008 & 0,083 & 0,153 \\
\hline ELFSM & 0,234 & 0,008 & 0,226 & 0,174 \\
\hline CPFLLESTEPAULISTA & 0,107 & 0,004 & 0,104 & 0,194 \\
\hline ESCELSA & 0,425 & 0,009 & 0,417 & 0,194 \\
\hline IENERGIA & 0,212 & 0,003 & 0,209 & 0,209 \\
\hline CELG & 0,181 & 0,011 & 0,170 & 0,242 \\
\hline CEB & 0,237 & 0,008 & 0,229 & 0,259 \\
\hline ETO & 0,521 & 0,029 & 0,493 & 0,291 \\
\hline FORCEL & 0,008 & 0,008 & 0,000 & 0,413 \\
\hline EFLJC & 0,002 & 0,002 & 0,000 & 0,475 \\
\hline AMPLA & 0,631 & 0,005 & 0,627 & 0,544 \\
\hline EMT & 0,511 & 0,016 & 0,496 & 0,648 \\
\hline CEEE & 0,864 & 0,005 & 0,859 & 0,803 \\
\hline CEPISA & 1,366 & 0,014 & 1,352 & 0,818 \\
\hline LIGHT & 0,989 & 0,008 & 0,981 & 1,021 \\
\hline CEAL & 1,499 & 0,010 & 1,488 & 1,109 \\
\hline CELPA & 2,193 & 0,018 & 2,175 & 1,825 \\
\hline ELETROACRE & 2,264 & 0,017 & 2,247 & 2,097 \\
\hline CERON & 2,189 & 0,029 & 2,160 & 2,511 \\
\hline BOA VISTA & 1,745 & 0,040 & 1,705 & 2,582 \\
\hline CEA & 3,893 & 0,034 & 3,859 & 4,656 \\
\hline AME & 5,796 & 0,031 & 5,766 & 6,398 \\
\hline
\end{tabular}


Percebe-se na Tabela 4.12 que o VP normalizado da componente referente às perdas técnicas possui valores próximos a zero em todas as empresas (abaixo de 0,041 ). Por outro lado, a componente de perdas não técnicas atinge patamares mais elevados, de até 5,766.

Comparando-se na Tabela 4.12 o atributo de "PERDAS" com suas duas componentes, notase que a magnitude do atributo se aproxima das perdas não técnicas em todas as empresas, indicando que ela é mais representativa para o resultado.

Portanto, com base nos resultados ora expostos, conclui-se que o nível de perdas não técnicas apurado pela distribuidora em suas redes é o principal motivador para a implantação das REI no Brasil. Além desse, os outros dois maiores motivadores são os benefícios decorrentes de uma maior eficiência energética ("EFI_ENER”) e da melhoria da qualidade do serviço (“CONTIN").

Adicionalmente, ficou evidenciado na seção 4.3.1 que os custos relativos à compra e instalação de equipamentos (“AQ_INST") apresentam alta representatividade no resultado do saldo da implantação das REI. Assim, considerando-se que esse atributo é impactado pelo valor dos medidores eletrônicos inteligentes, apresenta-se, na sequência, uma análise de sensibilidade desse custo para o VPL do custo-benefício das REI nas distribuidoras brasileiras.

Essa análise também se faz necessária em virtude deste trabalho adotar o mesmo valor de compra de medidores definido por Lamin (2013), conforme discutido na seção A.5 do Apêndice A.

\subsection{ANÁLISE DE SENSIBILIDADE DO VALOR DO MEDIDOR ELETRÔNICO INTELIGENTE}

Nesta seção, apresenta-se a análise de sensibilidade do valor de compra dos medidores eletrônicos inteligentes ${ }^{18}$ para o saldo da implantação das REI nas concessionárias brasileiras.

\footnotetext{
${ }^{18}$ Considera-se que o valor de compra do medidor eletrônico inteligente representa o custo médio ponderado das unidades monofásicas, bifásicas e trifásicas.
} 
Realiza-se essa análise nas distribuidoras com maior magnitude de saldo nos 3 grupos resultantes do processo de clusterização com base no VPL do custo-benefício da implantação das REI. Essa escolha está alicerçada no fato de que o patamar de custo do medidor que acarreta em mudança no cenário atual dessas empresas também implica em mudança nas demais integrantes do grupo.

Complementarmente, devido à variedade de resultados das distribuidoras alocadas no cluster 1, nesse grupo realiza-se a análise de sensibilidade para as empresas com maiores resultados positivo e negativo. A Tabela 4.13 expõe as concessionárias consideradas.

Tabela 4.13 - Concessionárias nas quais foi realizada a análise de sensibilidade do custo do medidor eletrônico inteligente.

\begin{tabular}{|l|c|c|}
\hline CONCESSIONÁRIA & CLUSTER & SALDO DA IMPLANTAÇÃO DAS REI \\
\hline EBO & 1 & $-0,692$ \\
\hline CEAL & 1 & 1,109 \\
\hline BOA VISTA & 2 & 2,582 \\
\hline AME & 3 & 6,398 \\
\hline
\end{tabular}

\subsubsection{Evolução do saldo da implantação das REI em relação ao valor do medidor eletrônico inteligente}

A Figura 4.9 apresenta a evolução do saldo da implantação das REI em relação ao valor de compra do medidor eletrônico inteligente.

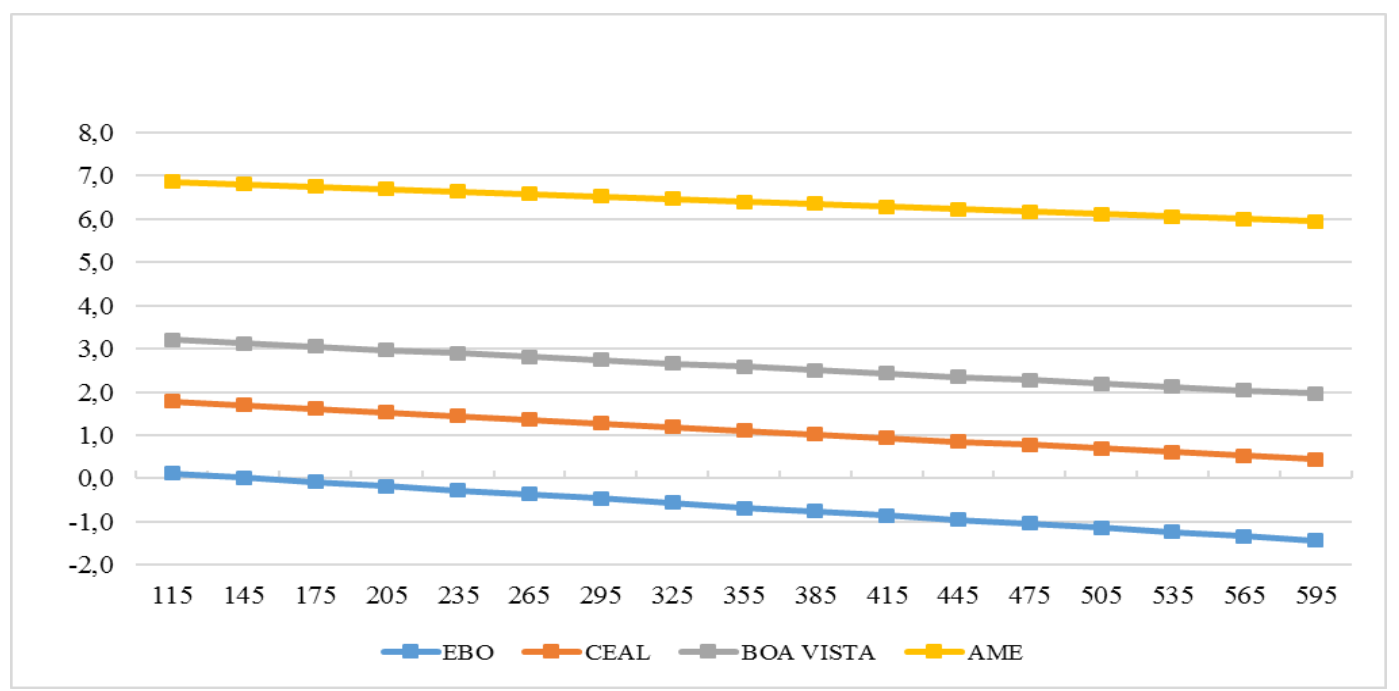

Figura 4.9 - Evolução do saldo da implantação das REI em relação ao valor de compra do medidor eletrônico inteligente. 
Depreende-se da análise na Figura 4.9 que o saldo da implantação das REI varia linearmente com o valor de compra do medidor eletrônico inteligente. Nota-se também que na EBO o cenário atual, de não viabilidade das novas tecnologias, é alterado com um custo aproximado de $\mathrm{R} \$ 160$ para o medidor, redução de 55\% no valor adotado neste trabalho.

Focando-se nas demais empresas exibidas na Figura 4.9, CEAL, BOA VISTA e AME, percebe-se que, ainda que o valor da medição atinja o patamar unitário de R $\$ 595$ permanece a atratividade das REI.

Interpolando-se os valores até o ponto em que todas as retas cruzam o eixo das abscissas, nota-se que o cenário de atratividade das REI é alterado na CEAL, BOA VISTA e AME para um valor do medidor de, respectivamente, $\mathrm{R} \$ 770, \mathrm{R} \$ 1.500$ e $\mathrm{R} \$ 3.700$.

Com base nesses resultados, considerando-se que a CEAL possui o resultado mais positivo entre as empresas alocadas no cluster 1, conforme exposto na Tabela 4.7, conclui-se que o valor de R $\$ 770$ inviabiliza as REI em 56 distribuidoras, mais de 90\% do total analisado.

Adicionalmente, tendo em vista que a EBO possui o resultado mais negativo de custobenefício e a AME o mais positivo, infere-se que o valor de $160 \mathrm{R} \$ /$ medidor viabiliza as REI em todas as empresas analisadas. De forma oposta, o patamar de $3.700 \mathrm{R} \$ /$ medidor inviabiliza essas redes em todas elas. 


\section{5 - CONCLUSÕES}

\section{1 - CONTRIBUIÇÕES DO TRABALHO}

Este trabalho apresentou os resultados de uma análise de custo-benefício da implantação das REI nas distribuidoras brasileiras, fazendo-se uso das mais recentes informações disponíveis, em geral, de 2015. Tal análise avaliou a viabilidade econômica da implantação das REI em 62 empresas, contemplando as características específicas das diferentes áreas de concessão de distribuição do Brasil. Por meio da aplicação de processos de clusterização e de técnica de correlação, também se identificaram os principais motivadores para utilização desse padrão de redes no país.

Após a parte introdutória que, dentre outros aspectos, expôs as diferenças entre as concessões de distribuição, o capítulo 2 apresentou uma revisão bibliográfica sobre as REI, abordando sua definição, benefícios e conjunturas internacional e nacional. Ainda nesse capítulo, discorreu-se sobre as análises de custo-benefício da implantação das REI já executadas no Brasil, e seus resultados. Destaca-se como fruto destas avaliações a constatação majoritária de que os motivadores nacionais para a implantação das REI são i) os custos evitados com a expansão do sistema (em decorrência da redução da demanda de pico), ii) a melhoria da qualidade do serviço, e iii) a redução das perdas não técnicas.

No capítulo 3, foram descritos os materiais e métodos empregados neste trabalho. Além da caracterização dos equipamentos, tecnologias, funcionalidades e do nível de penetração da medição eletrônica inteligente, abordaram-se a metodologia, valores e parâmetros aplicados na estimação dos custos e dos benefícios da implantação das REI nas distribuidoras. Neste ponto do relatório, exibiram-se os algoritmos de clusterização e a técnica de correlação utilizados na identificação dos motivadores das REI no país.

O capítulo 4 apresentou os resultados do trabalho, por meio dos quais ficou evidenciado que a aquisição e instalação dos equipamentos e a redução das perdas de energia representam os maiores pesos na receita das distribuidoras. Por outro lado, os custos evitados e os gastos com logística, administração e comunicação possuem os menores pesos. 
Na sequência, apresentaram-se as 25 empresas nas quais o custo-benefício da implantação das REI é negativo, indicando que não há, atualmente nestas concessionárias, viabilidade econômica para as novas redes. Comparando-se esses resultados com os de Lamin (2013) e ABRADEE (2011), que apontam que o saldo nacional é positivo, conclui-se que a heterogeneidade das distribuidoras afeta, de fato, a viabilidade econômica das REI.

Em complementação, foram mencionadas as 37 distribuidoras com saldo positivo, refletindo a atratividade das novas tecnologias. Além disso, demonstrou-se que em 56 empresas, uma pequena alteração nos custos ou benefícios pode alterar o cenário atual, enquanto nas demais apenas uma grande variação altera o resultado de viabilidade.

No que tange à clusterização, concluiu-se que o método aglomerativo hierárquico utilizandose o algoritmo de Ward apresenta os maiores níveis de homogeneidade nos grupos formados, o que o caracteriza como o mais adequado para aplicação neste trabalho. Servindo-se desse algoritmo, definiu-se o agrupamento das concessionárias em 3 clusters.

Ainda no capítulo 4, identificaram-se as componentes de i) aquisição e instalação dos equipamentos e ii) redução das perdas de energia como as mais representativas na análise do custo-benefício de implantação de REI nas distribuidoras brasileiras. Esse resultado é explicado pelo peso dessas componentes na receita das empresas e pela dispersão que as caracterizam.

Adicionalmente, também se discorreu sobre os motivadores para as REI no Brasil, o que foi possível via execução dos processos de clusterização e pela análise da correlação entre os 11 atributos de custos e de benefícios e o saldo da introdução das REI. As análises apontam que os motivadores para as novas tecnologias no país são os ganhos com eficiência energética ${ }^{19}$, a melhoria da qualidade do serviço, e a redução das perdas não técnicas. Também ficou evidenciado que a redução das perdas suplanta os demais aspectos e se configura como o principal motivador para as novas tecnologias no país.

\footnotetext{
${ }^{19}$ Neste trabalho, os benefícios relacionados à eficiência energética compreendem a redução da demanda de ponta (que implica na postergação de investimento para expansão do sistema), do consumo de energia e a redução da necessidade de novas plantas de geração.
} 
Avaliando-se por meio da técnica de correlação e da análise de representatividade as duas categorias que compõem esse atributo, conclui-se que a redução das perdas não técnicas explica com maior intensidade os atributos de perdas e de saldo.

Por fim, apresentou-se a análise de sensibilidade do custo de aquisição da medição eletrônica inteligente nos 3 grupos resultantes da clusterização. Os resultados evidenciam que o valor de $160 \mathrm{R} \$$ /medidor viabiliza as REI em todas as distribuidoras brasileiras. Por outro lado, o montante de $3.700 \mathrm{R} \$$ /medidor as inviabiliza. Além disso, mostrou-se que o custo de 770 $\mathrm{R} \$$ /medidor inviabiliza o novo padrão tecnológico em 56 empresas (mais de $90 \%$ do total analisado).

Diante do exposto, conclui-se que este trabalho culminou em subsídios para elaboradores de políticas públicas que versam sobre este tema, em níveis nacional e regional. Também podem se beneficiar dos produtos desse trabalho, a agência reguladora, em referência à isonomia e à abrangência de normas, e as distribuidoras, no que tange à avaliação da viabilidade econômica das tecnologias.

\section{2 - SUGESTÃO DE TRABALHOS FUTUROS}

Devido a uma carência generalizada de informações, não foi possível executar a análise de custo-benefício da implantação das REI na concessionária CERR. Sugere-se que trabalhos futuros levantem as informações necessárias para que se torne possível a execução do citado estudo.

Este trabalho não considerou o efeito da inserção da geração de micro e pequeno porte nas redes de distribuição. Por isso, sugere-se como investigações futuras a incorporação dos impactos dessa geração na operação dos sistemas, nos esquemas de proteção, na redução da necessidade de geração centralizada, em uma maior participação dos consumidores, dentre outros.

Também não foi possível, dada a conjuntura cambial, atualizar o preço dos medidores eletrônicos inteligentes. Da mesma forma, não se quantificou o efeito do poder de negociação das grandes empresas nos preços de compra dos equipamentos. Assim, para tornar o trabalho ainda mais atual e adequado à realidade das diferentes concessionárias de distribuição brasileiras, indica-se a abordagem desses aspectos. 


\section{REFERÊNCIAS BIBLIOGRÁFICAS}

ABRADEE (2011). Programa Brasileiro de Rede Elétrica Inteligente: TI e Telecom Relatório da Fase III - Projeções de Investimento - Versão Final. Coordenação Fundação CPqD. Projeto Estratégico de P\&D - Chamada nº 011/2010. Brasília, Brasil.

AMIN, S. Massoud, WOLLENBERG, Bruce F. (2005). Toward a Smart Grid. IEEE Power \& Energy Magazine, vol. 3, issue 5, páginas 34-41.

ANEEL (2016a). Plano de Desenvolvimento da Distribuição (PDD). O PDD encaminhado em 2016 pelas distribuidoras está disponível na Superintendência de Regulação dos Serviços de Distribuição (SRD) da ANEEL. Brasília, Brasil.

ANEEL (2016b). Sistema de Apoio à Decisão (SAD). As informações relativas ao número de UC's, consumo total, receita e tarifa média, que constam no SAD estão disponíveis na página eletrônica da ANEEL, por meio do seguinte endereço: http://www2.aneel.gov.br/area.cfm?idArea=550 (acesso em 07/11/2016). Brasília, Brasil.

ANEEL (2016c). Compensação pela transgressão dos limites de continuidade. As informações relativas às compensações efetuadas pelas concessionárias pela transgressão dos limites de continuidade estão disponíveis na página eletrônica da ANEEL, por meio do seguinte endereço: http://www.aneel.gov.br/indicadores-de-compensacao-de-continuidade (acesso em 07/11/2016). Brasília, Brasil.

ANEEL (2016d). Monitoramento das perdas de energia. As informações relativas às perdas de energia encaminhadas 2016 pelas distribuidoras estão disponíveis na Superintendência de Gestão Tarifária (SGT) da ANEEL. Brasília, Brasil.

ANEEL (2016e). Informações relativas às despesas com perdas de energia no Brasil. As informações relativas às despesas com as perdas de energia no país estão disponíveis no seguinte endereço: http://www2.aneel.gov.br/area.cfm?idArea=801\&idPerfil=4 (acesso em 20/11/2016). Brasília, Brasil. 
CAMARGO, Ivan M. T. (1998). Noções básicas de engenharia econômica: aplicações ao setor elétrico. FINATEC 160 p.: il. CDU 330.322.212. Brasília, Brasil.

CGEE - Centro de Gestão e Estudos Estratégicos (2012). Redes Inteligentes: contexto nacional. Brasília, DF.

DOE - U.S. Department of Energy (2009). The Smart Grid: an introduction. Prepared for the Department of Energy by Litos Strategic Communication under contract No. DE-AC2604NT41817, Subtask 560.01.04. Washington, Estados Unidos.

DOE - U.S. Department of Energy (2016). Smart Grid Investment Grant Program (SGIG). Document of Documents. Disponível em https://www.smartgrid.gov/files/Document_of_Documents_20160225.pdf (acesso em 01/10/2016). Washington, Estados Unidos.

EC - European Commission (2008). Redes inteligentes: da inovação à implantação. Comunicação da comissão ao parlamento europeu, ao Conselho, ao comitê econômico e social europeu e ao comitê das regiões COM (2011) 202 final. Disponível em http://eurlex.europa.eu/legal-content/PT/TXT/?uri=CELEX\%3A52011DC0202 (acesso em 01/10/2016). Bruxelas, Bélgica.

EC - European Commission (2011). Smart Grid projects in Europe: lessons learned and $\begin{array}{llll}\text { current developments. } & \text { Disponível em }\end{array}$ https://ses.jrc.ec.europa.eu/sites/ses/files/documents/smart_grid_projects_in_europe.pdf (acesso em 20/11/2016). Amsterdam, Holanda.

EC - European Commission (2012). Guideline for conducting a cost-benefit analysis of $\begin{array}{lllll}\text { smart } & \text { grid } & \text { Drojects. } & \text { em }\end{array}$ http://publications.jrc.ec.europa.eu/repository/bitstream/JRC67964/2012.2783jrc_rr_cba_for_smart_grids_(online).pdf. (acesso em 09/10/2016). Bruxelas, Bélgica.

EC - European Commission (2014). Smart Grid Projects Outlook 2014. Disponível em https://www.scribd.com/document/272051212/Ld-na-26609-En-n-Smart-Grid-ProjectsOutlook-2014-Online. (acesso em 03/10/2016). Bruxelas, Bélgica. 
ENERGY UK - Smart Metering Projects Maps (2012). Disponível em https://www.google.com/maps/d/viewer?mid=19VuB2oies9alz5weWYwRKdB1j9k\&hl=e $\underline{\mathrm{n} \& 11=3.639517840139907 \% 2 C 7.837370999999962 \& \mathrm{z}=1}$ (acesso em 01/10/2016).

EPRI - Electric Power Research Institute (2010). Methodological Approach for Estimating the Benefits and Costs of Smart Grid Demonstration Projects. EPRI 1020342 - Final Report. Palo Alto, Estados Unidos.

FERREIRA FILHO, Anésio de L.; VASCONCELOS, Marcos V. L., CORREIA, Pedro (2013). O desenvolvimento de Smart Grids no Brasil e o papel das Universidades. X Conferência Brasileira sobre Qualidade da Energia Elétrica - CBQEE. Araxá, Brasil.

FERREIRA FILHO, Anésio de L.; VASCONCELOS, Marcos V. L., ALMEIDA, Davi V. R. (2016). Clusterização de distribuidoras para análise de custo-benefício da implantação das Redes Elétricas Inteligentes no Brasil. Simpósio Brasileiro de Sistemas Elétricos (SBSE) 2016. Natal-RN, Brasil.

HAIR Jr, J. F.; ANDERSON, R. E.; TAHAM, R. L.; BLACK, W. C. (2007); trad. Adonai Schlup Sant'Anna e Anselmo Chaves Neto. Análise Multivariada de Dados. $5^{\text {a }}$ edição. Bookman. Porto Alegre, brasil.

IEA - International Energy Agency (2011). Technology Roadmap. Smart Grids. Disponível no endereço eletrônico https://www.iea.org/publications/freepublications/publication/smartgrids_roadmap.pdf (acesso em 03/10/2016). Paris, França.

KAUFMAN, Leonard; ROUSSEEUW, Peter J. (2005); Fiding Groups in Data. Na introduction to cluster analysis. Wiley Intersciense. p. 3-49. New Jersey, Estados Unidos.

LAMIN, Hugo (2013). Análise de Impacto Regulatório da implantação de redes inteligentes no Brasil. Tese de Doutorado em Engenharia Elétrica, Publicação PPGENE.TD-076/13, Departamento de Engenharia Elétrica, Universidade de Brasília, Brasília, DF, 300p. 
MME - Ministério de Minas e Energia (2011). Relatório - Smart Grid - Grupo de Trabalho de Redes Elétricas Inteligentes. Relatório resultante do Grupo de Trabalho instaurado pela Portaria MME nº 440/2010. Brasília, Brasil.

NIST - National Institute of Standards and Technology (2009). Report to NIST on the Smart Grid Interporability Standards Roadmap. Disponível em https://www.nist.gov/sites/default/files/documents/smartgrid/Report_to_NIST_August10_2 .pdf (acesso em 03/10/2016). Estados Unidos.

REDESINTELIGENTESBRASIL (2016). Informações relativas aos projetos em desenvolvimento no Brasil sore as REI. As informações relativas ao número de projetos sobre as REI executados no âmbito do Programa de P\&D da ANEEL estão disponíveis no seguinte endereço: http://redesinteligentesbrasil.org.br/ (acesso em 01/10/2016). Brasília, Brasil.

SGTF - Smart Grid Task Force (2009). Mission and Work Programme. Disponível em https://ec.europa.eu/energy/sites/ener/files/documents/mission_and_workprogramme.pdf. (acesso em 05/10/2016). Bruxelas, Bélgica.

SILVA, Lorena Melo (2016). Contexto regulatório, técnico e as perspectivas brasileiras em Redes Elétricas Inteligentes aplicadas em concessões de distribuição. Dissertação de Mestrado em Engenharia Elétrica. Departamento de Engenharia Elétrica, Universidade de Brasília, Brasília, DF, 125 p.

TIMM, Neil H. (2002); Applied Multivariate Analysis. Springer texts in statistics. p. 515530. Nova Iorque, Estados Unidos.

XU, Rui.; WUNSCH II, Donald C. (2009); Clustering. Wiley. IEEE Press. p. 11-46. Estados Unidos. 


\section{APÊNDICE A - DADOS UTILIZADOS}

Este apêndice exibe os dados das 62 distribuidoras utilizados na estimação dos custos e dos benefícios da implantação das REI. O levantamento dessas informações decorre de um intenso trabalho de consulta a bancos de dados da ANEEL.

Destaca-se que os dados dispostos neste apêndice tem caráter público e, na sua grande maioria, podem acessados nos endereços eletrônicos da agência. As informações que não estão disponibilizadas na rede mundial de computadores, podem ser solicitadas à ANEEL por meio do Serviço de Informações ao Cidadão (e-sic), estabelecido pela Lei $\mathrm{n}^{\circ}$ $12.527 / 2011$.

\section{A.1 NÚMERO DE UNIDADES CONSUMIDORAS E SEU CRESCIMENTO MÉDIO HISTÓRICO}

O número de UC das concessionárias, que está disponível em endereço eletrônico da ANEEL $^{20}$, refere-se a dezembro de 2015. Faz-se uso da mesma informação considerada nos cálculos tarifários das distribuidoras. Esse dado é utilizado na estimação da quantidade de medidores eletrônicos inteligentes a serem instalados pelas empresas durante os ciclos de implantação das tecnologias.

Com respeito ao crescimento médio do número de UC, utiliza-se o histórico disponível, que engloba o período de 2003 a 2015. Essa informação é empregada na projeção da evolução do número de UC nos anos em que serão implantadas as REI, em consonância com o perfil e duração dos ciclos de instalação da medição.

A Tabela A.1 apresenta o número de UC das concessionárias e o respectivo crescimento médio histórico.

${ }^{20} \mathrm{http}: / /$ www2.aneel.gov.br/area.cfm?idArea $=550$ 
Tabela A.1 - Número de UC das concessionárias e respectivo crescimento médio histórico.

\begin{tabular}{|c|c|c|}
\hline CONCESSIONÁRIA & $\begin{array}{c}\text { NÚMERO } \\
\text { DE UC }\end{array}$ & $\begin{array}{l}\text { CRESCIMENTO MÉDIO } \\
\text { HISTÓRICO DO } \\
\text { NÚMERO DE UC }\end{array}$ \\
\hline AES-SUL & 1.308 .263 & $2,30 \%$ \\
\hline AME & 897.041 & $4,66 \%$ \\
\hline AMPLA & 2.606 .745 & $2,57 \%$ \\
\hline BANDEIRANTE & 1.780 .032 & $3,04 \%$ \\
\hline BOA VISTA & 106.620 & $4,95 \%$ \\
\hline CAIUÁ & 239.918 & $2,40 \%$ \\
\hline CEA & 196.008 & $4,68 \%$ \\
\hline CEAL & 1.045 .270 & $4,23 \%$ \\
\hline CEB & 1.012 .024 & $3,58 \%$ \\
\hline CEEE & 1.627 .834 & $2,06 \%$ \\
\hline CELESC & 2.768 .457 & $3,24 \%$ \\
\hline CELG & 2.801 .309 & $3,78 \%$ \\
\hline CELPA & 2.310 .972 & $5,74 \%$ \\
\hline CELPE & 3.523 .136 & $3,62 \%$ \\
\hline CEMAR & 2.261 .570 & $6,02 \%$ \\
\hline CEMIG & 8.102 .770 & $6,06 \%$ \\
\hline CEPISA & 1.172 .997 & $5,20 \%$ \\
\hline CERON & 589.332 & $3,05 \%$ \\
\hline CFLO & 56.675 & $4,81 \%$ \\
\hline CHESP & 34.957 & $4,64 \%$ \\
\hline CNEE & 114.651 & $2,81 \%$ \\
\hline COCEL & 48.406 & $2,69 \%$ \\
\hline COELBA & 5.727 .274 & $2,68 \%$ \\
\hline COCELCE & 3.378 .330 & $3,92 \%$ \\
\hline COOPERALIANÇA & 35.532 & $4,64 \%$ \\
\hline COPEL & 4.417 .949 & $4,01 \%$ \\
\hline COSERN & 1.346 .442 & $2,94 \%$ \\
\hline CPFLJAGUARI & 38.825 & $3,01 \%$ \\
\hline CPFLLESTEPAULISTA & 56.394 & $4,56 \%$ \\
\hline CPFLMOCOCA & 45.577 & $3,53 \%$ \\
\hline CPFLPIRATININGA & 1.627 .843 & $2,04 \%$ \\
\hline CPFLSANTACRUZ & 204.141 & $2,28 \%$ \\
\hline CPFLSULPAULISTA & 82.267 & $2,69 \%$ \\
\hline CPFLPAULISTA & 4.164 .996 & $2,93 \%$ \\
\hline DEMEI & 31.776 & $2,32 \%$ \\
\hline DMED & 72.513 & $2,75 \%$ \\
\hline EBO & 204.656 & $2,35 \%$ \\
\hline EDEVP & 178.279 & $2,46 \%$ \\
\hline EEB & 152.417 & $2,16 \%$ \\
\hline EFLJC & 3.604 & $3,69 \%$ \\
\hline EFLUL & 6.520 & $4,58 \%$ \\
\hline ELEKTRO & 2.503 .125 & $4,55 \%$ \\
\hline ELETROACRE & 242.694 & $2,69 \%$ \\
\hline ELETROCAR & 36.068 & $5,68 \%$ \\
\hline ELETROPAULO & 6.774 .570 & $1,74 \%$ \\
\hline ELFSM & 106.036 & $2,47 \%$ \\
\hline EMG & 433.471 & $4,33 \%$ \\
\hline SEM & 970.550 & $3,93 \%$ \\
\hline EMT & 1.296 .574 & $2,73 \%$ \\
\hline ENF & 102.533 & $2,05 \%$ \\
\hline $\mathrm{EPB}$ & 1.355 .210 & $4,20 \%$ \\
\hline ESCELSA & 1.476 .338 & $4,26 \%$ \\
\hline ESE & 731.462 & $3,80 \%$ \\
\hline ETO & 567.452 & $3,54 \%$ \\
\hline FORCEL & 7.328 & $2,38 \%$ \\
\hline HIDROPAN & 17.792 & $3,33 \%$ \\
\hline IENERGIA & 33.576 & $3,01 \%$ \\
\hline LIGHT & 3.793 .752 & $2,50 \%$ \\
\hline MUXENERGIA & 10.867 & $4,65 \%$ \\
\hline RGE & 1.433 .842 & $2,78 \%$ \\
\hline SULGIPE & 139.299 & $4,12 \%$ \\
\hline UHENPAL & 15.333 & $1,54 \%$ \\
\hline
\end{tabular}

\section{A.2 MERCADO E SEU CRESCIMENTO MÉDIO HISTÓRICO}

As informações de mercado e crescimento histórico médio, exibidas na Tabela A.2, estão disponíveis no mesmo endereço eletrônico da ANEEL onde são acessados os dados de UC. 
Tabela A.2 - Mercado das concessionárias e respectivo crescimento médio histórico.

\begin{tabular}{|c|c|c|}
\hline CONCESSIONÁRIA & $\begin{array}{c}\text { MERCADO } \\
\text { (MWh) }\end{array}$ & \begin{tabular}{|c|} 
CRESCIMENTO \\
MÉDIO HISTÓRICO \\
DO MERCADO
\end{tabular} \\
\hline AES-SUL & $7.241 .130,30$ & $0,52 \%$ \\
\hline AME & $6.438 .504,80$ & $6,56 \%$ \\
\hline AMPLA & $9.748 .463,97$ & $6,56 \%$ \\
\hline BANDEIRANTE & $9.238 .719,62$ & $1,84 \%$ \\
\hline BOA VISTA & $757.428,81$ & $7,89 \%$ \\
\hline CAIUA & $1.087 .136,64$ & $3,25 \%$ \\
\hline CEA & $1.057 .461,62$ & $6,60 \%$ \\
\hline CEAL & $3.480 .902,34$ & $5,19 \%$ \\
\hline CEB & $6.088 .533,98$ & $4,55 \%$ \\
\hline CEEE & 7.673.375,98 & $2,03 \%$ \\
\hline CELESC & $15.801 .694,53$ & $1,06 \%$ \\
\hline CELG & $12.006 .419,17$ & $5,10 \%$ \\
\hline CELPA & $8.147 .821,52$ & $5,77 \%$ \\
\hline CELPE & $11.445 .289,82$ & $3,56 \%$ \\
\hline ETO & $2.132 .100,15$ & $8,63 \%$ \\
\hline CEMAR & $5.842 .468,47$ & $7,36 \%$ \\
\hline EMT & $8.048 .007,80$ & $6,86 \%$ \\
\hline CEMIG & $26.496 .181,09$ & $2,67 \%$ \\
\hline CEPISA & $3.171 .856,86$ & $6,82 \%$ \\
\hline CERON & $2.989 .617,38$ & $7,45 \%$ \\
\hline CFLO & $285.929,34$ & $2,88 \%$ \\
\hline CHESP & $114.343,71$ & $4,93 \%$ \\
\hline CNEE & $616.907,95$ & $4,33 \%$ \\
\hline COCEL & $311.775,40$ & $5,20 \%$ \\
\hline COELBA & $16.907 .317,06$ & $5,02 \%$ \\
\hline COELCE & $10.178 .589,43$ & $5,69 \%$ \\
\hline COOPERALIANÇA & $179.835,96$ & $4,50 \%$ \\
\hline COPEL & $24.043 .956,40$ & $3,04 \%$ \\
\hline COSERN & 4.666.995,02 & $3,92 \%$ \\
\hline CPFLJAGUARI & $491.741,12$ & $2,20 \%$ \\
\hline CPFLLESTEPAULISTA & $287.587,34$ & $1,28 \%$ \\
\hline CPFLMOCOCA & $203.658,07$ & $1,74 \%$ \\
\hline CPFLPAULISTA & $22.050 .523,90$ & $1,23 \%$ \\
\hline CPFLPIRATININGA & $9.120 .971,08$ & $1,86 \%$ \\
\hline CPFLSANTACRUZ & $929.435,45$ & $2,04 \%$ \\
\hline CPFLSULPAULISTA & $392.199,84$ & $1,42 \%$ \\
\hline DEMEI & $127.836,67$ & $3,78 \%$ \\
\hline DMED & $400.664,25$ & $3,34 \%$ \\
\hline EDEVP & $848.407,84$ & $3,20 \%$ \\
\hline EEB & $717.213,05$ & $0,99 \%$ \\
\hline EFLJC & $16.730,61$ & $0,93 \%$ \\
\hline EFLUL & $77.118,54$ & $3,61 \%$ \\
\hline ELEKTRO & $12.651 .598,44$ & $1,82 \%$ \\
\hline ELETROACRE & $920.695,45$ & $7,94 \%$ \\
\hline ELETROCAR & $173.692,94$ & $1,89 \%$ \\
\hline ELETROPAULO & $36.317 .519,33$ & $0,89 \%$ \\
\hline ELFSM & $561.033,15$ & $5,64 \%$ \\
\hline EBO & $660.489,35$ & $3,05 \%$ \\
\hline EMG & $1.219 .763,41$ & $9,93 \%$ \\
\hline ENF & $328.859,43$ & $0,70 \%$ \\
\hline EPB & $3.824 .499,78$ & $6,19 \%$ \\
\hline ESE & $2.446 .316,44$ & $3,51 \%$ \\
\hline EMS & $4.508 .892,30$ & $4,17 \%$ \\
\hline ESCELSA & $6.480 .842,45$ & $1,75 \%$ \\
\hline FORCEL & $55.398,96$ & $8,07 \%$ \\
\hline HIDROPAN & $105.979,05$ & $4,55 \%$ \\
\hline IENERGIA & $207.922,25$ & $4,53 \%$ \\
\hline LIGHT & $21.354 .314,44$ & $1,43 \%$ \\
\hline MUXENERGIA & $61.512,04$ & $7,23 \%$ \\
\hline RGE & $6.742 .231,77$ & $0,91 \%$ \\
\hline SULGIPE & $366.296,60$ & $5,64 \%$ \\
\hline UHENPAL & $63.063,67$ & $2,43 \%$ \\
\hline
\end{tabular}




\section{A.3 WACC REAL DEPOIS DE IMPOSTOS}

O Custo Médio Ponderado de Capital (WACC na sigla em inglês) está definido nos Procedimentos de Regulação Tarifária da ANEEL (PRORET) ${ }^{21}$ e representa a taxa de retorno pelo investimento realizado pelas distribuidoras na concessão.

Segundo a versão vigente do submódulo 2.4 (Custo de Capital) do PRORET, aprovada pela Resolução Normativa ANEEL n 648/2015, o WACC real depois de impostos (ou líquido) que vigora desde março de 2015 é igual a 8,09\%.

Destaca-se que as empresas de distribuição estão submetidas a regimes tributários diferentes, em razão de políticas regionais de desenvolvimento. Por esse motivo, o WACC bruto, que se diferencia do WACC liquido exatamente pela inclusão dos impostos, não é igual para todas as concessionárias. Para se evitar o efeito dessas discrepâncias de impostos nos resultados de VPL, utiliza-se neste trabalho, para todas as empresas, o valor líquido de WACC.

\section{A.4 RECEITA DE FORNECIMENTO E TARIFA MÉDIA}

A receita de fornecimento e a tarifa média de 2015 das distribuidoras também estão disponíveis no endereço eletrônico da ANEEL citado anteriormente.

Ressalta-se que o valor de tarifa média utilizado não inclui os impostos incidentes nas faturas de energia elétrica (ICMS e PIS/COFINS), que são percebidos pelos consumidores. Agindo dessa forma, evita-se o efeito das diferentes alíquotas de ICMS aplicadas pelos estados brasileiros.

A Tabela A.3 apresenta a receita de fornecimento e a tarifa média de 2015 das concessionárias.

\footnotetext{
${ }^{21}$ Os Procedimentos de Regulação Tarifária (PRORET) consolidam a regulamentação acerca dos processos tarifários das distribuidoras de energia elétrica brasileiras.
} 
Tabela A.3 - Receita de Fornecimento e Tarifa Média.

\begin{tabular}{|c|c|c|}
\hline CONCESSIONÁRIA & RECEITA (R\$) & $\begin{array}{c}\text { TARIFA MÉDIA } \\
\text { (R\$/MWh) }\end{array}$ \\
\hline AES-SUL & $3.128 .892 .281,95$ & 432,10 \\
\hline AME & $1.815 .840 .626,79$ & 282,03 \\
\hline AMPLA & $4.617 .506 .723,59$ & 473,67 \\
\hline BANDEIRANTE & $3.971 .314 .776,03$ & 429,86 \\
\hline BOA VISTA & $209.105 .173,50$ & 276,07 \\
\hline CAIUA & $412.341 .486,00$ & 379,29 \\
\hline CEA & $313.634 .955,36$ & 296,59 \\
\hline CEAL & $1.338 .436 .448,79$ & 384,51 \\
\hline CEB & $2.375 .345 .850,25$ & 390,13 \\
\hline CEEE & $3.333 .567 .085,60$ & 434,43 \\
\hline CELESC & 5.955.387.473,12 & 376,88 \\
\hline CELG & $4.813 .338 .910,92$ & 400,90 \\
\hline CELPA & $3.472 .664 .074,77$ & 426,21 \\
\hline CELPE & $3.766 .586 .271,67$ & 329,09 \\
\hline ETO & $883.446 .922,86$ & 414,36 \\
\hline CEMAR & $2.135 .281 .053,26$ & 365,48 \\
\hline EMT & $4.007 .384 .351,17$ & 497,93 \\
\hline CEMIG & $11.350 .508 .188,72$ & 428,38 \\
\hline CEPISA & $1.338 .173 .100,77$ & 421,89 \\
\hline CERON & $1.552 .475 .601,24$ & 519,29 \\
\hline CFLO & $119.770 .354,53$ & 418,88 \\
\hline CHESP & $53.746 .125,48$ & 470,04 \\
\hline CNEE & $260.689 .760,11$ & 422,57 \\
\hline COCEL & $127.289 .128,02$ & 408,27 \\
\hline COELBA & $5.184 .376 .847,21$ & 306,64 \\
\hline COELCE & $3.748 .900 .420,23$ & 368,31 \\
\hline COOPERALIANÇA & $77.645 .811,14$ & 431,76 \\
\hline COPEL & $10.180 .067 .878,23$ & 423,39 \\
\hline COSERN & 1.468.486.394,48 & 314,65 \\
\hline CPFLJAGUARI & $174.354 .690,92$ & 354,57 \\
\hline CPFLLESTEPAULISTA & $106.320 .470,19$ & 369,70 \\
\hline CPFLMOCOCA & $83.085 .541,94$ & 407,97 \\
\hline CPFLPAULISTA & $8.986 .272 .261,73$ & 407,53 \\
\hline CPFLPIRATININGA & $3.889 .564 .272,28$ & 426,44 \\
\hline CPFLSANTACRUZ & $411.989 .180,73$ & 443,27 \\
\hline CPFLSULPAULISTA & $151.480 .231,71$ & 386,23 \\
\hline DEMEI & $52.218 .507,76$ & 408,48 \\
\hline DMED & $137.228 .615,94$ & 342,50 \\
\hline EDEVP & $316.542 .917,53$ & 373,10 \\
\hline EEB & $288.382 .858,18$ & 402,09 \\
\hline EFLJC & $7.686 .593,12$ & 459,43 \\
\hline EFLUL & $31.605 .767,98$ & 409,83 \\
\hline ELEKTRO & 5.376.264.466,84 & 424,95 \\
\hline ELETROACRE & $377.242 .033,73$ & 409,74 \\
\hline ELETROCAR & $76.285 .732,49$ & 439,20 \\
\hline ELETROPAULO & $13.872 .037 .352,29$ & 381,97 \\
\hline ELFSM & $235.312 .366,53$ & 419,43 \\
\hline EBO & $214.244 .491,81$ & 324,37 \\
\hline EMG & $495.981 .208,21$ & 406,62 \\
\hline ENF & $139.516 .957,99$ & 424,24 \\
\hline EPB & $1.213 .701 .547,84$ & 317,35 \\
\hline ESE & $792.348 .733,63$ & 323,89 \\
\hline EMS & $1.757 .383 .335,81$ & 389,76 \\
\hline ESCELSA & $2.639 .909 .839,18$ & 407,34 \\
\hline FORCEL & $21.651 .685,26$ & 390,83 \\
\hline HIDROPAN & $48.623 .648,86$ & 458,80 \\
\hline IENERGIA & $72.026 .556,08$ & 346,41 \\
\hline LIGHT & $8.773 .945 .429,68$ & 410,87 \\
\hline MUXENERGIA & $27.281 .476,93$ & 443,51 \\
\hline RGE & $2.861 .397 .204,57$ & 424,40 \\
\hline SULGIPE & $118.050 .778,90$ & 322,28 \\
\hline UHENPAL & $28.472 .964,66$ & 451,50 \\
\hline
\end{tabular}

\section{A.5 CUSTO DOS MEDIDORES}

Para o custo dos medidores, adota-se, neste trabalho, os mesmos valores utilizados por Lamin (2013), de R \$ 355,00 para o equipamento eletrônico inteligente e R \$ 25,00 para o 
básico. Destaca-se que essas quantias representam a média ponderada dos custos dos medidores monofásicos, bifásicos e trifásicos ponderados pela quantidade de consumidores atendidos por cada tipo de ligação.

Ressalta-se que o custo desses medidores é fortemente impactado pela cotação do dólar no Brasil, em razão da quantidade de insumos importados utilizados na sua fabricação. Dada a forte oscilação do mercado de câmbio em 2016, período em que a moeda americana atingiu valores no intervalo de 3,10 a 4,20 R \$/dólar, o custo desses componentes variou de forma expressiva no corrente ano.

Em função disso, neste trabalho i) utiliza-se o mesmo valor estimado por Lamin (2013), e ii) apresenta-se uma análise de sensibilidade para avaliar o impacto da variação do custo desse equipamento nos resultados de custo-benefício da implantação das REI.

Destaca-se que os custos dos mostradores digitais e os gastos com telecomunicações, TI e automação são estimados como percentuais do valor do medidor eletrônico inteligente.

\section{A.6 GASTOS COM LOGÍSTICA, LEgAiS E COM CAMPANHAS DE COMUNICAÇÃO}

Seguindo o que foi definido por Lamin (2013), adota-se o valor de 12,50 R \$/medidor para a estimação do custo com a logística de implantação dos componentes das REI. Para os gastos legais e com campanhas de comunicação, considera-se 0,50 R\$/UC e 1,00 R\$/UC, respectivamente.

\section{A.7 DEC APURADO}

O valor do indicador DEC $^{22}$ apurado pelas distribuidoras em 2015, exposto na Tabela A.4, está disponível em página eletrônica da ANEEL $^{23}$. Sobre o patamar de cada empresa, aplicase a redução estimada de energia não fornecida com a implantação das novas tecnologias.

\footnotetext{
${ }^{22} \mathrm{O}$ indicador de Duração Equivalente de Interrupção por Unidade Consumidora (DEC) apurado aponta quantas horas em média os consumidores de uma distribuidora ficam sem o fornecimento de energia elétrica em um período. Neste trabalho utiliza-se o DEC anual.

${ }^{23}$ http://www.aneel.gov.br/indicadores-coletivos-de-continuidade
} 
Tabela A.4 - DEC Apurado.

\begin{tabular}{|c|c|}
\hline CONCESSIONÁRIA & DEC APURADO (h) \\
\hline AES-SUL & 19,11 \\
\hline AME & 46,65 \\
\hline AMPLA & 27,79 \\
\hline BANDEIRANTE & 8,43 \\
\hline BOA VISTA & 22,67 \\
\hline CAIUA & 11,84 \\
\hline CEA & 85,36 \\
\hline CEAL & 29,56 \\
\hline CEB & 15,50 \\
\hline CEEE & 17,09 \\
\hline CELESC & 14,67 \\
\hline CELG & 43,24 \\
\hline CELPA & 37,93 \\
\hline CELPE & 19,31 \\
\hline ETO & 33,22 \\
\hline CEMAR & 15,28 \\
\hline EMT & 30,24 \\
\hline CEMIG & 11,53 \\
\hline CEPISA & 26,21 \\
\hline CERON & 40,79 \\
\hline CFLO & 5,22 \\
\hline CHESP & 14,80 \\
\hline CNEE & 7,78 \\
\hline COCEL & 9,49 \\
\hline COELBA & 24,79 \\
\hline COELCE & 12,25 \\
\hline COOPERALIANÇA & 5,08 \\
\hline COPEL & 13,67 \\
\hline COSERN & 14,72 \\
\hline CPFLJAGUARI & 6,93 \\
\hline CPFLLESTEPAULISTA & 7,92 \\
\hline CPFLMOCOCA & 7,05 \\
\hline CPFLPAULISTA & 7,75 \\
\hline CPFLPIRATININGA & 7,25 \\
\hline CPFLSANTACRUZ & 8,46 \\
\hline CPFLSULPAULISTA & 11,50 \\
\hline DEMEI & 8,93 \\
\hline DMED & 1,20 \\
\hline EDEVP & 7,05 \\
\hline EEB & 15,37 \\
\hline EFLJC & 1,27 \\
\hline EFLUL & 5,70 \\
\hline ELEKTRO & 8,51 \\
\hline ELETROACRE & 56,38 \\
\hline ELETROCAR & 12,24 \\
\hline ELETROPAULO & 23,62 \\
\hline ELFSM & 7,90 \\
\hline EBO & 5,53 \\
\hline EMG & 10,18 \\
\hline ENF & 8,76 \\
\hline EPB & 18,20 \\
\hline ESE & 13,38 \\
\hline EMS & 13,93 \\
\hline ESCELSA & 9,06 \\
\hline FORCEL & 0,69 \\
\hline HIDROPAN & 5,98 \\
\hline IENERGIA & 15,74 \\
\hline LIGHT & 12,61 \\
\hline MUXENERGIA & 4,88 \\
\hline RGE & 15,98 \\
\hline \begin{tabular}{|l} 
SULGIPE \\
\end{tabular} & 11,29 \\
\hline UHENPAL & 14,49 \\
\hline
\end{tabular}

\section{A.8 ENERGIA NÃO DISTRIBUÍDA (END)}

Considera-se o valor de 5,10 R \$/kWh para a energia não distribuída, conforme utilizado por Lamin (2013). 


\section{A.9 COMPENSAÇÕES POR VIOLAÇÃO DE INDICADORES}

O montante compensado, em 2015, devido à transgressão dos limites de continuidade individuais, apresentado na Tabela A.5, está disponível em página eletrônica da ANEEL ${ }^{24}$.

Tabela A.5 - Compensação por violação de indicadores.

\begin{tabular}{|c|c|}
\hline CONCESSIONÁRIA & COMPENSAÇÕES (R\$) \\
\hline AES-SUL & $20.694 .776,40$ \\
\hline AME & $9.810 .880,29$ \\
\hline AMPLA & $55.212 .555,28$ \\
\hline BANDEIRANTE & $5.855 .712,26$ \\
\hline BOA VISTA & $1.762 .192,60$ \\
\hline CAIUA & $1.450 .587,78$ \\
\hline CEA & - \\
\hline CEAL & $8.482 .580,04$ \\
\hline CEB & $10.147 .531,71$ \\
\hline CEEE & $15.621 .941,35$ \\
\hline CELESC & $12.043 .448,01$ \\
\hline CELG & $98.401 .384,18$ \\
\hline CELPA & $13.547 .012,65$ \\
\hline CELPE & $16.604 .111,01$ \\
\hline ETO & $1.655 .008,19$ \\
\hline CEMAR & $6.578 .062,15$ \\
\hline EMT & $19.642 .530,96$ \\
\hline CEMIG & $37.332 .535,48$ \\
\hline CEPISA & $4.676 .198,39$ \\
\hline CERON & $15.005 .212,83$ \\
\hline CFLO & $42.361,59$ \\
\hline CHESP & $306.105,51$ \\
\hline CNEE & $420.131,93$ \\
\hline COCEL & $200.326,62$ \\
\hline COELBA & $41.182 .355,85$ \\
\hline COELCE & $7.929 .811,98$ \\
\hline COOPERALIANÇA & $3.822,40$ \\
\hline COPEL & $23.163 .400,22$ \\
\hline COSERN & $4.033 .283,93$ \\
\hline CPFLJAGUARI & $140.476,20$ \\
\hline CPFLLESTEPAULISTA & $241.099,65$ \\
\hline CPFLMOCOCA & $161.636,20$ \\
\hline CPFLPAULISTA & $13.526 .936,18$ \\
\hline CPFLPIRATININGA & $3.844 .397,41$ \\
\hline CPFLSANTACRUZ & $785.976,96$ \\
\hline CPFLSULPAULISTA & $513.836,36$ \\
\hline DEMEI & $151.265,02$ \\
\hline DMED & $9.489,02$ \\
\hline EDEVP & $371.489,46$ \\
\hline EEB & $1.339 .964,11$ \\
\hline EFLJC & 165,03 \\
\hline EFLUL & $3.527,40$ \\
\hline ELEKTRO & $13.335 .252,47$ \\
\hline ELETROACRE & $7.683 .933,22$ \\
\hline ELETROCAR & $122.861,74$ \\
\hline ELETROPAULO & $126.335 .437,88$ \\
\hline ELFSM & $217.038,48$ \\
\hline EBO & $68.403,81$ \\
\hline EMG & $812.122,04$ \\
\hline ENF & $140.822,79$ \\
\hline EPB & $3.556 .541,75$ \\
\hline ESE & $1.384 .233,97$ \\
\hline EMS & $7.931 .784,02$ \\
\hline ESCELSA & $4.719 .499,72$ \\
\hline FORCEL & - \\
\hline HIDROPAN & $16.760,39$ \\
\hline IENERGIA & $605.758,94$ \\
\hline \begin{tabular}{|l|} 
LIGHT \\
\end{tabular} & $43.864 .964,19$ \\
\hline \begin{tabular}{|l|} 
MUXENERGIA \\
\end{tabular} & 208,05 \\
\hline RGE & $14.173 .907,26$ \\
\hline SULGIPE & $74.271,90$ \\
\hline UHENPAL & $15.810,42$ \\
\hline
\end{tabular}

\footnotetext{
${ }^{24}$ http://www.aneel.gov.br/indicadores-de-compensacao-de-continuidade
} 


\section{A.10 CUSTO DE LEITURA}

Adota-se o valor de R \$ 0,50/mês como custo médio de leitura por unidade consumidora, conforme estimado por Lamin (2013). Esse valor é utilizado na estimação do benefício devido a redução da quantidade de leituras realizadas pelas distribuidoras. Com a implantação de uma infraestrutura de telecomunicações de maior capacidade, os medidores eletrônicos inteligentes podem enviar remotamente os dados necessários para o faturamento dos consumidores.

\section{A.11 CUSTOS DA RELIGAÇÃO NORMAL, DE EMERGÊNCIA E DO DESLIGAMENTO PROGRAMADO}

Os custos, em 2015, com a religação normal, de emergência e desligamento programado de cada distribuidora, estão disponíveis nas resoluções de homologação do resultado do reajuste ou revisão tarifária das empresas, que podem ser acessadas em endereço eletrônico da ANEEL ${ }^{25}$.

Os valores utilizados neste trabalho representam o custo médio resultante da ponderação do custo individual para ligações monofásicas, bifásicas e trifásicas pela quantidade de consumidores com cada tipo de ligação.

A informação sobre a quantidade de UC com ligações monofásicas, bifásicas e trifásicas de cada empresa está disponível na Base de Dados Geográficas da Distribuidora ${ }^{26}$ (BDGD) das distribuidoras.

A Tabela A.6 exibe os custos da religação normal, de emergência e do desligamento programado das distribuidoras em 2015.

\footnotetext{
${ }^{25}$ http://biblioteca.aneel.gov.br/index.html

${ }^{26}$ A BDGD é encaminhada anualmente para ANEEL pelas distribuidoras.
} 
Tabela A.6 - Custos da religação normal, de emergência e do desligamento programado.

\begin{tabular}{|c|c|c|}
\hline CONCESSIONÁRIA & $\begin{array}{l}\text { RELIGAÇÃO } \\
\text { NORMAL } \\
\text { (R\$) }\end{array}$ & $\begin{array}{c}\text { RELIGAÇÃO DE } \\
\text { URGÊNCIA E } \\
\text { DESLIGAMENTO } \\
\text { PROGRAMADO (R\$) }\end{array}$ \\
\hline AES-SUL & 9,98 & 41,70 \\
\hline AME & 10,38 & 44,46 \\
\hline AMPLA & 9,83 & 40,20 \\
\hline BANDEIRANTE & 10,77 & 51,19 \\
\hline BOA VISTA & 10,38 & 44,46 \\
\hline CAIUA & 10,89 & 47,44 \\
\hline CEA & 10,40 & 44,52 \\
\hline CEAL & 11,53 & 45,06 \\
\hline CEB & 11,63 & 46,92 \\
\hline CEEE & 10,31 & 44,17 \\
\hline CELESC & 9,82 & 40,75 \\
\hline CELG & 11,68 & 46,01 \\
\hline CELPA & 10,22 & 43,75 \\
\hline CELPE & 7,57 & 35,03 \\
\hline ETO & 8,21 & 37,13 \\
\hline CEMAR & 7,86 & 36,22 \\
\hline EMT & 9,87 & 44,80 \\
\hline CEMIG & 12,53 & 50,18 \\
\hline CEPISA & 12,64 & 47,34 \\
\hline CERON & 11,54 & 48,91 \\
\hline CFLO & 10,09 & 43,22 \\
\hline CHESP & 8,91 & 39,01 \\
\hline CNEE & 11,38 & 50,94 \\
\hline COCEL & 9,96 & 44,47 \\
\hline COELBA & 7,72 & 35,97 \\
\hline COELCE & 7,46 & 34,78 \\
\hline COOPERALIANÇA & 9,59 & 40,44 \\
\hline COPEL & 10,57 & 45,33 \\
\hline COSERN & 9,63 & 39,99 \\
\hline CPFLJAGUARI & 11,23 & 49,80 \\
\hline CPFLLESTEPAULISTA & 11,81 & 50,14 \\
\hline CPFLMOCOCA & 11,61 & 49,64 \\
\hline CPFLPAULISTA & 10,49 & 45,54 \\
\hline CPFLPIRATININGA & 10,81 & 49,57 \\
\hline CPFLSANTACRUZ & 10,95 & 44,99 \\
\hline CPFLSULPAULISTA & 10,22 & 45,58 \\
\hline DEMEI & 9,16 & 37,25 \\
\hline DMED & 11,07 & 47,96 \\
\hline EDEVP & 9,91 & 41,76 \\
\hline EEB & 11,49 & 51,40 \\
\hline EFLJC & 10,30 & 42,24 \\
\hline EFLUL & 13,65 & 50,08 \\
\hline ELEKTRO & 10,25 & 46,24 \\
\hline ELETROACRE & 10,40 & 44,52 \\
\hline ELETROCAR & 9,87 & 41,74 \\
\hline ELETROPAULO & 8,62 & 39,33 \\
\hline ELFSM & 18,93 & 59,39 \\
\hline EBO & 8,24 & 36,23 \\
\hline EMG & 8,27 & 36,97 \\
\hline$\overline{E N F}$ & 9,97 & 41,04 \\
\hline EPB & 8,30 & 37,34 \\
\hline ESE & 8,58 & 37,50 \\
\hline EMS & 10,47 & 45,53 \\
\hline ESCELSA & 9,90 & 43,48 \\
\hline FORCEL & 11,74 & 49,40 \\
\hline HIDROPAN & 13,14 & 48,52 \\
\hline IENERGIA & 10,57 & 43,88 \\
\hline LIGHT & 13,72 & 51,50 \\
\hline MUXENERGIA & 8,60 & 38,18 \\
\hline RGE & 9,55 & 40,12 \\
\hline SULGIPE & 8,00 & 38,04 \\
\hline UHENPAL & 11,15 & 43,68 \\
\hline
\end{tabular}

\section{A.12 VALOR DA COMPRA DE ENERGIA}

O valor da compra de energia que consta na tarifa de cada distribuidora está disponível na Nota Técnica que subsidia a sua revisão tarifária, a qual está disponível em endereço 
eletrônico da $\mathrm{ANEEL}^{27}$. Considerando que as empresas passam por revisões tarifárias em anos distintos, os valores utilizados neste trabalho não têm como referência a mesma data.

A Tabela A.7 apresenta o valor de compra da energia pelas concessionárias em 2012 e 2015.

Tabela A.7 - Valor da compra de energia pelas distribuidoras.

\begin{tabular}{|c|c|}
\hline CONCESSIONÁRIA & $\begin{array}{c}\text { COMPRA DA } \\
\text { ENERGIA (R\$MWh) }\end{array}$ \\
\hline AES-SUL & 197,20 \\
\hline AME & 227,72 \\
\hline AMPLA & 162,59 \\
\hline BANDEIRANTE & 176,20 \\
\hline BOA VISTA & 278,02 \\
\hline CAIUA & 173,31 \\
\hline CEA & 145,39 \\
\hline CEAL & 136,10 \\
\hline CEB & 171,24 \\
\hline CEEE & 186,54 \\
\hline CELESC & 193,60 \\
\hline CELG & 170,53 \\
\hline CELPA & 143,70 \\
\hline CELPE & 150,80 \\
\hline ETO & 147,34 \\
\hline CEMAR & 127,52 \\
\hline EMT & 194,39 \\
\hline CEMIG & 170,05 \\
\hline CEPISA & 136,64 \\
\hline CERON & 226,22 \\
\hline CFLO & 254,07 \\
\hline CHESP & 208,90 \\
\hline CNEE & 158,65 \\
\hline COCEL & 254,13 \\
\hline COELBA & 125,33 \\
\hline COELCE & 162,82 \\
\hline COOPERALIANÇA & 230,56 \\
\hline COPEL & 179,80 \\
\hline COSERN & 148,17 \\
\hline CPFLJAGUARI & 148,45 \\
\hline CPFLLESTEPAULISTA & 139,41 \\
\hline CPFLMOCOCA & 139,95 \\
\hline CPFLPAULISTA & 182,81 \\
\hline CPFLPIRATININGA & 188,02 \\
\hline CPFLSANTACRUZ & 174,25 \\
\hline CPFLSULPAULISTA & 138,53 \\
\hline DEMEI & 203,50 \\
\hline DMED & 162,27 \\
\hline EDEVP & 173,43 \\
\hline EEB & 187,15 \\
\hline EFLJC & 230,90 \\
\hline EFLUL & 231,61 \\
\hline ELEKTRO & 184,00 \\
\hline ELETROACRE & 106,84 \\
\hline ELETROCAR & 189,50 \\
\hline ELETROPAULO & 168,40 \\
\hline ELFSM & 211,76 \\
\hline EBO & 140,84 \\
\hline EMG & 181,78 \\
\hline ENF & 200,50 \\
\hline EPB & 133,79 \\
\hline ESE & 126,68 \\
\hline EMS & 161,82 \\
\hline ESCELSA & 165,35 \\
\hline FORCEL & 237,16 \\
\hline HIDROPAN & 199,50 \\
\hline IENERGIA & 177,00 \\
\hline LIGHT & 198,51 \\
\hline MUXENERGIA & 198,51 \\
\hline RGE & 168,90 \\
\hline SULGIPE & 162,57 \\
\hline UHENPAL & 234,64 \\
\hline
\end{tabular}

27 http://biblioteca.aneel.gov.br/index.html 


\section{A.13 GaSto COM EXPANSÃo da REDE, DEMANDA DE PONTA E SEU CRESCIMENTO MÉDIO HISTÓRICO}

O gasto das distribuidoras com expansão da rede, a demanda de ponta em 2015 e o seu crescimento médio histórico, expostos na Tabela A.8, estão disponíveis no Plano de Desenvolvimento da Distribuição (PDD) ${ }^{28}$.

Os gastos com a expansão e o crescimento médio histórico se baseiam nos valores apurados entre 2010 e 2015. Considerando-se que parte das informações de algumas concessionárias não está disponível, os dados não contemplam o mesmo período para todas as empresas.

Tabela A.8 - Gasto com a expansão, demanda de ponta e crescimento médio histórico.

\begin{tabular}{|l|r|r|r|}
\hline CONCESSIONÁRIA & $\begin{array}{c}\text { GASTO COM A } \\
\text { EXPANSÃO DA REDE } \\
\text { (R\$) }\end{array}$ & $\begin{array}{c}\text { DEMANDA PONTA } \\
\text { (MW) }\end{array}$ & $\begin{array}{c}\text { CRESCIMENTO } \\
\text { MÉDIO HISTÓRICO } \\
\text { DA DEMANDA DE } \\
\text { PONTA }\end{array}$ \\
\hline AES-SUL & $248.378 .215,55$ & $5.121,50$ & $7,46 \%$ \\
\hline AME & $245.938 .546,25$ & $5.680,31$ & $5,17 \%$ \\
\hline AMPLA & $395.671 .694,01$ & $7.576,10$ & $6,04 \%$ \\
\hline BANDEIRANTE & $167.581 .941,45$ & $6.203,13$ & $2,16 \%$ \\
\hline BOA VISTA & $10.687 .809,46$ & 371,45 & $14,53 \%$ \\
\hline CAIUA & $20.377 .686,60$ & 802,33 & $6,32 \%$ \\
\hline CEA & $40.145 .393,13$ & 937,16 & $10,01 \%$ \\
\hline CEAL & $58.665 .421,73$ & $1.834,23$ & $4,16 \%$ \\
\hline CEB & $122.430 .813,10$ & $3.389,60$ & $1,42 \%$ \\
\hline CEEE & $56.874 .107,59$ & $4.986,21$ & $7,17 \%$ \\
\hline CELESC & $340.228 .040,48$ & $10.460,00$ & $5,69 \%$ \\
\hline CELG & $179.345 .386,39$ & $6.808,23$ & $5,49 \%$ \\
\hline CELPA & $629.538 .936,92$ & $5.243,48$ & $4,31 \%$ \\
\hline CELPE & $341.494 .108,14$ & $5.659,97$ & $4,97 \%$ \\
\hline ETO & $160.806 .922,87$ & $1.142,98$ & $5,11 \%$ \\
\hline CEMAR & $338.750 .629,48$ & $3.193,39$ & $7,70 \%$ \\
\hline EMT & $262.134 .133,13$ & $3.598,48$ & $6,42 \%$ \\
\hline CEMIG & $1.107 .693 .816,44$ & $17.992,00$ & $4,00 \%$ \\
\hline CEPISA & $144.962 .511,64$ & $1.974,84$ & $6,57 \%$ \\
\hline CERON & $92.670 .872,37$ & $1.674,44$ & $2,78 \%$ \\
\hline CFLO & $3.546 .358,66$ & 80,60 & $1,42 \%$ \\
\hline CHESP & $3.312 .780,40$ & 91,82 & $4,64 \%$ \\
\hline CNEE & $7.865 .891,02$ & 385,81 & $7,40 \%$ \\
\hline COCEL & $4.050 .221,18$ & 60,35 & $5,55 \%$ \\
\hline COELBA & $995.305 .973,06$ & $8.319,51$ & $5,95 \%$ \\
\hline COELCE & $233.907 .785,41$ & $4.833,29$ & $4,62 \%$ \\
\hline COOPERALIANÇA & $2.632 .936,31$ & 48,00 & $4,18 \%$ \\
\hline COPEL & $552.903 .641,79$ & $12.552,20$ & $3,87 \%$ \\
\hline COSERN & $121.225 .393,34$ & $2.201,99$ & $5,91 \%$ \\
\hline CPFLJAGUARI & $6.509 .947,23$ & 227,75 & $6,09 \%$ \\
\hline CPFLLESTEPAULISTA & $11.305 .897,88$ & 226,07 & $0,78 \%$ \\
\hline & & & \\
\hline & & & \\
\hline
\end{tabular}

\begin{tabular}{|l|r|r|r|}
\hline CONCESSIONÁRIA & $\begin{array}{c}\text { GASTO COM A } \\
\text { EXPANO DA REDE } \\
\text { (R\$) }\end{array}$ & $\begin{array}{c}\text { DEMANDA PONTA } \\
\text { (MW) }\end{array}$ & $\begin{array}{c}\text { CRESCIMENTO } \\
\text { MÉDIO HISTÓRICO } \\
\text { DAEMANDA DE } \\
\text { PONTA }\end{array}$ \\
\hline CPFLMOCOCA & $8.016 .262,83$ & 145,23 & $1,13 \%$ \\
\hline CPFLPAULISTA & $413.895 .636,56$ & $13.568,34$ & $4,40 \%$ \\
\hline CPFLPIRATININGA & $186.122 .928,34$ & $5.405,58$ & $2,78 \%$ \\
\hline CPFLSANTACRUZ & $25.134 .827,44$ & 756,60 & $5,60 \%$ \\
\hline CPFLSULPAULISTA & $12.239 .127,40$ & 276,38 & $2,34 \%$ \\
\hline DEMEI & $2.109 .617,58$ & 68,28 & $7,43 \%$ \\
\hline DMED & $3.252 .852,96$ & 214,00 & $3,34 \%$ \\
\hline EDEVP & $9.355 .492,05$ & 491,89 & $3,26 \%$ \\
\hline EEB & $17.546 .280,32$ & 476,85 & $2,01 \%$ \\
\hline EFLCC & $132.870,22$ & 73,00 & $1,42 \%$ \\
\hline EFLUL & $1.011 .172,92$ & 25,20 & $1,42 \%$ \\
\hline ELEKTRO & $254.912 .315,89$ & $6.855,40$ & $2,19 \%$ \\
\hline ELETROACRE & $33.816 .784,40$ & 527,40 & $5,31 \%$ \\
\hline ELETROCAR & $7.197 .067,47$ & 80,01 & $6,58 \%$ \\
\hline ELETROPAULO & $593.642 .824,07$ & $20.338,00$ & $2,53 \%$ \\
\hline ELFSM & $11.400 .542,34$ & 452,82 & $8,02 \%$ \\
\hline EBO & $10.458 .520,82$ & 302,84 & $1,36 \%$ \\
\hline EMG & $40.145 .393,13$ & 926,32 & $6,40 \%$ \\
\hline ENF & $10.136 .684,96$ & 206,26 & $1,32 \%$ \\
\hline EPB & $10.458 .520,82$ & 302,84 & $1,36 \%$ \\
\hline ESE & $62.324 .940,33$ & $1.162,33$ & $4,89 \%$ \\
\hline EMS & $151.207 .914,30$ & $2.851,45$ & $6,60 \%$ \\
\hline ESCELSA & $166.073 .409,06$ & $5.248,36$ & $6,11 \%$ \\
\hline FORCEL & $869.146,86$ & 36,50 & $2,71 \%$ \\
\hline HIDROPAN & $732.301,88$ & 68,28 & $2,71 \%$ \\
\hline IENERGIA & $2.274 .541,52$ & 47,50 & $6,93 \%$ \\
\hline LIGHT & $519.482 .037,74$ & $14.770,60$ & $1,71 \%$ \\
\hline MUXENERGIA & $422.235,94$ & 18,71 & $7,74 \%$ \\
\hline RGE & $11.299 .260,01$ & $4.590,30$ & $3,46 \%$ \\
\hline SULGIPE & $1.381 .370,78$ & 145,08 & $3,96 \%$ \\
\hline UHENPAL & & & $4,88 \%$ \\
\hline
\end{tabular}

\section{A.14 CUSTO DA GERAÇÃO}

Adota-se o valor de $\mathrm{R} \$ 1.700 \mathrm{R} \$ / \mathrm{kW}$ como custo de referência do investimento em plantas de geração, conforme estimado por Lamin (2013).

\footnotetext{
${ }^{28}$ O PDD apresenta o resultado dos estudos de planejamento do sistema de distribuição, incluindo plano de expansão, plano de obras, e relação de obras realizadas pelas concessionárias e permissionárias de distribuição de energia elétrica nos horizontes de 5 e 10 anos. Anualmente o plano é atualizado.
} 


\section{A.15 PERDAS TÉCNICAS E NÃO TÉCNICAS APURADAS}

Os percentuais apurados de perdas técnicas e não técnicas são encaminhados periodicamente pelas concessionárias à ANEEL. Utilizam-se os valores de 2014 porque até a realização deste trabalho as informações de 2015 ainda não estavam disponíveis.

A Tabela A.9 apresenta o percentual de perdas técnicas e não técnicas apurados pelas distribuidoras em 2014.

Tabela A.9 - Percentual de perdas técnicas e não técnicas apurados pelas distribuidoras.

\begin{tabular}{|l|c|c|}
\hline CONCESSIONÁRIA & $\begin{array}{c}\text { PERDAS } \\
\text { TÉCNICAS }\end{array}$ & $\begin{array}{c}\text { PERDAS NÃO } \\
\text { TÉCNICAS }\end{array}$ \\
\hline AES-SUL & $7,63 \%$ & $1,32 \%$ \\
\hline AME & $7,77 \%$ & $43,96 \%$ \\
\hline AMPLA & $8,18 \%$ & $11,89 \%$ \\
\hline BANDEIRANTE & $5,33 \%$ & $3,53 \%$ \\
\hline BOA VISTA & $7,04 \%$ & $7,16 \%$ \\
\hline CAIUA & $6,33 \%$ & $1,93 \%$ \\
\hline CEA & $11,40 \%$ & $29,66 \%$ \\
\hline CEAL & $8,42 \%$ & $18,07 \%$ \\
\hline CEB & $7,95 \%$ & $3,55 \%$ \\
\hline CEEE & $6,69 \%$ & $20,17 \%$ \\
\hline CELESC & $6,35 \%$ & $3,44 \%$ \\
\hline CELG & $9,79 \%$ & $2,37 \%$ \\
\hline CELPA & $12,16 \%$ & $20,15 \%$ \\
\hline CELPE & $9,68 \%$ & $7,58 \%$ \\
\hline ETO & $13,51 \%$ & $3,30 \%$ \\
\hline CEMAR & $9,93 \%$ & $7,75 \%$ \\
\hline EMT & $9,89 \%$ & $4,80 \%$ \\
\hline CEMIG & $10,62 \%$ & $1,53 \%$ \\
\hline CEPISA & $8,67 \%$ & $10,75 \%$ \\
\hline CERON & $12,74 \%$ & $16,53 \%$ \\
\hline CFLO & $3,39 \%$ & $0,47 \%$ \\
\hline CHESP & $10,56 \%$ & $0,72 \%$ \\
\hline CNEE & $8,50 \%$ & $0,00 \%$ \\
\hline COCEL & $4,79 \%$ & $1,25 \%$ \\
\hline COELBA & $10,47 \%$ & $4,27 \%$ \\
\hline COELCE & $10,72 \%$ & $2,11 \%$ \\
\hline COOPERALIANÇA & $9,21 \%$ & $2,30 \%$ \\
\hline COPEL & $6,01 \%$ & $2,29 \%$ \\
\hline COSERN & $9,46 \%$ & $0,80 \%$ \\
\hline CPFLJAGUARI & $3,49 \%$ & $0,75 \%$ \\
\hline CPFLLESTEPAULISTA & $8,16 \%$ & $2,74 \%$ \\
\hline
\end{tabular}

\begin{tabular}{|l|c|c|}
\hline CONCESSIONÁRIA & $\begin{array}{c}\text { PERDAS } \\
\text { TÉCNICAS }\end{array}$ & $\begin{array}{c}\text { PERDAS NÃO } \\
\text { TÉCNICAS }\end{array}$ \\
\hline CPFLMOCOCA & $7,75 \%$ & $1,64 \%$ \\
\hline CPFLPAULISTA & $6,01 \%$ & $2,53 \%$ \\
\hline CPFLPIRATININGA & $4,31 \%$ & $2,75 \%$ \\
\hline CPFLSANTACRUZ & $8,97 \%$ & $1,19 \%$ \\
\hline CPFLSULPAULISTA & $7,34 \%$ & $0,35 \%$ \\
\hline DEMEI & $5,08 \%$ & $4,17 \%$ \\
\hline DMED & $4,68 \%$ & $0,34 \%$ \\
\hline EDEVP & $6,94 \%$ & $1,15 \%$ \\
\hline EEB & $4,94 \%$ & $0,67 \%$ \\
\hline EFLJC & $4,36 \%$ & $0,00 \%$ \\
\hline EFLUL & $0,25 \%$ & $0,00 \%$ \\
\hline ELEKTRO & $6,35 \%$ & $3,48 \%$ \\
\hline ELETROACRE & $9,85 \%$ & $14,83 \%$ \\
\hline ELETROCAR & $7,62 \%$ & $0,00 \%$ \\
\hline ELETROPAULO & $6,13 \%$ & $3,35 \%$ \\
\hline ELFSM & $5,98 \%$ & $3,05 \%$ \\
\hline EBO & $5,95 \%$ & $0,17 \%$ \\
\hline EMG & $9,62 \%$ & $0,54 \%$ \\
\hline ENF & $5,35 \%$ & $0,00 \%$ \\
\hline EPB & $10,61 \%$ & $2,00 \%$ \\
\hline ESE & $6,06 \%$ & $2,67 \%$ \\
\hline EMS & $9,93 \%$ & $4,25 \%$ \\
\hline ESCELSA & $8,58 \%$ & $6,61 \%$ \\
\hline FORCEL & $3,21 \%$ & $0,00 \%$ \\
\hline HIDROPAN & $3,56 \%$ & $0,79 \%$ \\
\hline IENERGIA & $2,72 \%$ & $3,55 \%$ \\
\hline LIGHT & $7,80 \%$ & $18,96 \%$ \\
\hline MUXENERGIA & $3,74 \%$ & $0,91 \%$ \\
\hline RGE & $9,08 \%$ & $1,09 \%$ \\
\hline SULGIPE & $9,61 \%$ & $5,82 \%$ \\
\hline UHENPAL & $14,15 \%$ & $1,59 \%$ \\
\hline
\end{tabular}

\section{A.16 MONTANTE E VALOR DE CO2 EMITIDO E NÃO EMITIDO}

$\mathrm{O}$ montante de $\mathrm{CO}_{2} / \mathrm{MWh}$ emitido pelo setor elétrico em 2015 é estimado pelo Ministério da Ciência, Tecnologia, Inovações e Comunicações e está disponível em endereço eletrônico do órgão ${ }^{29}$.

\footnotetext{
${ }^{29}$ http://www.mct.gov.br/index.php/content/view/321144.html.
} 
Com respeito ao preço do $\mathrm{CO}_{2}$ não emitido que pode ser transacionado no mercado de carbono, adota-se 30,00 €/ton estimado por Lamin (2013). Utilizando o câmbio de 3,60 $\mathrm{R} \$ / €^{30}$, chega-se a $108,00 \mathrm{R} \$ /$ ton.

\section{A.17 GASTOS COM CALL CENTER}

Adota-se o valor de R $\$ 287$ milhões como gastos em todo o Brasil com Call Centers, conforme estimado por Lamin (2013). Para se definir o montante relativo a cada concessionária, utiliza-se a proporção do número de UC da empresa com o total do país.

Com efeito, o tamanho da estrutura de atendimento telefônico das distribuidoras e, assim, a necessidade de gastos com esse canal, está relacionada à quantidade de consumidores por elas atendidos. A Tabela A.10 exibe os gastos das distribuidoras com Call Center.

Tabela A.10 - Gastos das distribuidoras com Call Center.

\begin{tabular}{|l|r|}
\hline \multicolumn{1}{|c|}{ CONCESSIONÁRIA } & $\begin{array}{r}\text { GASTOS COM } \mathbf{C A L L} \\
\text { CENTER } \mathbf{( R \mathbf { } )}\end{array}$ \\
\hline AES-SUL & $5.013 .576,81$ \\
\hline AME & $3.437 .675,72$ \\
\hline AMPLA & $9.989 .739,47$ \\
\hline BANDEIRANTE & $6.821 .508,48$ \\
\hline BOA VISTA & $408.593,35$ \\
\hline CAIUA & $919.423,17$ \\
\hline CEA & $751.149,55$ \\
\hline CEAL & $4.005 .724,71$ \\
\hline CEB & $3.878 .318,09$ \\
\hline CEEE & $6.238 .249,34$ \\
\hline CELESC & $10.609 .389,56$ \\
\hline CELG & $10.735 .286,28$ \\
\hline CELPA & $8.856 .197,59$ \\
\hline CELPE & $13.501 .500,04$ \\
\hline ETO & $2.174 .611,82$ \\
\hline CEMAR & $8.666 .877,30$ \\
\hline EMT & $59.354 .579,82$ \\
\hline CEMIG & $31.051 .753,17$ \\
\hline CEPISA & $4.495 .205,14$ \\
\hline CERON & $2.258 .461,22$ \\
\hline CFLO & $217.192,16$ \\
\hline CHESP & $133.963,59$ \\
\hline CNEE & $5.178 .071,85$ \\
\hline COCEL & $185.503,37$ \\
\hline COELBA & $21.948 .284,18$ \\
\hline COELCE & $12.946 .568,80$ \\
\hline COOPERALIANÇA & $136.167,12$ \\
\hline COPEL & $16.930 .637,53$ \\
\hline COSERN & $5.159 .887,87$ \\
\hline CPFLJAGUARI & $148.786,69$ \\
\hline CPFLLESTEPAULISTA & $216.115,30$ \\
\hline & \\
\hline
\end{tabular}

\begin{tabular}{|c|c|}
\hline CONCESSIONÁRIA & $\begin{array}{c}\text { GASTOS COM CALL } \\
\text { CENTER (R\$) }\end{array}$ \\
\hline CPFLMOCOCA & $174.661,97$ \\
\hline CPFLPAULISTA & $15.961 .261,12$ \\
\hline CPFLPIRATININGA & $6.238 .283,83$ \\
\hline CPFLSANTACRUZ & $782.317,15$ \\
\hline CPFLSULPAULISTA & $315.266,83$ \\
\hline DEMEI & $121.773,23$ \\
\hline DMED & $277.887,16$ \\
\hline EDEVP & $683.207,78$ \\
\hline EEB & $584.098,41$ \\
\hline EFLJC & $13.811,39$ \\
\hline EFLUL & $24.986,20$ \\
\hline ELEKTRO & $9.592 .573,86$ \\
\hline ELETROACRE & $930.057,64$ \\
\hline ELETROCAR & $138.221,21$ \\
\hline ELETROPAULO & $25.961 .773,01$ \\
\hline \begin{tabular}{|l|} 
ELFSM \\
\end{tabular} & $406.355,32$ \\
\hline EBO & $784.290,75$ \\
\hline EMG & $1.661 .164,58$ \\
\hline ENF & $392.930,99$ \\
\hline EPB & $5.193 .488,94$ \\
\hline ESE & $2.803 .137,38$ \\
\hline EMS & $3.719 .379,80$ \\
\hline ESCELSA & $5.657 .680,42$ \\
\hline FORCEL & $28.082,65$ \\
\hline HIDROPAN & $68.183,20$ \\
\hline IENERGIA & $128.671,26$ \\
\hline LIGHT & $14.538 .894,87$ \\
\hline MUXENERGIA & $41.644,94$ \\
\hline RGE & $5.494 .825,58$ \\
\hline SULGIPE & $533.827,09$ \\
\hline UHENPAL & $58.759,72$ \\
\hline
\end{tabular}

\footnotetext{
${ }^{30}$ Cotação do dia 19/07/2016.
} 


\section{A.18 INADIMPLÊNCIA}

Os percentuais de inadimplência percebidos pelas concessionárias em 2015, apresentados na Tabela A.11, estão disponíveis em página eletrônica da ANEEL ${ }^{31}$. Neste trabalho utilizamse os percentuais inadimplidos em 24 meses.

Tabela A.11 - Percentual de inadimplência das concessionárias em 2015.

\begin{tabular}{|l|c|}
\hline CONCESSIONÁRIA & INADIMPLENCIA \\
\hline AES-SUL & $0,72 \%$ \\
\hline AME & $0,93 \%$ \\
\hline AMPLA & $1,83 \%$ \\
\hline BANDEIRANTE & $0,66 \%$ \\
\hline BOA VISTA & $2,45 \%$ \\
\hline CAIUA & $0,29 \%$ \\
\hline CEA & $12,19 \%$ \\
\hline CEAL & $0,33 \%$ \\
\hline CEB & $0,72 \%$ \\
\hline CEEE & $0,97 \%$ \\
\hline CELESC & $0,55 \%$ \\
\hline CELG & $3,99 \%$ \\
\hline CELPA & $1,57 \%$ \\
\hline CELPE & $2,25 \%$ \\
\hline ETO & $0,47 \%$ \\
\hline CEMAR & $0,22 \%$ \\
\hline EMT & $0,68 \%$ \\
\hline CEMIG & $0,73 \%$ \\
\hline CEPISA & $0,57 \%$ \\
\hline CERON & $2,87 \%$ \\
\hline CFLO & $0,04 \%$ \\
\hline CHESP & $0,13 \%$ \\
\hline CNEE & $0,24 \%$ \\
\hline COCEL & $0,08 \%$ \\
\hline COELBA & $1,10 \%$ \\
\hline COELCE & $0,65 \%$ \\
\hline COOPERALIANÇA & $0,27 \%$ \\
\hline COPEL & $0,20 \%$ \\
\hline COSERN & $0,29 \%$ \\
\hline CPFLJAGUARI & $0,04 \%$ \\
\hline CPFLLESTEPAULISTA & $1,15 \%$ \\
\hline & \\
\hline & \\
\hline
\end{tabular}

\begin{tabular}{|l|c|}
\hline CONCESSIONÁRIA & INADIMPLÊNCIA \\
\hline CPFLMOCOCA & $0,16 \%$ \\
\hline CPFLPAULISTA & $0,72 \%$ \\
\hline CPFLPIRATININGA & $1,03 \%$ \\
\hline CPFLSANTACRUZ & $0,24 \%$ \\
\hline CPFLSULPAULISTA & $0,35 \%$ \\
\hline DEMEI & $2,04 \%$ \\
\hline DMED & $0,37 \%$ \\
\hline EDEVP & $0,45 \%$ \\
\hline EEB & $0,11 \%$ \\
\hline EFLJC & $0,12 \%$ \\
\hline EFLUL & $0,01 \%$ \\
\hline ELEKTRO & $0,67 \%$ \\
\hline ELETROACRE & $1,10 \%$ \\
\hline ELETROCAR & $0,12 \%$ \\
\hline ELETROPAULO & $1,10 \%$ \\
\hline ELFSM & $0,10 \%$ \\
\hline EBO & $0,14 \%$ \\
\hline EMG & $0,24 \%$ \\
\hline ENF & $0,14 \%$ \\
\hline EPB & $0,59 \%$ \\
\hline ESE & $0,27 \%$ \\
\hline EMS & $1,08 \%$ \\
\hline ESCELSA & $2,08 \%$ \\
\hline FORCEL & $0,12 \%$ \\
\hline HIDROPAN & $0,01 \%$ \\
\hline IENERGIA & $0,06 \%$ \\
\hline LIGHT & $1,56 \%$ \\
\hline MUXENERGIA & $1,48 \%$ \\
\hline RGE & $0,50 \%$ \\
\hline SULGIPE & $0,97 \%$ \\
\hline UHENPAL & $0,24 \%$ \\
\hline
\end{tabular}

\section{A.19 CUSTO DE FATURAS DE PAPEL}

Conforme estimado por Lamin (2013), o gasto anual com a emissão de faturas de papel é de 8,87 R \$/UC no primeiro ciclo de implantação das tecnologias e de 11,40 R \$/UC no segundo ciclo. Esses valores são utilizados neste trabalho.

\section{A.20 PERCEPÇÃO DOS CUSTOS E DOS BENEFÍCIOS PELOS AGENTES DO SETOR ELÉTRICO E PELA SOCIEDADE}

A Tabela A.12 exibe a percepção dos custos pelos agentes do setor elétrico e pela sociedade.

\footnotetext{
${ }^{31} \mathrm{http}: / /$ www.aneel.gov.br/indicadores-da-distribuicao.
} 
Tabela A.12 - Percepção dos custos pelos agentes do setor elétrico e pela sociedade.

Adaptado de Lamin (2013).

\begin{tabular}{|l|l|c|c|c|}
\hline \multicolumn{1}{|c|}{ COMPONENTE DE CUSTO } & CONSUMIDOR & CONCESSIONÁRIA & ÓRGÃOS PÚBLICOS & SOCIEDADE \\
\hline Aquisição e instalação de equipamentos & & $\mathrm{X}$ & & \\
\hline O\&M e subscrição & & $\mathrm{X}$ & & \\
\hline Logística & & $\mathrm{X}$ & & \\
\hline Administrativos & & $\mathrm{X}$ & $\mathrm{X}$ & \\
\hline Campanhas de comunicação & & $\mathrm{X}$ & & \\
\hline
\end{tabular}

Destaca-se que a legislação determina a manutenção do equilíbrio-financeiro das concessões de distribuição, o que contribui para a atratividade do setor. Isso implica que, em última análise, os custos suportados pelas concessionárias são repassados às tarifas dos seus consumidores. Por outro lado, os benefícios percebidos por essas empresas também são compartilhados com seus consumidores.

A Tabela A.13 exibe a percepção dos benefícios pelos agentes do setor elétrico e pela sociedade.

Tabela A.13 - Percepção dos benefícios pelos agentes do setor elétrico e pela sociedade.

Adaptado de Lamin (2013).

\begin{tabular}{|l|c|c|c|c|}
\hline \multicolumn{1}{|c|}{ COMPONENTE DE BENEFÍCIO } & CONSUMIDOR & CONCESSIONÁRIA & ÓRGÃOS PÚBLICOS & SOCIEDADE \\
\hline Demanda de Ponta & & $\mathrm{X}$ & & \\
\hline Consumo de energia & $\mathrm{X}$ & & & $\mathrm{X}$ \\
\hline Novas plantas de geração & & $\mathrm{X}$ & $\mathrm{X}$ \\
\hline Energia Não Distribuída & $\mathrm{X}$ & $\mathrm{X}$ & \\
\hline Compensações por violação de indicadores & & $\mathrm{X}$ & & \\
\hline Recuperação de Receita & & $\mathrm{X}$ & & \\
\hline Perdas Não Técnicas & & $\mathrm{X}$ & & \\
\hline Perdas Técnicas & & $\mathrm{X}$ & & \\
\hline Leitura Remota & & $\mathrm{X}$ & & \\
\hline Corte e Religamento & $\mathrm{X}$ & & $\mathrm{X}$ \\
\hline Desligamento Programado & & $\mathrm{X}$ & & \\
\hline Emissão de CO $\mathrm{O}_{2}$ & & $\mathrm{X}$ & & \\
\hline Call Center & & $\mathrm{X}$ & & \\
\hline Inadimplência & & $\mathrm{X}$ & & \\
\hline Fatura de Papel & & & \\
\hline Custos evitados & & & \\
\hline
\end{tabular}

